\author{
UNIVERSIDADE DE SÃO PAULO \\ INSTITUTO DE QUÍMICA DE SÃO CARLOS - IQSC \\ PROGRAMA DE PÓS-GRADUAÇÃO EM QUÍMICA ANALÍTICA
}

\title{
AVALIAÇÃO DO ACÚMULO E EMISSÃO DE CARBONO DO SOLO SOB SISTEMAS PRODUTIVOS DE PASTAGEM
}

ALFREDO AUGUSTO PEREIRA XAVIER

Dissertação apresentada ao Instituto de Química de São Carlos da Universidade de São Paulo como parte dos requisitos para a obtenção do título de Mestre em Ciências.

Área de concentração: Química Analítica e Inorgânica

Orientadora: Dra. Débora Marcondes Bastos Pereira Milori

São Carlos 
Dedico este trabalho aos meus pais Alfredo Antunes Xavier Neto e Vera Lourdes Pereira Xavier, pessoas responsáveis pelo que há de bom em mim. Obrigado pelo amor, apoio e compreensão que sempre depositaram em mim. 


\section{AGRADECIMENTOS}

Primeiramente a Deus

... por mais uma encarnação, por iluminar meu caminho e me dar forças para seguir em frente, permitindo a superação dos obstáculos para a conclusão desta etapa da minha vida profissional.

Aos meus familiares, especialmente minha irmã Mainara, minhas avós Lourdes (in memorian) e Lázara.

... pela compreensão, força, incentivo, carinho e educação.

À minha namorada Samara

... pela paciência, amor, conselhos, apoio tanto nos momentos bons quanto nos momentos ruins e por todo companheirismo.

À Dra. Débora Marcondes Bastos Pereira Milori da Embrapa Instrumentação

... pela confiança, orientação, oportunidade, incentivo, amizade e todo o ensinamento fornecido.

Às Dras. Aline Segnini e Edilene Ferreira

... pelas instruções e auxílio que contribuíram para o meu crescimento acadêmico e pela grande amizade.

Aos Drs. Wilson Tadeu Lopes da Silva, Ladislau Martin Neto, Paulino Ribeiro Villas Boas ... pelas sugestões e propostas fornecidas.

Aos colegas do Laboratório de Óptica e Fotônica, Aida, Amanda, Anielle, Alex, Bruno, Camila, Cléber, Gustavo, Ilcemara, Ivan, Jader, Kleydson, Lilian, Marco Aurélio, Michelle, Noemi, Pedro, Renan e Thiago.

... pelo auxílio, amizade e convivência.

Ao Prof. Dr. Newton La Scala Júnior e aos alunos de seu grupo

... pela colaboração com as medidas de respiração do solo e pela disponibilização dos equipamentos para tais medidas. 


\section{À Dra. Patrícia Perondi Anchão Oliveira}

... pela coordenação da rede PECUS e suporte ao projeto desenvolvido.

Ao técnico de solos Pedro Bomfim

... pelo auxílio nas medidas de campo

À Embrapa Instrumentação

... pela infraestrutura e ambiente de trabalho fornecidos para a realização desse projeto.

Aos professores do IQSC/USP.

... pelo conhecimento.

Às bibliotecárias do IQSC/USP

... pela atenção e pronto atendimento.

À Sílvia, Andréia e o Gustavo da sessão de pós-graduação do IQSC/USP

... pela simpatia, atenção e pelo excelente atendimento.

\section{À CAPES}

... pelo auxílio financeiro concedido.

Aos professores da banca

... pela disposição em examinar e contribuir para este trabalho.

Muito obrigado a todos 
"Deus nos concede, a cada dia, uma página de vida nova no livro do tempo. Aquilo que colocarmos nela, corre por nossa conta."

Chico Xavier 


\section{RESUMO}

O manejo adequado do solo é de suma importância na incorporação da matéria orgânica no mesmo, sequestrando carbono da atmosfera. Neste trabalho avaliaram-se dois manejos do sistema produtivo da pecuária, em pastagens de Brachiaria decumbens: (A3) pastagem em recuperação, onde nitrogênio foi aplicado, e (A4) pastagem degradada, onde nenhum tipo de correção é efetuado. Utilizou-se uma área de Mata Atlântica (MT) próxima ao experimento como referência. $\mathrm{O}$ foco principal do trabalho foi o acúmulo de carbono no solo e a emissão de $\mathrm{CO}_{2}$. A partir dos teores de carbono e valores de densidade foram estimados os estoques de carbono (ECs), em superfície $(0-30 \mathrm{~cm})$ e em profundidade $(0-100 \mathrm{~cm})$, em cada um dos sistemas, aplicando as correções por massa equivalente e por teores de argila. Para a estimativa de emissão de $\mathrm{CO}_{2}$ dos solos utilizou-se um sistema portátil que monitora o fluxo de $\mathrm{CO}_{2}$ no interior da câmara através de espectroscopia de absorção no infravermelho. Os resultados mostraram que o sistema $\mathrm{A} 3$ acumulou o maior $\mathrm{EC}$, com $142 \mathrm{Mg} \mathrm{ha}^{-1}$, enquanto aproximadamente $99 \mathrm{Mg} \mathrm{ha}^{-1}$ foi obtido para o sistema A4. Na mata o EC foi de $115 \mathrm{Mg} \mathrm{ha}^{-1}$. Os dados de respiração do solo mostraram situação similar para ambas as áreas de pastagem. Outra proposta desse trabalho foi avaliar a qualidade da matéria orgânica do solo (MOS) utilizando a espectroscopia de fluorescência induzida por laser (LIFS). Observou-se o aumento do grau de humificação da MOS $\left(\mathrm{H}_{\mathrm{FIL}}\right)$ com o aumento da profundidade. Os menores valores de humificação foram obtidos na área em recuperação, indicando certa fragilidade deste estoque de carbono ser perdido caso a área não seja bem manejada. Avaliou-se também o potencial da espectroscopia de emissão óptica com plasma induzido por laser (LIBS) para a quantificação de carbono total em solos. Os dados dos teores de carbono obtidos por análise elementar foram utilizados para a calibração do sistema LIBS de acordo com a textura dos solos. O coeficiente de correlação entre os valores de referência (CHNS) e os valores preditos por LIBS na validação foi de 0,87 (erro 25\%) para textura arenosa e 0,92 (erro 16\%) para textura argilosa. Este trabalho demonstrou a importância do manejo adequado para recuperação de pastagens no Brasil e o risco de se perder esse carbono para atmosfera devido à alta labilidade do carbono armazenado. As pastagens bem manejadas podem levar este sistema produtivo a patamares ambientalmente sustentáveis e contribuir para mitigação do efeito estufa. As técnicas fotônicas apresentaram potencial para determinação de carbono no solo e avaliação de sua estrutura química. Desta forma, espera-se que futuramente este tipo de instrumentação possa ser aplicada ao campo, fornecendo parâmetros que ajudem na tomada de decisões para um desenvolvimento agrícola sustentável. 
Palavras-chave: Estoque de carbono, matéria orgânica, solo inteiro, grau de humificação, LIBS, LIFS. 


\begin{abstract}
Proper soil management is important to organic matter incorporation, sequestering carbon from atmosphere. This study was developed for two livestock managements: (A3) pasture recovering of Brachiaria decumbens, where nitrogen is applied, and (A4) degraded pasture of Brachiaria decumbens, with no correction. The reference system was a native forest area (Brazilian Atlantic Forest) next to the experiment. This study aims to compare the soil carbon accumulations and $\mathrm{CO} 2$ emissions for both productive systems. Soil carbon content and soil bulk density values were measured to calculate carbon stocks (CSs) in surface $(0-30 \mathrm{~cm})$ and at depth $(0-100 \mathrm{~cm})$ in each system, applying equivalent mass and clay content corrections. $\mathrm{CO}_{2}$ emissions were estimated using a portable system, which monitors the $\mathrm{CO}_{2}$ flux within a chamber through infrared absorption spectroscopy. The soil carbon stocks were estimated around $142 \mathrm{Mg} \mathrm{ha}^{-1}$ for $\mathrm{A} 3$ and $99 \mathrm{Mg} \mathrm{ha}^{-1}$ for A4, while around $115 \mathrm{Mg} \mathrm{ha}^{-1}$ was found in the forest. The results for $\mathrm{CO}_{2}$ emission showed a similar situation for both pasture areas. Another purpose of this study was to evaluate the soil organic matter (SOM) quality using laser-induced fluorescence spectroscopy (LIFS). An increasing of humification degree of SOM $\left(\mathrm{H}_{\text {LIF }}\right)$ was observed with increasing of depth. The lowest $\mathrm{H}_{\text {LIFS }}$ values were obtained for the recovering area, indicating a certain fragility of carbon stocks, which can be lost if the area is not well managed. In addition, Laser-induced breakdown spectroscopy (LIBS) was used for total soil carbon quantification. Using the data from elemental analysis, mathematical models were developed to calibrate the LIBS system for each class of soil texture. For carbon quantification, the correlation between reference technique (CHN) and LIBS prediction was 0.87 for sandy soils (error around 21\%) and 0.92 for clayed soils (error around 16\%). This study demonstrated the importance of pasture recovering in Brazil from the point of view of soil carbon sequestration, and the risk of this stock to be lost due to high lability of stored carbon. Well-managed pastures can lead this production system to environmentally sustainable levels and contribute to mitigate the greenhouse effect. Systems with high potential for portability to determine soil carbon and evaluation of its chemical structure have been successfully tested. Thus, it is expected that in a near future, this kind of instrumentation can be effectively applied in the field and provide parameters that help in the decision making for a sustainable agricultural development.
\end{abstract}

Keywords: Carbon stocks, organic matter, whole soil, humification degree, LIBS, LIFS. 


\section{LISTA DE FIGURAS}

Figura 1 - Representação de um equipamento comercial de LIBS. 30

Figura 2 - Etapas do processo de ablação a laser.

Figura 3 - Períodos de tempo importantes após a formação do plasma e a predominância de diferentes espécies.

Figura 4 - Diagrama de transição eletrônica de fluorescência molecular.

Figura 5 - Representação dos pontos de coleta do experimento a partir de coordenadas geográficas obtidas por GPS

Figura 6 - a) Anéis de Kopecky cravados nos perfis amostrais na parede da trincheira e b)

Remoção do anel da parede da trincheira.

Figura 7 - a) Fechamento das cápsulas de estanho e b) Cápsulas de estanho contendo a amostra de solo sendo inserida no carrossel do analisador elementar.....

Figura 8 - Cubo representativo de um perfil de solo

Figura 9 - ECs de uma área de pastagem comparado à mata nativa

Figura 10 - Sistema de LIFS portátil com excitação em 405 nm: (1) chave de energia laser;

(2) caixa de controle laser; (3) cabo óptico; (4) sonda.

Figura 11 - Esquema do equipamento LIFS portátil.

Figura 12 - Momento da análise por LIFS.

Figura 13 - Espectro de LIFS típico para amostras de solos. 46

Figura 14 - Câmara de leitura acoplada ao colar cravado ao solo 48

Figura 15 - Exemplo de regressão linear para as medidas de concentração de $\mathrm{CO}_{2}$ dentro da câmara de medição.

Figura 16 - Equipamento LI-COR 8100 utilizado para as análises de fluxo de $\mathrm{CO}_{2}$ do solo nas áreas em estudo.

Figura 17 - Comparação entre uma moeda e uma pastilha de solo prensado.

Figura 18 - Sistema LIBS de bancada da Ocean Optics, modelo LIBS 2500 plus: (1) fonte de energia; (2) laser; (3) câmara de ablação; (4) conjunto de espectrômetros.

Figura 19 - Classificação dos solos das áreas de manejo segundo o USDA .............................55

Figura 20 - ECs dos sistemas de pastagem e mata nativa em todo o perfil.

Figura 21 - ECs dos sistemas de pastagem e mata nativa nas camadas de 0-30 cm e de 30-100 $\mathrm{cm}$

Figura 22 - ECs dos sistemas de pastagem e mata nativa em todo o perfil utilizando a correção por massa equivalente. 
Figura 23 - ECs dos sistemas de pastagem e mata nativa nas camadas de 0-30 $\mathrm{cm}$ e de $30-100$ cm utilizando a correção por massa equivalente.

Figura 24 - ECs dos sistemas de pastagem e mata nativa em todo o perfil utilizando a correção pelos teores de argila

Figura 25 - ECs dos sistemas de pastagem e mata nativa em todo o perfil utilizando os três tipos de correções.

Figura 26 - Índices de humificação $\left(\mathrm{H}_{\mathrm{FIL}}\right)$ determinados por LIFS em amostras de solos, em diferentes profundidades.

Figura 27 - Espectros médios obtidos por LIFS de diferentes repetições de campo a) trincheira $\mathrm{T} 5$ e b) trincheira $\mathrm{T} 3$, ambas da área degradada.

Figura 28 - Fluxo médio de $\mathrm{CO}_{2}$ do solo por áreas de manejo e dias de medida. a) A3 - Em recuperação; b) A4 - Degradada; c) MT - Mata Atlântica.

Figura 29 - Temperatura média do solo por áreas de manejo e dias de medida 75

Figura 30 - Dados das emissões médias de $\mathrm{CO}_{2}$ em cada área de manejo .76

Figura 31 - Espectro típico de solo obtido por LIBS, destacando (seta) a região do pico de carbono $(193,03 \mathrm{~nm})$.

Figura 32 - Site do NIST (National Institute of Standards and Technology) onde são mostradas as possíveis linhas de emissão do Carbono, Alumínio e Ferro.

Figura 33 - Linha de emissão de C (193,03 nm) parcialmente interferida por Al (193,58 nm)

Figura 34 - Espectros LIBS (a) antes da correção do offset e (b) após a correção (região de $191,82-192,54 \mathrm{~nm})$

Figura 35 - Linha de emissão do carbono (193,03 nm) interferida pelos picos de Alumínio (em 193,04 nm e 193,58 nm).

Figura 36 - Curva de calibração utilizando todo o conjunto amostral.

Figura 37 - Histograma dos resíduos

Figura 38 - Gráfico dos resíduos da curva de calibração

Figura 39 - Quantidade média de argila em cada área em questão.

Figura 40 - Curvas de Calibração para os 2 modelos distintos (a) Modelo argiloso e (b)

Modelo arenoso 86

Figura 41 - Curvas de validação dos modelos de LIBS separados por diferentes texturas, a) Todas as amostras; b) Modelo argiloso e c) Modelo Arenoso. São apresentados também os valores de correlação (R) e os EMAR em \% para cada situação avaliada. 


\section{LISTA DE TABELAS}

Tabela 1 - Dados granulométricos das amostras coletadas das áreas A3, A4 e MT.

Tabela 2 - Valores de densidades médias do solo $\left(\mathrm{g} \mathrm{cm}^{-3}\right)$ determinados nas diferentes profundidades considerando as seis replicatas do campo (trincheiras) (média \pm desvio padrão).

Tabela 3 - Teores médios de carbono em porcentagem determinados por análise elementar considerando as seis replicatas do campo (média \pm desvio padrão)

Tabela 4 - ECs calculados para as áreas em estudo de 0-30 cm e de 30-100 cm para cada trincheira coletada.

Tabela 5 - ECs calculados e corrigidos de 0-100 cm para cada trincheira das áreas em estudos

Tabela 6 - ECs calculados e corrigidos de 0-30 cm para cada trincheira das áreas em estudos

Tabela 7 - ECs calculados e corrigidos pelos teores de argila de $0-100 \mathrm{~cm}$ para cada trincheira das áreas em estudos

Tabela 8 - ECs dos sistemas de pastagem e mata nativa em todo o perfil $(0-100 \mathrm{~cm})$

utilizando os três tipos de correções.

Tabela 9 - Valores dos índices de humificação $\left(\mathrm{H}_{\mathrm{FIL}}\right)$ para cada trincheira em cada profundidade das áreas em estudo.

Tabela 10 - Equações das curvas de calibração e coeficiente de correlação R para determinação de carbono em solos por LIBS em diferentes áreas de pastagem e mata nativa. 


\section{LISTA DE ABREVIATURAS E SIGLAS}

AAS

ANOVA

BPM

$\mathrm{C}$

CCD

CHNS

$\mathrm{EC}(\mathrm{s})$

EMAR

FAAS

FIA

GEE

GT

ha

$\mathrm{H}_{\mathrm{FIL}}$

HPLC

ICP-MS

ICP-OES

IHSS

IPCC

IRGA

Laser

LIBS

LIFS

LOD

MCG

$\mathrm{Mg} \mathrm{C} \mathrm{ha-}$

Mha

mmol. $\mathrm{m}^{-2} \cdot \mathrm{s}^{-1}$

MO

MOS

NIST

PD
Atomic absorption spectroscopy

Análise de variância

Boas práticas de manejo

Carbono

Charge-Coupled Device

Análise elementar (Carbono; Hidrogênio; Nitrogênio e Enxofre)

Estoque(s) de carbono

Erro médio absoluto relativo

Flame atomic absorbtion spectroscopy

Flow injection analisys

Gases de efeito estufa

Gigatoneladas $\left(1\right.$ Petagrama $=1$ bilhão de toneladas $=10^{9}$ ton. $)$

Hectare

Índice de humificação

High-performance liquid chromatography

Inductively Coupled Plasma - Mass Spectroscopy

Inductively Coupled Plasma - Atomic Emission Spectrometry

International Humic Substance Society

Intergovernmental Panel on Climate Change

Infrared gas analyze

Light Amplification by Stimulated Emission of Radiation

Laser induced breakdown spectroscopy

Laser induced fluorescence spectroscopy

Limite de detecção

Mudanças climáticas globais

Mega grama por hectare

Milhões de hectares

mmol por metro quadrado $\mathrm{x}$ segundo

Matéria orgânica

Matéria orgânica do solo

National Institute of Standards and Technology

Plantio direto 
$\mathrm{R}$

$\mathrm{R}^{2}$

RMN

RPE

TDR

TOC

$\mathrm{UA} / \mathrm{ha}$
Coeficiente de correlação de Pearson

Coeficiente de determinação

Ressonância magnética nuclear

Ressonância paramagnética eletrônica

Time domain reflectometry

Total organic carbon

Unidade animal por hectare 


\section{SUMÁRIO}

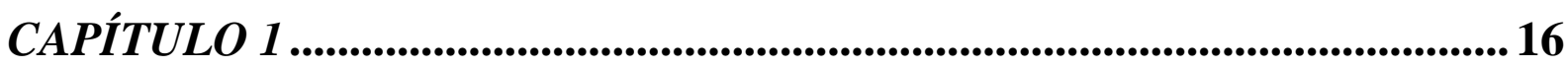

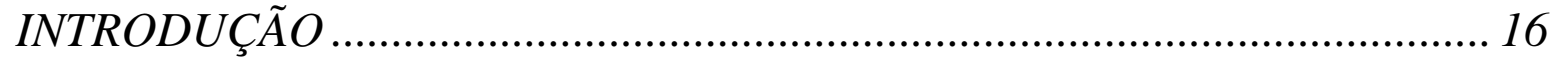

1.1 Mudanças climáticas ..............................................................................16

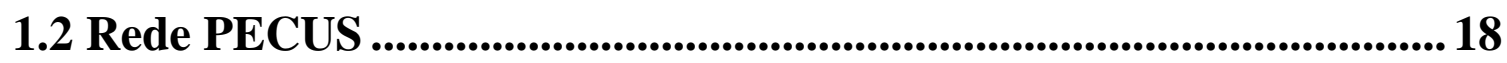

1.3 Objetivos............................................................................................................... 19

1.3.1 Objetivos específicos............................................................................................................ 19

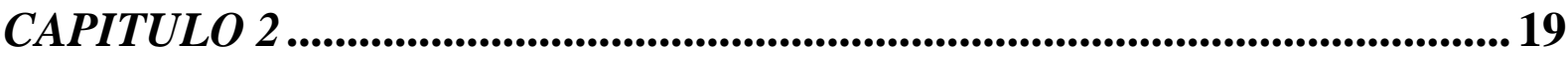

REVISÃO BIBLIOGRÁFICA ….......................................................... 21

2.1 Dinâmica de carbono no domínio terrestre ............................................21

2.2 Agropecuária mitigando o efeito da emissão de gases .......................... 22

2.3 Sistema produtivo de pastagem no Brasil.................................................. 23

2.4 Matéria Orgânica do Solo (MOS)................................................................. 25

2.5 Caracterização de carbono em solos ......................................................... 26

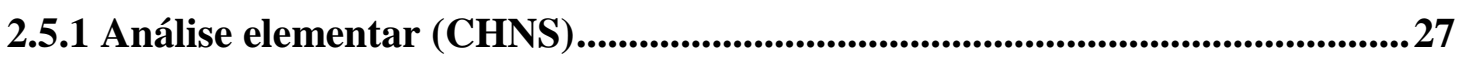

2.5.2 LIBS - Laser Induced Breakdown Spectroscopy ...............................................227

2.5.3 LIFS - Laser Induced Fluorescence Spectroscopy ..........................................32

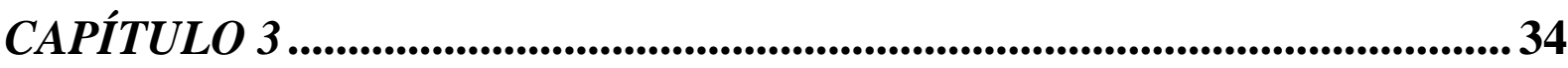

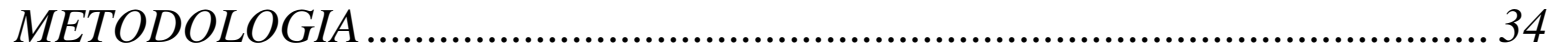

3.1 Área Experimental .....................................................................34

3.1.1 Área A3 - Em recuperação e média lotação animal ...........................................35

3.1.2 Área A4 - Degradada e média lotação animal ................................................36

3.1.3 Mata nativa ...........................................................................................................36

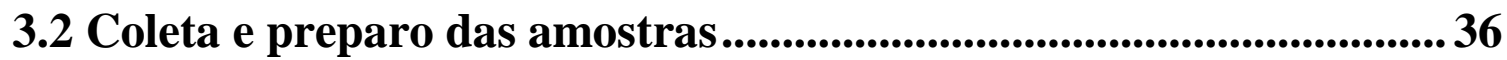

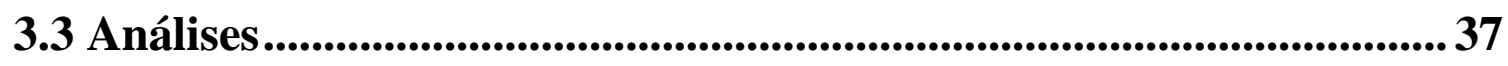

3.3.1 Análise granulométrica .......................................................................................................337

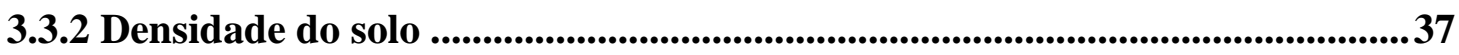

3.3.3 Quantificação do teor de carbono no solo ............................................................39 
3.3.4 Estimativa do Estoque de Carbono nas áreas de pastagem .40

3.3.4.1 Correção dos ECs por massa de solo equivalente.

3.3.4.2 Correção dos ECs pelos teores de argila do solo.................................... 44

3.3.5 LIFS - Laser induced fluorescence spectroscopy ..........................................45

3.3.6 Quantificação de emissão de $\mathrm{CO}_{2}$ (Respiração do solo) .....................................47

3.3.7 LIBS - Laser Induced Breakdown Spectroscopy ..............................................50

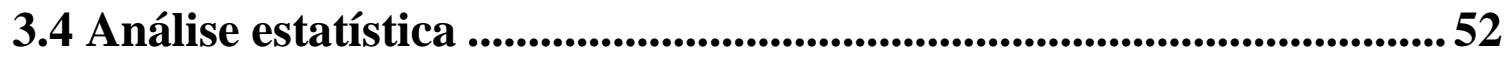

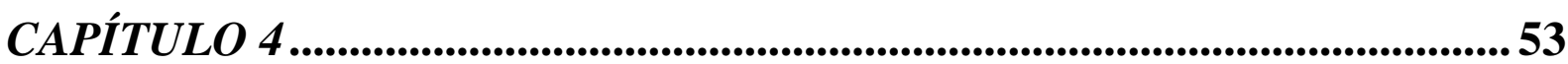

RESULTADOS E DISCUSSÕ ES...................................................... 53

4.1 Avaliação do ciclo do carbono.....................................................53

4.1.1 Análise granulométrica ...................................................................................................53

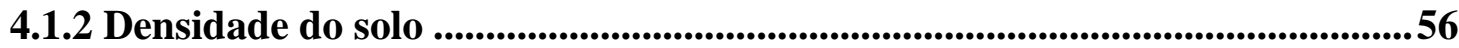

4.1.3 Quantificação do teor de carbono no solo ...............................................................57

4.1.4 Estimativa do Estoque de Carbono nas áreas de pastagem ............................59

4.1.4.1 Correção dos ECs por massa de solo equivalente...................................62

4.1.4.2 Correção dos ECs pelos teores de argila do solo.....................................66

4.1.4.3 Considerações finais sobre as estimativas dos ECs. .............................6 68

4.1.5 Avaliação da qualidade da MOS ............................................................................69

4.1.6 Quantificação de emissão de $\mathrm{CO}_{2}$ (Respiração do Solo) .................................... 73

4.2 Novas técnicas para a quantificação de carbono no solo................... 77

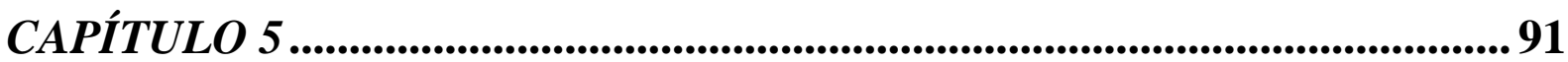

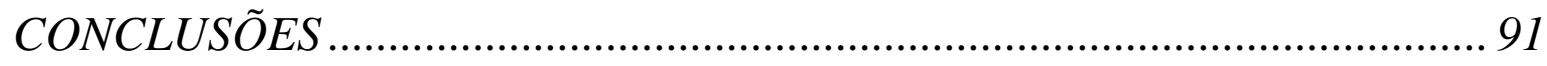

CAPÍTULO 6 [..............................................................................................93

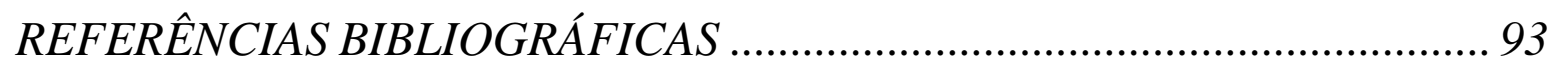




\section{CAPÍTULO 1}

INTRODUÇÃO

\subsection{Mudanças climáticas}

Em 1988, a Organização Meteorológica Mundial (World Meteorological Organization - WMO) e o Programa das Nações Unidas para o Meio Ambiente (United Nations Environment Programme - UNEP) criaram o IPCC (Intergovernmental Panel on Climate Change), cuja função é avaliar as mudanças climáticas, fornecer ao mundo uma visão científica clara sobre a atual situação climática do planeta, bem como os potenciais impactos ambientais e socioeconômicos, visando criar mecanismos para a adaptação e mitigação dos efeitos das mudanças climáticas globais (IPCC, 1988).

A atmosfera terrestre é composta por vários gases tais como o metano $\left(\mathrm{CH}_{4}\right)$, o óxido nitroso $\left(\mathrm{N}_{2} \mathrm{O}\right)$ e o gás carbônico $\left(\mathrm{CO}_{2}\right)$ sendo alguns deles, como o $\mathrm{CO}_{2}$, capazes de absorver parte da radiação infravermelha resultante do aquecimento da superfície terrestre pelo sol. Em seguida esses gases emitem a radiação infravermelha de volta para a superfície terrestre. $\mathrm{O}$ resultado deste processo é um confinamento dessa radiação na atmosfera da Terra, o que eleva a temperatura média do planeta.

O efeito estufa é um fenômeno climático natural responsável pela manutenção da temperatura no planeta e sem os gases do efeito estufa (GEE) a temperatura da Terra seria da ordem de $-14{ }^{\circ} \mathrm{C}$. Porém esse efeito vem sendo intensificado devido ao aumento dos GEE na atmosfera os quais impedem que a radiação infravermelha se dissipe para a estratosfera e seja refletida de volta para a Terra.

O aquecimento global é um evento climático de larga extensão, responsável pelo aumento da temperatura média superficial global ocorrido nos últimos 150 anos e por outras Mudanças Climáticas Globais (MCG). A razão deste aumento de temperatura ainda é objeto de muitos debates na comunidade científica. Segundo a maioria dos cientistas uma das hipóteses para o aumento da temperatura global que vem sendo registrado é o aumento da concentração de GEE.

A Revolução Industrial, iniciada em meados do século XVIII, levou a um aumento drástico na concentração atmosférica de dióxido de carbono $\left(\mathrm{CO}_{2}\right)$ devido à queima de combustíveis fósseis, ao desmatamento das florestas e a expansão da agricultura. Foi registrado a maior taxa de crescimento anual médio da concentração de 1,9 ppm por ano (1995 a 2005) desde o início das medições atmosféricas diretas contínuas (média de 1,4 ppm por ano entre 1960 a 2005). Nos dias de hoje a concentração de $\mathrm{CO}_{2}$ na atmosfera atinge a 
marca de 400 ppm segundo os últimos relatórios, $40 \%$ maior do que a concentração na era pré-industrial (CCST, 2007).

Além do $\mathrm{CO}_{2}$, também vem ocorrendo o aumento significativo na concentração de outros GEE como o metano $\left(\mathrm{CH}_{4}\right)$ e o óxido nitroso $\left(\mathrm{N}_{2} \mathrm{O}\right)$ os quais estão vinculados às práticas agrícolas.

Em 2001, o Terceiro Relatório de Avaliação do IPCC divulgou um aumento de mais de $0,6^{\circ} \mathrm{C}$ na temperatura média global. Também foi constatado o aumento da temperatura dos oceanos devido ao calor absorvido da atmosfera, promovendo o derretimento das geleiras, bem como a expansão da água do mar, o que resulta na elevação de seu nível.

Em Fevereiro de 2007 o IPCC divulgou os resultados do seu Quarto Relatório de Avaliação das Mudanças Climáticas do planeta e nele foi estimado que a temperatura média do planeta poderá ter um aumento médio entre $1,4^{\circ} \mathrm{C}$ e $5,8^{\circ} \mathrm{C}$ até o ano de 2100 , a menos que medidas enérgicas sejam tomadas (CCST, 2007).

Recentemente, em setembro de 2013, o IPCC publicou o último relatório (Assessment Report - AR5) mostrando que o nível do mar subiu 19 cm entre 1901 e 2010 e, em previsão extrema, podendo ficar $82 \mathrm{~cm}$ mais alto até 2100 se o aquecimento continuar (CLIMATE CHANGE, 2013).

No cenário mundial, o Brasil é um dos países mais importantes na pecuária. Em termos de quantidade de cabeças de gado, encontra-se na liderança. Desta forma, atento ao cenário de mudanças climáticas, o Brasil firmou um compromisso internacional de melhorar este sistema produtivo através da redução da emissão dos GEE e através do sequestro de carbono pelo solo resultando num balanço de carbono positivo, tornando a pecuária brasileira mais sustentável ambientalmente. Segundo a Organização das Nações Unidas (ONU), a pecuária é responsável por 14,5\% das emissões de GEE provocadas pelo homem (RURAL $\mathrm{BR}, 2014)$.

Um dos enfoques principais do presente trabalho está relacionado à sustentabilidade da pecuária brasileira e à avaliação de pastagens bem manejadas pelo entendimento do acúmulo e da estabilidade de carbono em diferentes situações de pastagens. A recuperação direta e a adoção do manejo intensivo das pastagens (OLIVEIRA; PENATTI; CORSI, 2008) têm apresentado potencial de mitigação dos gases de efeito estufa devido à elevada produção de massa de forragem das gramíneas tropicais com eficiência de uso de fertilizantes nitrogenados e ao acúmulo de matéria orgânica no solo. No Brasil, para essa prática ser viável há necessidade do uso de fertilizantes nitrogenados já que o potencial de intensificação é 
proporcional à dose de nitrogênio empregada na fertilização, tendo relação direta na quantidade da matéria orgânica.

Sendo assim, há necessidade de se avaliar o balanço entre carbono e nitrogênio em pastagens degradadas versus pastagens recuperadas e intensificadas em diferentes intensidades de uso, no sentido de verificar o melhor equilíbrio entre os malefícios ambientais das perdas nitrogenadas decorrentes do uso de fertilizantes e os benefícios do efeito de mitigação dos gases de efeito estufa. Mais que isso, estudos de variabilidade espacial, verticalização e caracterizações do solo em profundidades de até 1 metro têm mostrado resultados interessantes, principalmente quando se trata de espécies de gramíneas com sistema radicular abundante, com incorporação de carbono em profundidade (JANTALIA et al., 2006; SEGNINI, 2007, BODDEY et al., 2010).

Essa dissertação abordará os principais resultados obtidos em função das avaliações dos estoques de carbono (ECs) no solo para diferentes sistemas de pastagens, ou seja, destinados à pecuária, comparados com a área de referência (Mata Atlântica).

Foram utilizadas técnicas instrumentais relativamente novas para o desenvolvimento do projeto. A qualidade da matéria orgânica do solo (MOS) foi caracterizada e a estabilidade do carbono (índices de humificação da MOS) foi avaliada por espectroscopia de fluorescência induzida por laser (LIFS - Laser Induced Fluorescence Spectroscopy). A espectroscopia de emissão óptica com plasma induzido por laser (LIBS - Laser induced breakdown spectroscopy) foi utilizada na proposta de modelos para determinação alternativa de carbono e gerou resultados bastante promissores. As técnicas espectroscópicas LIBS e LIFS vêm apresentando grande potencial de portabilidade para uso no campo.

O projeto foi desenvolvido em parceria com a Embrapa, a Empresa Brasileira de Pesquisa Agropecuária e está inserido nos estudos da Rede PECUS.

\subsection{Rede PECUS}

A Rede PECUS abrange várias instituições de pesquisas, entre elas, unidades da Embrapa, universidades e outras instituições de pesquisa nacionais e internacionais, com apoio de agências de fomento à pesquisa e da iniciativa privada.

São avaliados sistemas extensivos e intensivos de produção a pasto, de integração lavoura-pecuária, silvipastoril, agrossilvipastoril e confinamentos para produção de bovinos, bubalinos, caprinos, ovinos, suínos e aves e tratamento de dejetos animais. Os processos 
relacionados à emissão e mitigação dos GEE são avaliados e estudados seguindo protocolos de pesquisa padronizados e previamente acordados pela rede.

Está envolvido nesses processos o conjunto solo-planta-animal-atmosfera, gerando assim um balanço de carbono mais completo sempre visando a comparação com a pastagem tradicional e a vegetação nativa das áreas em estudo.

O objetivo do projeto em rede visa também contribuir para a competitividade e sustentabilidade da pecuária brasileira, inseridos nos principais biomas brasileiros: Amazônia, Caatinga, Cerrado, Mata Atlântica, Pantanal e Pampa (Embrapa - Rede Pecus, 2011).

A liderança da Rede PECUS é da Embrapa Pecuária Sudeste, a qual realizou o planejamento experimental e toda a montagem dos sistemas de pastagens avaliados.

Os sistemas foram escolhidos pela grande problemática da parte ambiental da pecuária nacional, a degradação das pastagens. A recuperação e intensificação das pastagens seria uma forma de mitigar rapidamente os impactos ambientais do momento. Os resultados do projeto PECUS devem atender a demanda atual de várias redes de pesquisa e dos inventários de emissão e remoções antrópicas de GEE em diversas escalas de abordagem.

\subsection{Objetivos}

Esse trabalho de mestrado teve como objetivo avaliar a dinâmica de carbono em diferentes sistemas de pastagem, ou seja, o sequestro de $\mathrm{C}$ em profundidade do solo e a emissão de $\mathrm{CO}_{2}$ devido à atividade biológica. A vulnerabilidade do carbono no solo nos diferentes manejos foi avaliada pelo grau de humificação da MOS, o qual foi estimado pela espectroscopia de fluorescência induzida por laser (LIFS).

Além disso, este trabalho também teve como proposta avaliar o potencial da quantificação do carbono no solo pela espectroscopia de emissão óptica com plasma induzido por laser (LIBS).

\subsubsection{Objetivos específicos}

- Quantificar o carbono em perfis de solo via análise elementar (CHNS) em diferentes sistemas de manejo de pastagem;

- Avaliar os estoques de carbono em superfície $(0-30 \mathrm{~cm})$ nos diferentes sistemas de manejo de pastagem tendo como referência uma área de floresta nativa;

- Avaliar os estoques de carbono em profundidade $(0-100 \mathrm{~cm})$ nos diferentes sistemas de manejo de pastagem tendo como referência uma área de floresta nativa; 
- Comparar os estoques de carbono superficiais e em profundidade para os diferentes manejos;

- Avaliar efeitos de textura e densidade na estimativa dos estoques de carbono do solo (correção por teor de argila e massa equivalente);

- Avaliar a vulnerabilidade do carbono no solo através do grau de humificação da matéria orgânica estimada pela espectroscopia de fluorescência induzida por laser (LIFS);

- Estimar a emissão de $\mathrm{CO}_{2}$ do solo em diferentes sistemas de manejo de pastagem;

- Desenvolver um modelo para quantificação de carbono utilizando a espectroscopia LIBS;

- Validar o modelo gerado através de predição de C de amostras de solos desconhecidas do modelo. 
CAPITULO 2 REVISÃO BIBLIOGRÁFICA

\subsection{Dinâmica de carbono no domínio terrestre}

O carbono do planeta está distribuído em cinco principais reservatórios. São eles: a biota, compreendendo toda a parte de carbono presente na biomassa terrestre, o carbono geológico formado carvão mineral, petróleo e gás, o solo (carbono orgânico e inorgânico), a atmosfera e os oceanos.

Estima-se que $56010^{15} \mathrm{~g}$ (560 gigatoneladas $(\mathrm{Gt})$ ou petagrama $(\mathrm{Pg})=10^{15} \mathrm{~g}$ ) de carbono orgânico estão contidos na biota terrestre (plantas e animais) enquanto que os solos contêm aproximadamente $250010^{15} \mathrm{~g}$. Esse reservatório de carbono tem quase 3,3 vezes mais carbono que a atmosfera, que possui aproximadamente $76010^{15} \mathrm{~g}$. Assim, a quantidade de carbono nos solos é mais de quatro vezes a quantidade de carbono na biota terrestre e mais de três vezes a da atmosfera. Os oceanos detêm por volta de $3840010^{15} \mathrm{~g}$ e o carbono geológico está presente em $413010^{15} \mathrm{~g}$. Entretanto, o reservatório mais fácil de manejar-se é o solo, em se tratando de incorporação do carbono da atmosfera (LAL, 2008).

A quantidade de carbono orgânico no solo é espacialmente e temporalmente variável, dependendo do balanço de insumos contra saídas. As entradas são devido à absorção de dióxido de carbono da atmosfera no processo de fotossíntese e sua incorporação ao solo pelos resíduos de plantas e animais. As saídas são devido à decomposição da MOS, que libera dióxido de carbono em condições aeróbias e metano em condições anaeróbicas. Em certas condições, decomposição de matéria orgânica (MO) também pode causar a liberação de óxido nitroso (HILLEL; HOSENZWEIG, 2009).

O balanço de carbono do solo é muito influenciado pela atividade antrópica, incluindo a retirada da vegetação natural e os padrões de uso da terra em pastagens, áreas agrícolas, industriais e urbanas. As perdas combinadas a partir de biomassa nativa da Terra e perdas dos solos devido ao desmatamento e cultivo durante os últimos três séculos têm sido estimadas em cerca de $17010^{15} \mathrm{~g}$ de carbono. Desmatamento contínuo para a agricultura nos trópicos, aparentemente, resulta em emissões adicionais da ordem de $1,610^{15} \mathrm{~g}$ de carbono por ano (CCST, 2007).

Recentemente, com mudanças climáticas globais sendo evidenciadas, o interesse pelo conhecimento sobre a dinâmica da MOS tem aumentado. Os estudos para a potencialização 
do solo como agente sequestrante de carbono da atmosfera têm sido intensificados, como estratégia para ajudar a mitigar as emissões de carbono antropogênico (POST et al., 2004).

\subsection{Agropecuária mitigando o efeito da emissão de gases}

A agricultura pode ser uma aliada importante para a mitigação da concentração de $\mathrm{CO}_{2}$ na atmosfera. Pela fotossíntese os vegetais podem-se converter o $\mathrm{CO}_{2}$ da atmosfera em massa vegetal e, além disso, por meio de um manejo adequado desta massa pode-se reter parte do carbono no solo. Esse mecanismo é classificado como "sequestro de carbono" da atmosfera pelo solo (LAL, 2004abc).

Os solos em geral, são os principais absorventes, depositários e liberadores de carbono orgânico e podem atuar como fonte ou dreno de carbono para a atmosfera, dependendo das condições naturais e, sobretudo, do tipo de manejo adotado (ZANATTA et al., 2007).

Os ECs variam conforme a intensidade dos processos de adição de resíduos vegetais e de decomposição destes compostos orgânicos, sendo vários os fatores biológicos, químicos e físicos que conferem às frações orgânicas de proteção ao ataque de microrganismos.

Práticas agrícolas, pastagens e florestas desempenham um papel essencial na captura de carbono atmosférico através da fotossíntese. Além do mais, o carbono presente no solo reduz a erosão, conserva a água, favorece o desenvolvimento da microbiota e melhora a estrutura do solo e produtividade (LAL et al., 2004c).

A dinâmica da MOS é o resultado da interação entre os diversos fatores ambientais e as interferências antropogênicas. $\mathrm{O}$ adequado entendimento dessa dinâmica permite melhor manejo de solo, uma vez que a MOS afeta diretamente sua qualidade e produtividade (ROSCOE; MERCANTE; SALTON, 2006).

Alternativas viáveis para a mitigação das emissões pela agricultura seriam as possibilidades de sequestro de carbono pelo solo por meio de ações de reflorestamento, recuperação de áreas degradadas, sistemas de integração lavoura-pecuária (NICOLOSO, 2005), como a utilização de pastagens de gramíneas da espécie Brachiaria (BOLINDER et al., 1999; BODDEY et al., 2001) e o uso de práticas conservacionistas de manejo, como o sistema de plantio direto (PD) (BAYER et al., 2002ab; BAYER et al., 2006ab; LAL, 2004abc). 
Porém, mudanças climáticas que vêm acontecendo e o uso inadequado da vegetação e solo podem interferir negativamente na dinâmica dos nutrientes no solo, indicando que o EC na superfície é vulnerável (CIAIS et al., 2005).

Esse uso inadequado do solo gera emissão de $\mathrm{CO}_{2}$, produzido essencialmente pela respiração das raízes das plantas e pela decomposição da MO promovida pela ação dos microrganismos. No caso de solos desprovidos de vegetação, a produção de $\mathrm{CO}_{2}$ em seu interior está relacionada à atividade microbiana. Além da produção desse gás, faz parte do processo de emissão o transporte do gás do interior do solo até a superfície, que é governado pela equação de difusão, ou seja, a taxa com que o $\mathrm{CO}_{2}$ é liberado do solo para a atmosfera é controlada pelo gradiente de concentração de $\mathrm{CO}_{2}$ existente entre o solo e a atmosfera. (GARCIA et al., 1997).

\subsection{Sistema produtivo de pastagem no Brasil}

O Brasil dispõe de uma área total de aproximadamente 850 milhões de hectares (Mha) onde 554 Mha (65\%) são constituídos por vegetação nativa, 60 Mha (7\%) são empregados em áreas produtivas de frutas e silviculturas, 38 Mha (4\%) estão distribuídos nas porções urbanas e cerca de 200 Mha (23\%) são destinados à pastagens (ICONE, 2012).

Desses 200 Mha de pastagens ou 23\% do uso total da terra no Brasil, 100 Mha são pastagens cultivadas com gramíneas tropicais (SPAROVEK; CORRECHEL; BARRETO, 2007). Consequentemente, para a expansão dessas pastagens cultivadas, há a necessidade de um bom manejo, com entrada do nitrogênio no sistema, desenvolvimento radicular em profundidade, controle de lotação animal e não revolvimento do solo, tendo como resultado, o acúmulo de MOS (JANTALIA et al., 2006).

Nos últimos anos, muitas pesquisas voltaram-se para entender o papel da produção agrícola e das pastagens sobre a dinâmica do $\mathrm{C}$ no solo, sendo que áreas sob pastagens de gramíneas, principalmente do gênero Brachiaria, ocupam mais de 144 milhões de hectares no Brasil, representando aproximadamente $70 \%$ de nossas pastagens.

Rezende e colaboradores (1999) verificaram que as pastagens apresentam um grande potencial para retirar $\mathrm{CO}_{2}$ da atmosfera e enriquecer o solo com MO. Esses autores também mostraram que após 10 anos de retirada da vegetação nativa e da instalação das pastagens cultivadas de Brachiaria, o EC foi reposto pela forrageira e apresentou tendência de aumentar, por meio da decomposição de seus resíduos aéreos e raízes, acumulando grande 
quantidade de carbono, enriquecimento este que pode se aproximar, ou às vezes, até ultrapassar, os níveis observados no solo sob vegetação nativa.

Entretanto, a continuação deste acúmulo de carbono no solo depende significativamente de um bom manejo da pastagem. Taxas de lotação animal, uso correto de fertilizantes e corretivos de solos para suprir as deficiências de macro e micronutrientes são fatores essenciais para manter a sustentabilidade da pastagem (JANTALIA et al., 2006). Mais que isso, estudos de variabilidade espacial e caracterizações do solo em profundidades de até $100 \mathrm{~cm}$ têm mostrado resultados interessantes, principalmente quando se trata de espécies de gramíneas com sistema radicular abundante, com incorporação de carbono em profundidade (JANTALIA et al., 2006; SEGNINI, 2007; BODDEY et al., 2010).

Qualquer mudança no EC provocada por introdução dessas espécies de gramíneas proporciona um enorme impacto no balanço de GEE (BODDEY et al., 2001). Nesses sistemas, com o uso de fontes nitrogenadas e calcário, pode ocorrer enriquecimento do perfil do solo com cálcio, o que também estimula o desenvolvimento radicular em profundidade (PRIMAVESI et al., 2004). Com isso, a utilização das gramíneas forrageiras, com o intuito de formar cobertura ao solo, associado também ao não revolvimento do solo, possibilita a diversificação da produção agrícola. Com a inserção de animais no sistema, eleva-se a produção de resíduos (fezes e urina), favorecendo o processo de acúmulo de MOS (ROSCOE; MERCANTE; SALTON, 2006). Essas forrageiras tropicais são conhecidas também pela sua capacidade de adaptação às condições de clima e solos tropicais.

Segundo a Embrapa Agrobiologia, estimativas recentes, indicam que mais de 50\% das áreas sob pastagens se encontram em processo de degradação. Um dos principais sinais de degradação da pastagem é a perda de vigor, ou em outras palavras, a pastagem passa a sustentar cada vez menos animais com o passar do tempo. Se a forrageira não cresce mais com a mesma intensidade, a produção de resíduos (folhas e raízes velhas), que alimentam as formas de vida do solo, diminui. Assim, a MOS vai diminuindo, e o carbono, retornando para o ar na forma de $\mathrm{CO}_{2}$. É importante que se entenda que o efeito desse processo no meio ambiente é notado somente a longo prazo, porém, não se pode dizer o mesmo quanto a perda econômica do produtor (ALVES et al., 2003).

A pecuária é uma atividade de grande representatividade ao Brasil, tanto economicamente quanto ambientalmente, assumindo lotação média de 0,8 UA/ha (Unidade animal por hectare). Especialistas afirmam que em 2021 a pecuária brasileira irá criar 220 milhões de cabeças em 150 milhões de hectares. (RURAL CENTRO, 2011). 
Em reflexo, esses dados mostram a evolução agrotecnológica que o país vem vivendo ao longo dos anos, principalmente no que diz respeito à economia e as boas práticas de manejo (BPM) agropecuário, influenciando diretamente as estratégias de mitigação de carbono na atmosfera, sendo esta uma resposta rápida e eficaz às MCG.

Como este é um tema de grande importância, os governos precisam de previsões de tendências futuras das mudanças globais de forma que possam tomar decisões políticas que evitem impactos indesejáveis. O quarto relatório do IPCC faz algumas previsões a respeito das mudanças climáticas as quais são a base para os atuais debates políticos e científicos (CCST, 2007).

Assim, a busca de alternativas sustentáveis dos pontos de vista econômico, social e ambiental são fundamentais, sendo a intensificação de pastagens uma opção muito interessante, não só para reduzir o impacto ambiental negativo do uso de pastagens degradadas na pecuária, mas também para liberar área para a agricultura e assim reduzir a necessidade de eliminação de florestas, que exercem um grande serviço ambiental na regulação das condições climáticas favoráveis à agropecuária.

\subsection{Matéria Orgânica do Solo (MOS)}

A MOS é definida como uma mistura de compostos em vários estágios de decomposição resultantes da degradação biológica de plantas e animais (STEVENSON,1994). A MOS está intimamente relacionada com vários parâmetros físicos e químicos do solo tais como a retenção de água, densidade do solo, $\mathrm{pH}$, capacidade de troca catiônica, aeração e atividade microbiana. A quantidade de MOS é influenciada pelo tipo de vegetação, textura e umidade (SANTOS, 2006).

Portanto, a MOS tem sido considerada um indicador importante para a classificação da qualidade do solo, a qual reflete diretamente na produtividade vegetal (ARAÚJO et al., 2008). A MOS também desempenha papel importante na qualidade ambiental, já que participa do ciclo do carbono do planeta e por esse motivo tem atraído atenções por conta do fenômeno do aquecimento global (CERRI, 2007).

Pode-se dizer que a MOS é constituída, basicamente, de dois tipos de substâncias: as húmicas (ácido húmico, ácido fúlvico e humina) e não húmicas (proteínas, aminoácidos, polissacarídeos, ácidos orgânicos, entre outros). As substâncias húmicas são os componentes mais recalcitrantes da MOS e são constituídas de uma mistura heterogênea de grupos funcionais, as quais se diferenciam de acordo com suas características de solubilidade. 
Estas substâncias são formadas a partir do processo de humificação, o qual altera estruturas químicas da MOS pela degradação de resíduos orgânicos, ou seja, resulta na formação de grupos fluorescentes como anéis aromáticos e compostos insaturados, que podem ser avaliados por espectroscopia de fluorescência. O processo de humificação da matéria orgânica do solo é afetado pelo clima, tipo de solo e sistemas de manejo (SEGNINI, 2007).

As características químicas da MOS são indicativos sobre as práticas de manejo adotadas àquele solo. As frações estáveis (ou humificadas) da MOS são diretamente influenciadas pelo manejo do solo, sendo o grau de humificação um "medidor" de quão a MOS está estável, ou seja, resistente à decomposição microbiana.

\subsection{Caracterização de carbono em solos}

A medição de carbono do solo é foco de atenção de convenções e acordos internacionais presentes, relacionados às mudanças climáticas globais (CCST, 2007; CLIMATE CHANGE, 2013). A relevância dos estudos sobre MOS como um componente importante na definição da qualidade dos sistemas agrícolas e a capacidade do solo em "sequestrar" carbono da atmosfera tem sido relatado por diversos autores (LAL et al., 2004abc).

Contudo, é necessário que os métodos de quantificação de carbono sejam eficientes o suficiente para oferecer melhores estimativas dos inventários de carbono. Mais que isso, tais métodos instrumentais precisam conferir precisão e exatidão nas determinações e serem os mais "limpos" possíveis em termos de geração de resíduos (SEGNINI et al., 2008). O conhecimento mais exato e preciso sobre os teores de carbono no solo é fundamental em diversas áreas da ciência do solo, entretanto vários métodos para a quantificação têm sido utilizados.

Há ainda hoje carência de informações consistentes quanto à definição e recomendação do método mais adequado para a obtenção de resultados confiáveis e satisfatórios, principalmente para uso em metodologias não convencionais como métodos espectroscópicos (SEGNINI et al., 2008). Além disso, quando se faz necessário grande quantidade de amostras e análises, o uso de métodos caros, laboriosos e demorados, que geram grande quantidade de resíduos químicos não são mais desejáveis.

A determinação de carbono por métodos tradicionais demandam tempo para o preparo da amostra e custo para a realização da medida. Esse é o caso do método Walkley-Black, 
utilizado em trabalhos anteriores, onde há geração excessiva de resíduos químicos para essas determinações.

\subsubsection{Análise elementar (CHNS)}

A análise elementar (CHNS) é a técnica instrumental que já dispensa boa parte do preparo de amostra e assim gera uma quantidade menor de resíduos químicos. Atualmente, é a técnica mais confiável na determinação de carbono em amostras de solo, podendo ser utilizada como referência na estimativa de carbono por outras técnicas instrumentais.

Essa técnica permite a determinação porcentual dos quatro elementos químicos, carbono $(\mathrm{C})$, hidrogênio $(\mathrm{H})$, nitrogênio $(\mathrm{N})$ e enxofre $(\mathrm{S})$ de uma amostra. A tecnologia associada à análise CHNS é a combustão seca, dessa forma a amostra é totalmente queimada e em seguida os gases da sua combustão são analisados. Os produtos dessa combustão são $\mathrm{CO}_{2}$ para análise de $\mathrm{C}, \mathrm{H}_{2} \mathrm{O}$ para análise de $\mathrm{H}$ e $\mathrm{NO}$ para análise de $\mathrm{N}$, os quais são eluídos e separados por uma coluna cromatográfica.

Porém, o custo por amostra em análise por CHNS ainda é elevado, levando em conta a manutenção do equipamento, troca de colunas cromatográficas e compras de gases de arraste. Pensando em minimizar ainda mais o tempo de preparo de amostras e o gasto com reagentes químicos, a comunidade científica busca o desenvolvimento e aplicação de alguns métodos analíticos conseguindo unir precisão, exatidão, simplicidade, rapidez, pequena geração de resíduos e custo acessível para a análise de solos. Na espectroscopia existem técnicas utilizando LIBS e infravermelho que apresentam potencial de suprir todos estes itens (MILORI et al., 2011ab).

\subsubsection{LIBS - Laser Induced Breakdown Spectroscopy}

A sigla "Laser" significa Light Amplification by Stimulated Emission of Radiation, ou seja, Amplificação da luz por emissão estimulada de radiação, sendo que seu uso começou na década de 60, com o surgimento do primeiro laser de rubi.

Dois anos depois, Brech e Cross produziram vapores na superfície de materiais metálicos e não metálicos e esses vapores foram excitados por uma fonte auxiliar, formando assim um microplasma a fim de se obter o primeiro espectro de emissão. Esses e outros fatos subsequentes são considerados o nascimento das técnicas de emissão atômica utilizando laser como fonte de energia, a qual se denominava LIBS (PASQUINI et al., 2007).

Alguns equipamentos comerciais utilizando lasers foram produzidos na época após esses fatos, porém com altos custos. Logo técnicas como a espectrometria de emissão óptica 
por plasma acoplado indutivamente (ICP-OES) e espectroscopia de absorção atômica (AAS) cresceram mais frente às técnicas a laser, as quais ganharam espaço por sua simplicidade e baixo custo (Espectroscopia de absorção atômica de chama - FAAS), por permitirem determinações simultâneas (ICP-OES e ICP-MS (espectrometria de massas)) ou também por permitirem acoplamentos com técnicas de separação e especiação como sistemas de injeção em fluxo (FIA) e Cromatografia Líquida de Alta Eficiência (HPLC), além de cobrir uma ampla faixa de concentrações e limites de detecção da ordem de $\mu \mathrm{g} / \mathrm{L}$ a pg/L.

Nos dias de hoje as técnicas ICP-OES e AAS são amplamente utilizadas para as determinações e quantificações de metais, como macro e micronutrientes em qualquer tipo de amostra.

Embora as determinações sejam realizadas em tempos abaixo de 1 minuto, a conversão e/ou preparo das amostras sólidas em solução para injeção, necessitam de tempos entre 5 minutos e 48 horas dependendo das amostras. Juntamente com o elevado trabalho e tempo para o preparo das amostras, outro ponto negativo é o alto consumo de reagentes para essas digestões, onde são utilizados misturas de ácidos fortes, contribuindo assim para uma maior geração de resíduos indesejáveis. Além do mais, a etapa de preparo da amostra corresponde a maior parte dos erros cometidos na sequência analítica (SANTOS JUNIOR et al., 2006).

Logo, prevaleceu a ideia que o tratamento da amostra previamente à análise demandava maior custo e seria a etapa geradora da maior parte de erros, fatores que levaram os pesquisadores a procurarem métodos mais rápidos de preparo de amostras e técnicas que precisassem o mínimo ou nenhum preparo das amostras.

Inovações como a utilização da análise elementar para a determinação de carbono em amostras variadas, já eliminam boa parte da etapa demorada de preparo das amostras e gastos com reagentes químicos. Buscando melhorar o método de determinação de carbono, outro objetivo desse trabalho de pesquisa foi a possibilidade da utilização de instrumentação avançada, para a estimativa de carbono em solos.

O interesse em LIBS teve crescimento na década de 80, onde novos lasers foram desenvolvidos com altas energias e preços mais acessíveis. Porém apenas a partir 1995 ocorreu um notável aumento nos trabalhos publicados com LIBS. (SANTOS JUNIOR et al., 2006).

A técnica LIBS é um tipo de espectroscopia de emissão atômica que utiliza um pulso de laser de alta energia para, simultaneamente, preparar a amostra e excitar os átomos. Uma análise qualitativa do espectro de emissão fornece uma "digital" da amostra com relação à sua 
composição elementar, incluindo a determinação quantitativa do carbono em solos intactos. Com ela é possível a quantificação de praticamente todos os elementos da tabela periódica, dispensando parte ou total preparo de amostras, onde as medidas são baratas e rápidas com a disponibilidade de se realizar medidas in situ (MIZIOLEK; PALLESCHI; SCHECHTER, 2006).

A ablação na superfície da amostra causada pelo pulso do laser de alta energia ocorre de modo a gerar um plasma onde são encontradas espécies iônicas excitadas e/ou atômicas, as quais retornam ao estado fundamental emitindo radiações características que são medidas pelo sistema de aquisição de dados. As intensidades das linhas de emissão atômica presentes no espectro estão intimamente relacionadas à matriz, pois a formação do plasma ocorre na superfície da amostra onde é possível haver flutuação na temperatura e densidade eletrônica do plasma. Métodos multivariados podem ser usados como ferramentas para diminuir o efeito dessas variações a cada pulso (FERREIRA et al., 2010).

Essa técnica tem possibilitado medidas qualitativas e quantitativas em qualquer tipo de material, independente de seu estado físico, sólido, líquido ou gasoso. Apresenta análises rápidas (0,5 min) e in situ, com massas amostradas entre 0,1 e $100 \mu \mathrm{g}$ (tipicamente $1 \mu \mathrm{g}$ ).

As principais vantagens da técnica são: necessidade de pouco ou nenhum tratamento prévio da amostra, rapidez na obtenção dos resultados e também a possibilidade de se trabalhar com equipamentos portáteis no campo, ou seja, analisa-se diretamente a amostra de solo (DA SILVA et al., 2008). Aliado à "Química Verde", filosofia esta que combate o uso excessivo de reagentes químicos e geração de resíduos, a técnica LIBS vem sendo fortemente defendida no meio da pesquisa.

Da Silva (2008) utilizou sistemas LIBS de bancada e portátil no desenvolvimento de metodologia para quantificação de carbono em latossolos tropicais, empregando modelos de regressão linear simples e crescimento exponencial na construção do modelo. A curva de calibração obtida predisse teor de carbono de amostras desconhecidas com um erro em torno de $0,1 \%$.

Martin e colaboradores (2010) aplicaram a análise multivariada no tratamento de espectros obtidos com LIBS na quantificação de carbono em solos com diferentes conteúdos de argila, silte e areia. Os autores também mostram que a presença de ferro nas amostras apresenta relação direta com a quantidade de carbono.

Abaixo, na figura 1, é mostrado um diagrama com os principais componentes de um equipamento LIBS. 
Figura 1 - Representação de um equipamento comercial de LIBS.

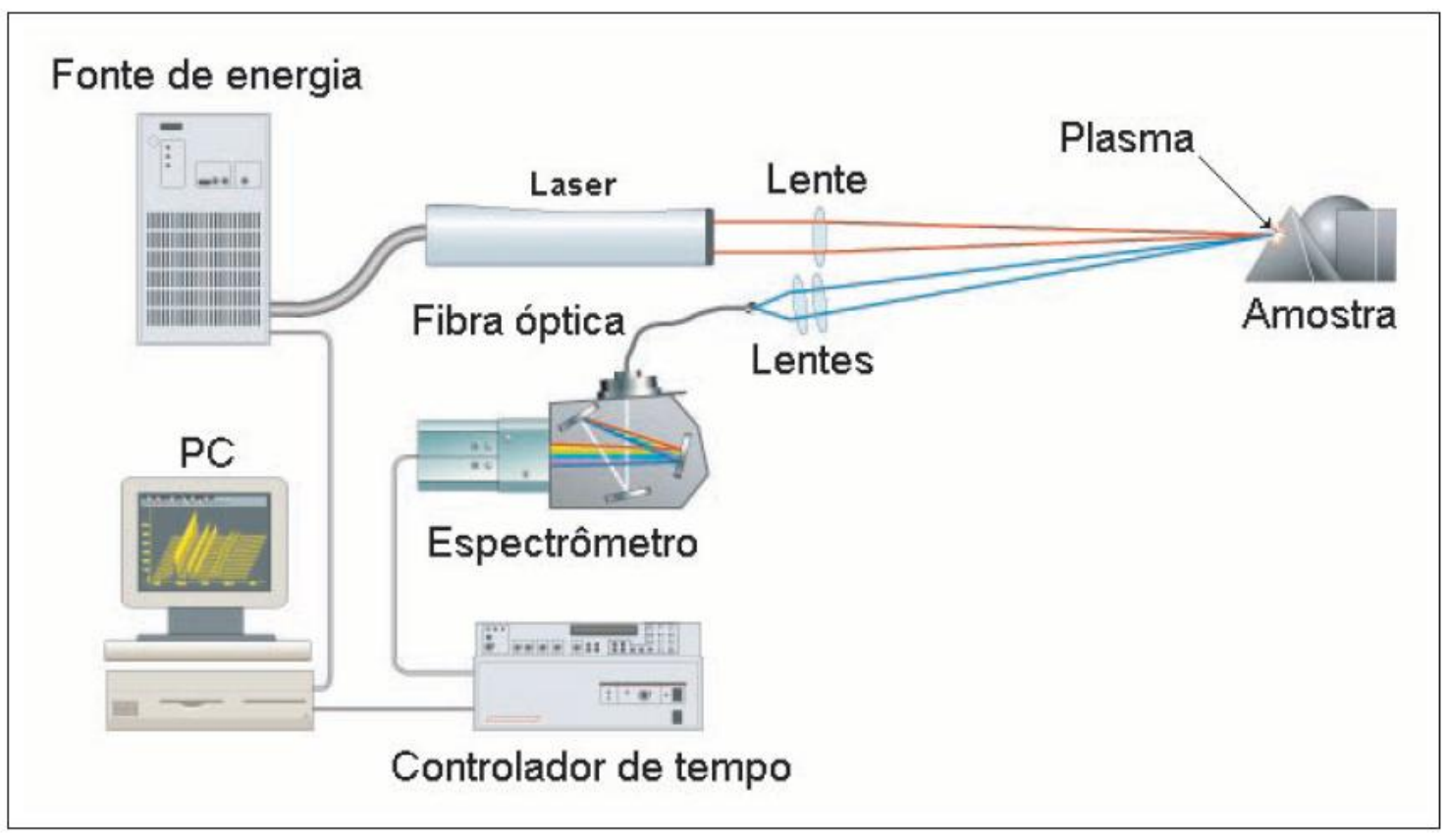

Fonte: http://www.appliedphotonics.co.uk/Libs/about_libs.htm (adaptado)

As etapas do processo de ablação geradas pelo pulso de laser são mostradas na figura 2. Primeiramente um pulso de laser atinge a superfície da amostra removendo uma pequena quantidade de amostra e iniciando o processo de formação do plasma. Essa energia rapidamente é convertida em aquecimento (cerca de $50.000 \mathrm{~K}$ ), fornecendo energia suficiente para a excitação para um estado de maior energia dos elementos presentes na amostra.

Durante as fases iniciais do plasma, a densidade de espécies é elevada, assim, em um primeiro momento as emissões são dominadas por uma luz branca, com pouca ou nenhuma variação com o comprimento de onda. É a chamada etapa de emissão contínua de luz, a qual ocorre entre 200 e 300 nanossegundos seguida do começo do esfriamento do plasma.

A diminuição da temperatura do plasma começa ocorrer por volta de 1 microssegundo, momento em que há a abertura dos espectrômetros para a aquisição do espectro. Portanto a aquisição dos espectrômetros é feita depois de certo intervalo de tempo, o Delay Time, que consiste no tempo entre o pulso do laser e o início da aquisição dos espectrômetros.

A luz emitida é coletada por um conjunto de lentes e é enviada pelas fibras óticas aos espectrômetros onde os dados são convertidos em espectro e interpretados pelo computador. 
Figura 2 - Etapas do processo de ablação a laser.

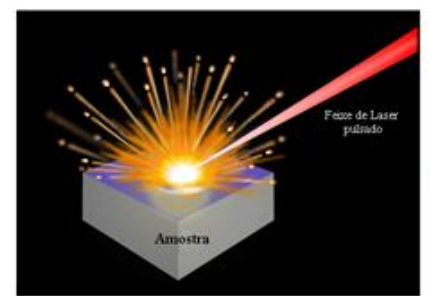

Laser Ablation: Remoção de uma pequena quantidade de massa da superficie da amostra utilizando um feixe de laser pulsado

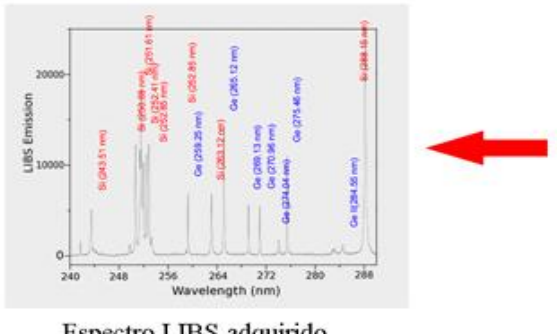

Espectro LIBS adquirido

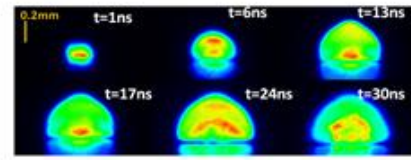

Iniciação e rápida expansão do plasma sobre a superficie da amostra
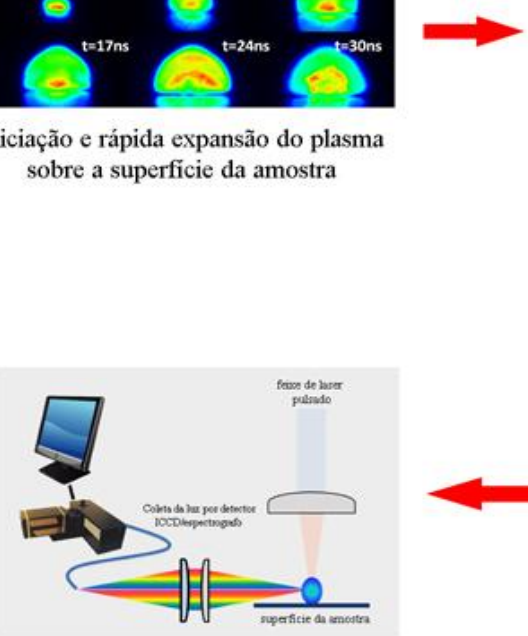

A luz emitida é coletada pelo conjunto de lentes e fibras óticas

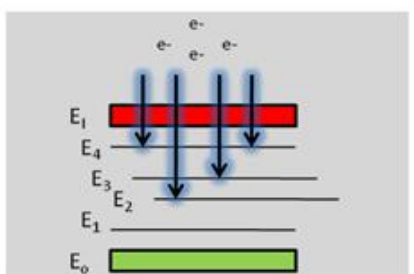

Emissão continua de luz na fase inicial ( $<200$ a 300ns)

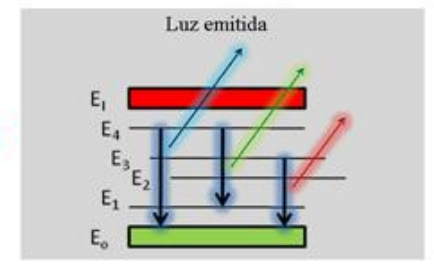

Emissão discreta de linhas atômicas $(>1 \mu \mathrm{sec})$

Fonte: http://www.appliedspectra.com/technology/LIBS.html (adaptado)

Na figura 3 é possível observar esta diminuição da intensidade das emissões no contínuo com o tempo. Nela, $t_{\mathrm{d}}$ representa o Delay Time, ou seja, o tempo entre a formação do plasma e o início da observação das emissões, e $t_{\mathrm{b}}$ representa o tempo durante o qual as emissões são monitoradas.

Figura 3 - Períodos de tempo importantes após a formação do plasma e a predominância de diferentes espécies.

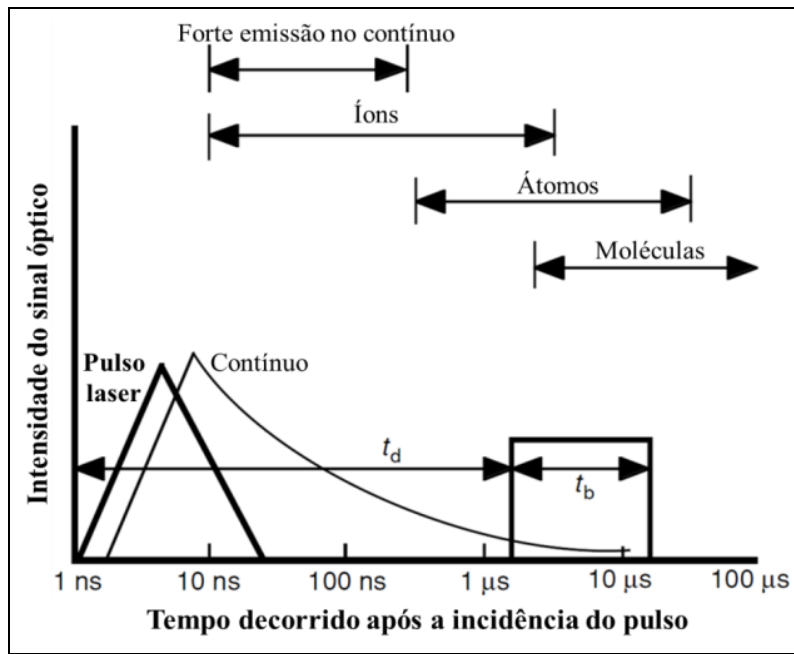

Fonte: MIZIOLEK; PALLESCHI; SCHECHTER (adaptado). 


\subsubsection{LIFS - Laser Induced Fluorescence Spectroscopy}

O fenômeno da luminescência ou fotoluminescência é dividido em fluorescência e fosforescência já que os dois processos ocorrem pela absorção de fótons fornecidos por uma fonte de energia externa e excitação eletrônica.

O estado fundamental de uma molécula é o estado de menor energia em que seus elétrons podem ocupar. Já os estados excitados são os diversos níveis energéticos com energia superior ao estado fundamental. Esses estados excitados podem ser atingidos quando a molécula recebe certo valor de energia. A absorção de energia ocorre de maneira rápida, da ordem de $10^{-14} \mathrm{~s}$.

A fluorescência (figura 4) é um processo rápido (da ordem de $10^{-5} \mathrm{~s}$ ) de decaimento radiativo de um estado excitado para o estado fundamental onde não ocorre mudança de spin eletrônico $\left(S_{1}{ }^{*} \Rightarrow>S_{0}\right)$. Já fosforescência há mudança de spin eletrônico $\left(T_{1}=>S_{0}\right)$ e o tempo de vida dos estados excitados pode chegar a ordem de segundos ou minutos. Essas transições eletrônicas são comuns em sistemas contendo elétrons não ligantes (n), ou elétrons ligantes $(\pi)$, que são excitados para orbitais antiligantes $\pi^{*}$ (SKOOG; HOLLER; NEUMAN, 2002).

Figura 4 - Diagrama de transição eletrônica de fluorescência molecular

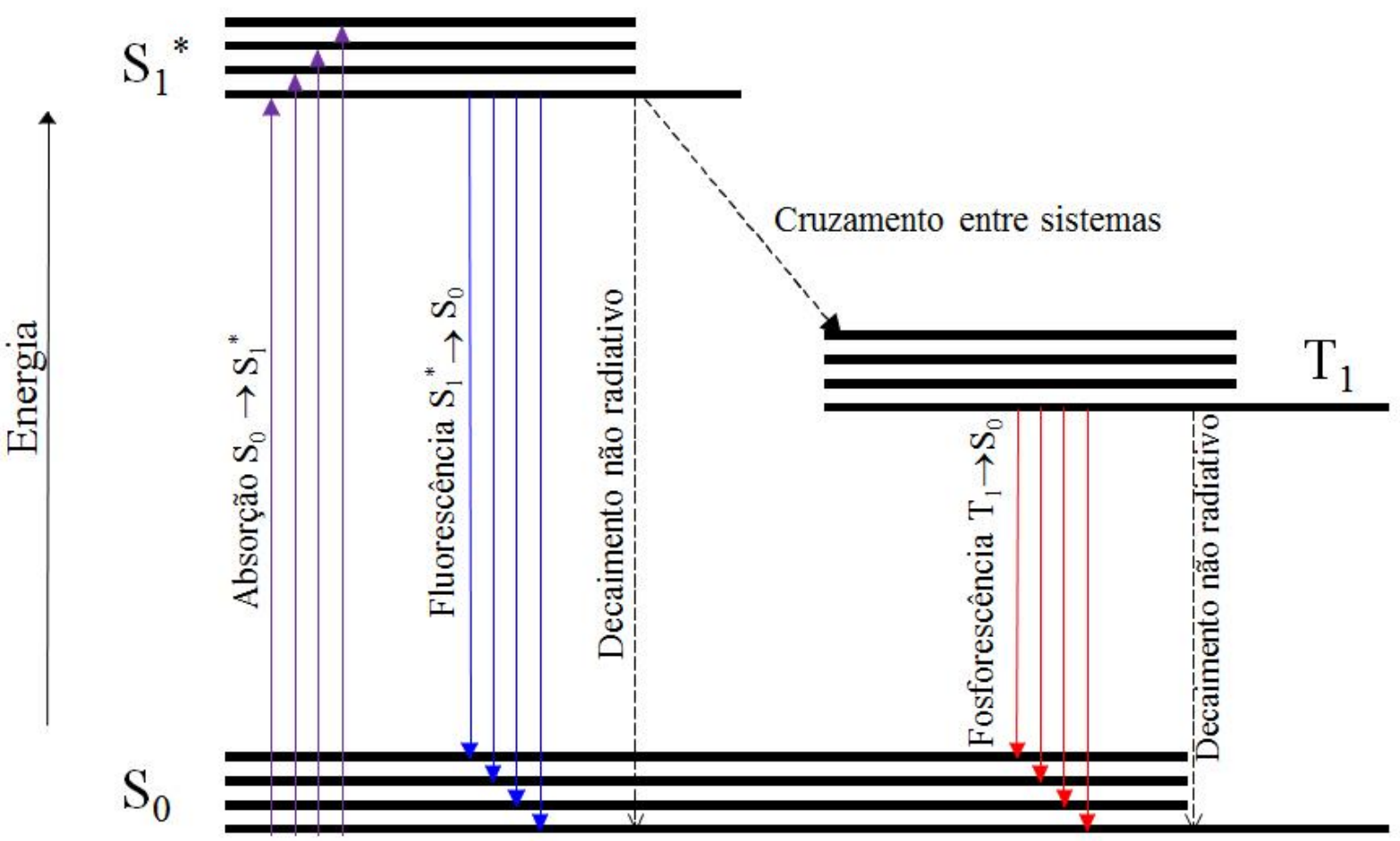

Fonte: Autoria própria 
Para o estudo da MOS, diversas técnicas são utilizadas para avaliar seu grau de humificação como as espectroscopia de absorção no UV-Vis e de fluorescência de luz UVvis, ressonância magnética nuclear (RMN) e ressonância paramagnética nuclear (RPE). Porém, para todos esses métodos, se faz necessário o fracionamento químico do solo inteiro, procedimento esse sugerido pela IHSS (International Humic Substance Society) que consiste na separação química da MOS em frações menos complexas.

Por outro lado, dentro do contexto de caracterização da MOS, a técnica LIFS (ou Espectroscopia FIL em português) tem a vantagem sobre RMN de ${ }^{13} \mathrm{C}$ e RPE devido à possibilidade de se trabalhar com a amostra in natura e sem a interferência de metais paramagnéticos, limitação presente em algumas técnicas espectroscópicas quando se analisa Latossolos ou outros solos que possuem concentrações consideráveis de íons paramagnéticos de $\mathrm{Fe}^{3+}$. LIFS também tem se mostrado bastante sensível e com reduzido custo e geração de resíduos (SEGNINI, 2007, 2010, 2011).

O princípio básico dessa técnica é utilizar um laser para excitar as moléculas mais rígidas da MOS em amostras não submetidas a fracionamento ou in situ e coletar o sinal de fluorescência do solo (MILORI et al., 2006). Essa excitação ocorre em grupos fluoróforos, ou seja, grupos orgânicos contendo anéis condensados e duplas ligações que apresentam fluorescência em comprimentos de ondas específicos. O resultado da interação do solo com o laser será a fluorescência de grupos funcionais da MO relacionados com o processo de humificação.

Milori e colaboradores (2006) estudaram a aplicabilidade da LIFS em amostras de solo, sem qualquer pré-tratamento ou fracionamento. O objetivo do trabalho desses autores foi propor um índice de humificação e correlacionar com os índices de humificação de ácidos húmicos dissolvidos já propostos anteriormente (MILORI et al., 2002). Os autores concluíram que o sinal de fluorescência emitido a partir de uma amostra de solo excitado com radiação no intervalo do azul ao ultravioleta próximo é devido a MO mais humificada.

Segnini e colaboradores (2010) mostraram a aplicabilidade do uso de equipamento portátil de LIFS na análise de solos com correlação de aproximadamente $90 \%$ ao comparar com LIFS de bancada e com RPE. 


\section{CAPÍTULO 3}

METODOLOGIA

\section{1 Área Experimental}

$\mathrm{O}$ experimento em questão contém dois sistemas distintos de pastagem e a área de mata nativa que estão localizados na Embrapa Pecuária Sudeste - Fazenda Canchim, em São Carlos/SP à Rodovia Washington Luiz, Km 234 (altitude de aproximadamente $850 \mathrm{~m}$ ). Toda a logística das coletas de solos foi conduzida pela equipe interdisciplinar presente na Embrapa Pecuária Sudeste e Instrumentação.

O clima local é considerado como tropical de altitude, que, segundo a classificação de Köppen, é o Cwa, clima quente com inverno seco. A área compreende um total de 22,5 hectares (ha), sendo 10,5 ha de Brachiaria decumbens e 12 ha de Panicum maximum cv.

\section{Mombaça.}

A dinâmica (sequestro e emissão) do carbono foi avaliada nos dois sistemas de pastagens destinados à pecuária bovina. $\mathrm{O}$ primeiro (A3) é um sistema de pastagem em recuperação, onde é executada correção do solo e fertilização com doses de nitrogênio (ureia) e o segundo (A4) corresponde a um sistema em degradação onde nenhum tipo de correção ou controle foi realizado. A mata nativa (Mata Atlântica) localizada próxima ao experimento foi utilizada como referência positiva. Foram coletadas amostras em seis trincheiras para cada uma das três áreas em questão.

$\mathrm{Na}$ figura 5 estão representadas as áreas de coleta dos solos do experimento de campo. A área nativa denominada Mata Atlântica, próxima ao experimento, foi utilizada como referência. Os pontos em verde representam as trincheiras abertas na área $\mathrm{A} 3$ e os pontos em amarelo representam as trincheiras abertas na área A4. 
Figura 5 - Representação dos pontos de coleta do experimento a partir de coordenadas geográficas obtidas por GPS.

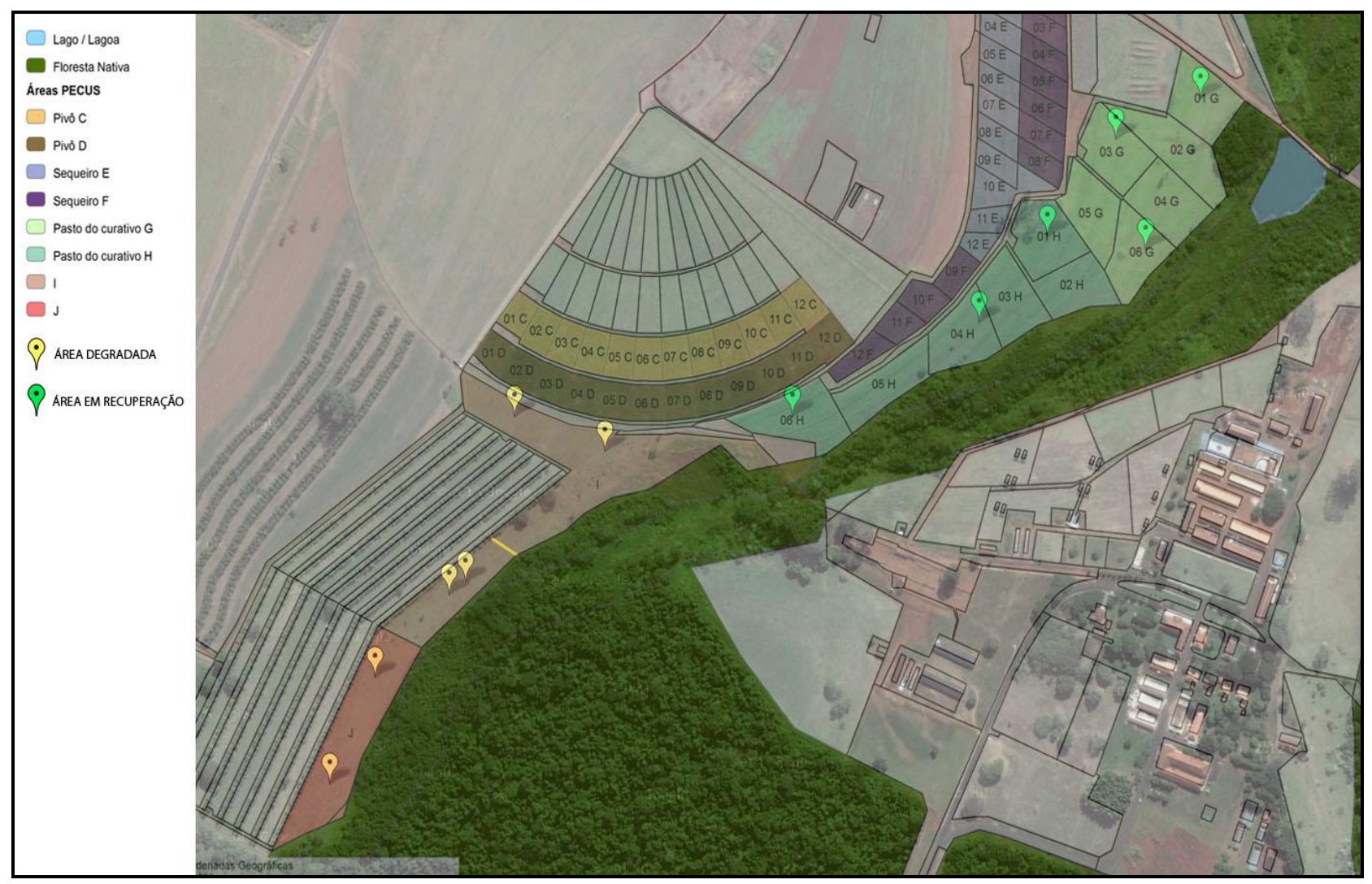

A3 - em recuperação, A4 - degradada, MT - Mata Atlântica.

Fonte: Google Earth (Autoria própria)

Cada área de pastagem possui duas subáreas em campo. Em cada subárea, foram abertas três trincheiras (T), totalizando seis replicatas para cada área de amostragem (T1 a T6). As áreas de pastagem foram denominadas como A3 - Em recuperação e média lotação animal (subáreas G e H) e A4 - Degradada e média lotação animal (subáreas I e J), em função do manejo e loteamento animal.

O processo de abertura das trincheiras foi demorado e trabalhoso, desde o deslocamento de retroescavadeiras até as coletas até $1 \mathrm{~m}$ de profundidade. Outro fator agravante foi que as trincheiras deveriam ser abertas e fechadas no mesmo dia devido à lotação animal e ao perigo eminente do gado ser ferir na trincheira aberta.

\subsection{1 Área A3 - Em recuperação e média lotação animal}

Foi utilizada uma pastagem de Brachiaria decumbens localizada em um Nitossolo Vermelho (Antiga Terra Roxa Estruturada). O sistema estava sendo utilizado por vacas de 
cria durante o período de estação de monta e gestação. Os processos de recuperação direta de pastagens, com correção do solo e fertilização foram calculados para atingir cerca de 2 a 3 UA/ha na estação das águas (novembro a abril) e 0,7 a 1 UA na época seca (maio a setembro) (OLIVEIRA; PENATTI; CORSI, 2008). A dose de nitrogênio foi calculada (200 Kg N/ha.ano) levando-se em consideração os resultados da análise de solo, especialmente o teor de $\mathrm{MO}$, e a lotação animal pretendida. A fonte de nitrogênio empregada foi a ureia e a forma de aplicação foi a lanço e parcelada em três ou quatro aplicações (adubações de cobertura) após os pastejos da época das águas.

\subsection{2 Área A4 - Degradada e média lotação animal}

Esse manejo apresentava a mesma vegetação da área em recuperação, Brachiaria decumbens. A área apresentava-se em degradação desde 1996 até o momento, mas passível de recuperação. É mantida com baixa lotação animal, invadida com grama batatais e Brachiaria humidicola e algumas espécies arbustivas. A pastagem não recebeu nenhum tipo de correção do solo e fertilização. Durante o período do projeto estava sendo manejada com machos Nelore.

\subsubsection{Mata nativa}

Os dois sistemas avaliados foram comparados com área de vegetação natural, a Mata Atlântica (Floresta Tropical Subcaducifólia), localizada próxima ao experimento montado.

\subsection{Coleta e preparo das amostras}

Para a coleta das amostras do solo foram abertas trincheiras com largura de $100 \mathrm{~cm}$ e com profundidade de $120 \mathrm{~cm}$ aproximadamente. As amostras foram coletadas em oito diferentes profundidades, de 0 a $100 \mathrm{~cm}$, nos intervalos de 0-5, 5-10, 10-20, 20-30, 30-40, 4060, 60-80 e 80-100 cm, em 6 trincheiras para cada uma das três áreas do projeto.

Foram coletadas cerca de $200 \mathrm{~g}$ de solo para cada amostra e o material coletado foi levado ao laboratório, onde se deu início ao preparo de amostras (200 a 300g). O preparo consistiu na secagem dos solos à temperatura ambiente e na limpeza das amostras, tais como, a remoção de raízes e restos vegetais por catação, seguido por homogeneização.

O solo foi triturado com a utilização de almofariz e pistilo e posteriormente peneirado a $2 \mathrm{~mm}$. Uma porção, de aproximadamente $5 \mathrm{~g}$, dessas amostras foi remoída e passada em 
peneira de 0,150 mm (100 mesh) para posteriores análises de determinações de carbono e caracterizações espectroscópicas.

\subsection{Análises}

\subsubsection{Análise granulométrica}

A análise granulométrica foi realizada utilizando o método de pipeta, que se baseia na diferença da velocidade de sedimentação entre partículas de diferentes dimensões. Em suma, o solo é peneirado a $2 \mathrm{~mm}$, para a retirada do material mais grosseiro, disperso em solução de pirofosfato de sódio $0,1 \mathrm{~mol} \mathrm{~L}^{-1}$ e após agitação mecânica, as partículas físicas foram separadas por sedimentação, seguindo a Lei de Stokes.

Essa classificação textural segundo a Embrapa está relacionada com o tamanho das partículas do solo, sendo as partículas menores que 0,002 $\mathrm{mm}$ classificadas como argila, entre $0,002 \mathrm{~mm}$ e $0,053 \mathrm{~mm}$ classificadas como silte e maiores que $0,053 \mathrm{~mm}$ classificadas como areia.

As análises foram realizadas na Embrapa Pecuária Sudeste.

\subsubsection{Densidade do solo}

Para a determinação das densidades do solo, amostras intactas de solo foram coletadas com anel de aço de volume conhecido. Utilizou-se o anel de Kopecky, de bordas cortantes e capacidade interna de $100 \mathrm{~cm}^{3}$ segundo metodologia preconizada pela Embrapa (1997). Esses anéis foram cravados em cada perfil (figura 6a), foram cuidadosamente retirados da parede da trincheira (figuras $6 \mathrm{~b}$ ) e então o excesso de terra foi removido com auxílio de uma faca ou espátula, até igualar com ambas as superfícies do anel. 
Figura 6 - a) Anéis de Kopecky cravados nos perfis amostrais na parede da trincheira e b) Remoção do anel da parede da trincheira.
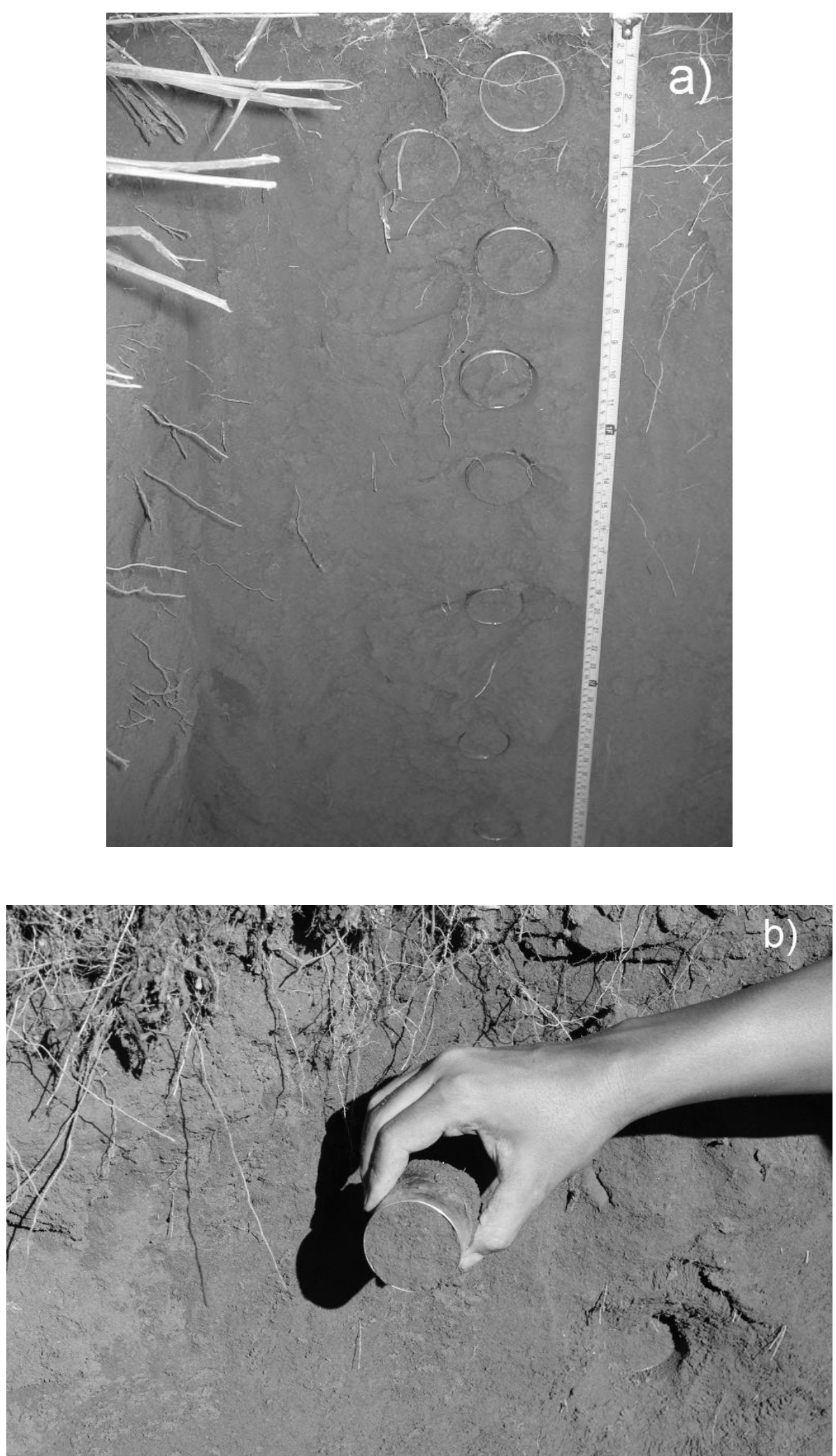

Fonte: Autoria própria 
O cálculo da densidade foi realizado após secagem de aproximadamente $24 \mathrm{~h}$ em estufa a $105{ }^{\circ} \mathrm{C}$ até massa constante. A partir da massa seca e o volume conhecido do anel, calculouse a densidade do solo.

\subsubsection{Quantificação do teor de carbono no solo}

Para as determinações de carbono utilizou-se um equipamento de análise elementar, CHNS/O da Perkin-Elmer (2400 Series II CHNS/O Elemental Analyzer) pertencente a Embrapa Instrumentação. As medidas foram realizadas em duplicata.

Foram pesados cerca de $10 \mathrm{mg}$ das amostras de solo inteiro, previamente peneiradas a 0,150 mm (100 mesh). As amostras foram pesadas diretamente em cápsulas de estanho consumíveis, utilizando a microbalança (Perkin-Elmer, modelo AD6) que é conectada ao CHNS/O para aquisição direta das massas.

Em seguida, as cápsulas de estanho foram fechadas manualmente e introduzidas no forno do analisador como mostrado nas figuras $7 \mathrm{a}$ e $7 \mathrm{~b}$. O estanho presente na cápsula é utilizado para acelerar o processo de combustão. Todos os resultados da análise elementar são baseados em um valor de padrão conhecido, a acetanilida, um padrão orgânico de composição elementar conhecida.

Figura 7 - a) Fechamento das cápsulas de estanho e b) Cápsulas de estanho contendo a amostra de solo sendo inserida no carrossel do analisador elementar

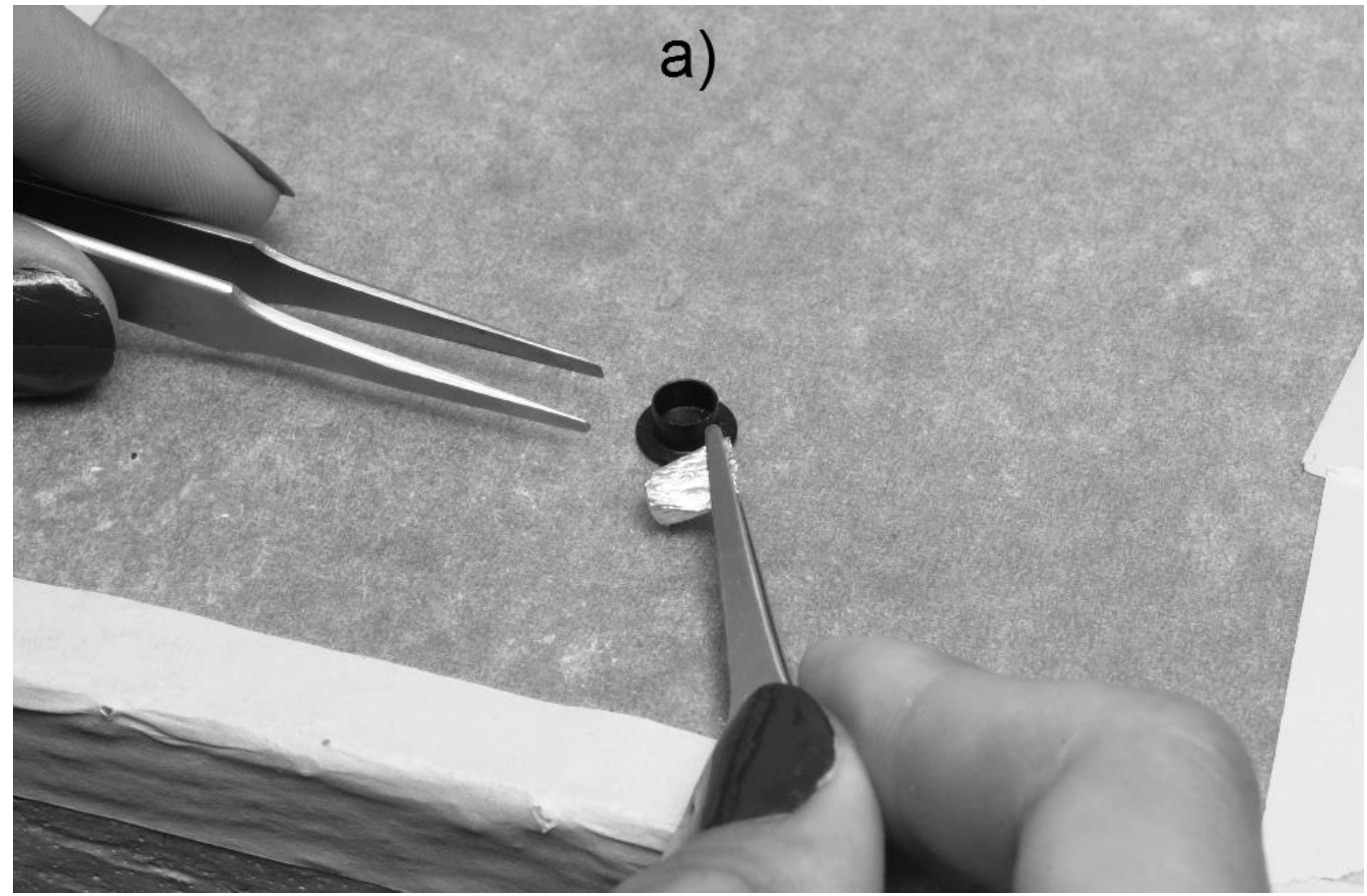




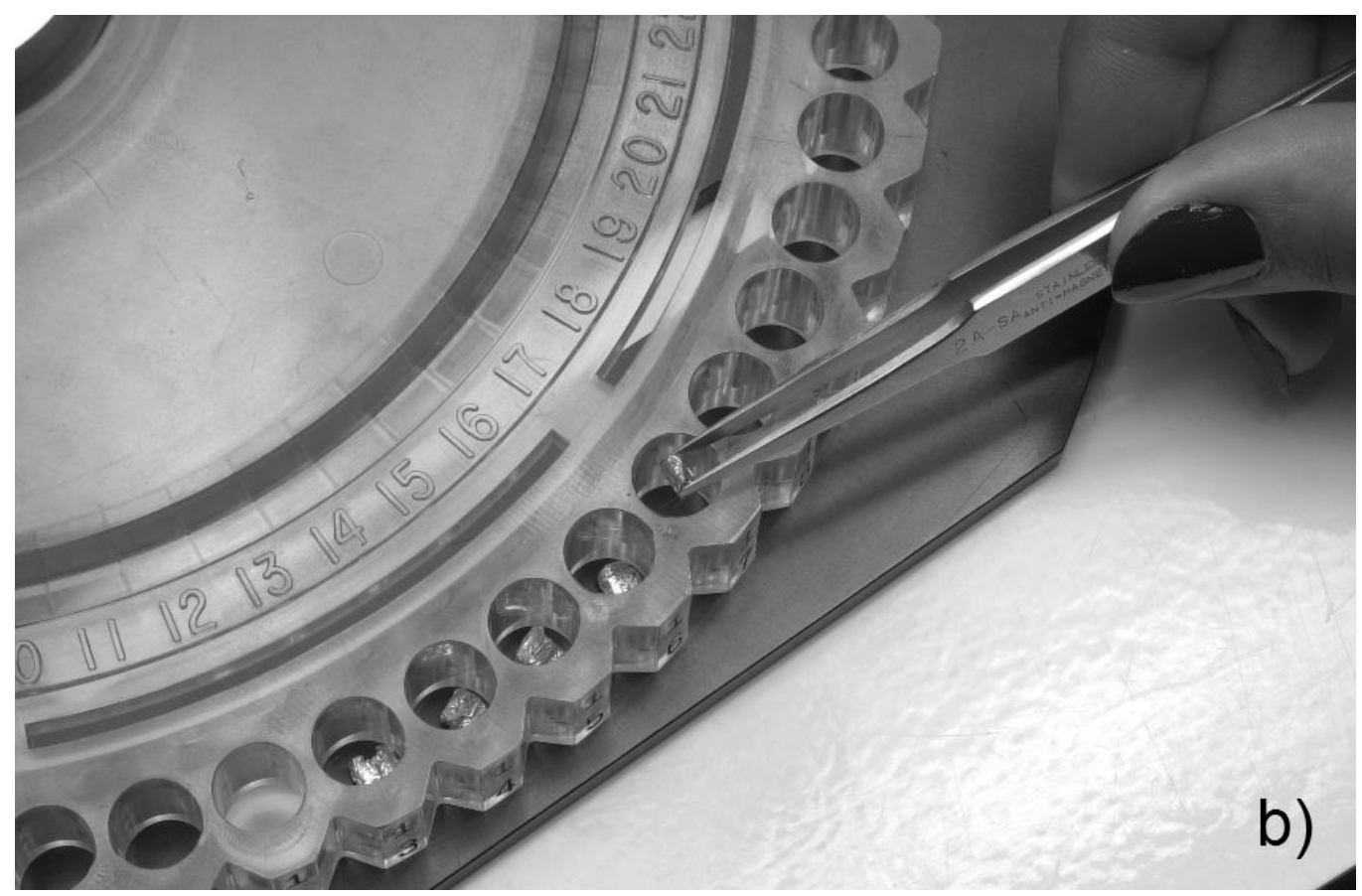

Fonte: http://pubs.usgs.gov/of/2002/of02-371/METHODS/

\subsubsection{Estimativa do Estoque de Carbono nas áreas de pastagem}

Além da determinação dos teores de carbono no solo, que pode ser quantificado por análise elementar, Walkley-Black ou outro método, é de suma importância fazer as estimativas de ECs dos solos em estudo.

A equação utilizada para a estimativa dos ECs pode ser demonstrada a partir da figura 8, onde é mostrado um hipotético cubo de solo, de lado " $l$ " o qual representa a espessura da camada de solo em que deseja-se estimar o EC e " $A$ " representando a área superficial desse cubo (VELDKAMP, 1994).

Figura 8 - Cubo representativo de um perfil de solo

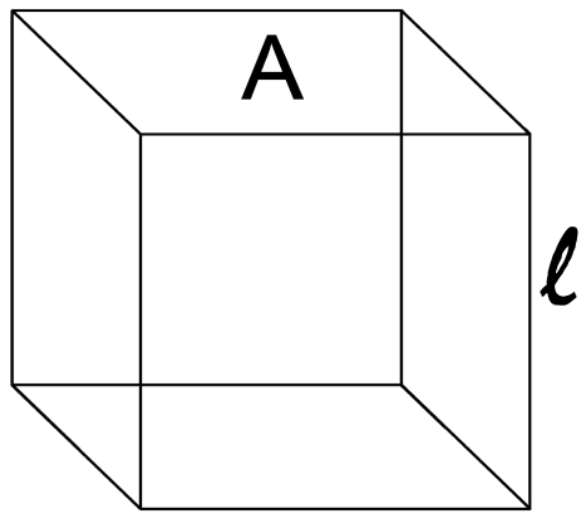

Fonte: Autoria própria 
A densidade desse cubo de solo pode ser representada por:

$D_{s}=M_{s} / V_{s} \quad$ ou $\quad M_{s}=D_{s} \cdot V_{s}$ Eq. 1

onde " $D_{\mathrm{s}}$ " é a densidade de solo em $\mathrm{g} \mathrm{cm}^{-3}$, " $\mathrm{M}_{\mathrm{s}}$ " é a massa de solo em $\mathrm{g}$ e "V" $\mathrm{V}_{\mathrm{s}}$ " o o volume do solo em $\mathrm{cm}^{3}$.

$\mathrm{O}$ volume do solo $\left(\mathrm{V}_{\mathrm{s}}\right)$, pode ser representado pelo produto da área da superfície do cubo (A) e a espessura da camada (1):

$$
V_{s}=A \cdot l
$$

A massa de carbono $\left(\mathrm{M}_{\mathrm{c}}\right)$ presente no solo é uma porcentagem da massa total de solo $\left(\mathrm{M}_{\mathrm{s}}\right)$, ou seja:

$$
M_{c}=\% C \cdot M_{s}
$$

Logo, a massa de carbono (Ms) pode ser reescrita da forma:

$$
M_{c}=\% C \cdot D_{s} \cdot V_{s}
$$

$\mathrm{Ou}$

$$
M_{c}=\% C \cdot D_{s} \cdot A \cdot l
$$

Passando a área (A) dividindo o termo $\mathrm{M}_{\mathrm{c}}$, teremos que:

$$
M_{c} / A=E C=\% C \cdot D_{s} \cdot l
$$

Então, o estoque de carbono (EC) é definido como a razão entre a massa de carbono e a área de solo, ou pode ser definido como mostrado na equação 7 , onde já são consideradas e corrigidas as unidades padrões $\left(\mathrm{Mg} \mathrm{ha}^{-1}\right)$ para a estimativa dos ECs.

$$
E C\left(M g h a^{-1}\right)=10 .\left(C \cdot D_{s} . l\right)
$$


Onde "C" é a quantidade de carbono em $\mathrm{g} \mathrm{kg}^{-1}$, " $\mathrm{D}_{\mathrm{s}}$ " a densidade do solo em $\mathrm{Mg} \mathrm{m}^{-3} \mathrm{e}$ "l" a espessura da camada em metros.

\subsubsection{Correção dos ECs por massa de solo equivalente}

A equação 7 é amplamente utilizada para o cálculo de ECs mas ainda é insuficiente para a avaliação da quantidade de carbono no solo, pois considera uma camada/profundidade fixa (SISTI et al., 2004). Se uma camada é mais compactada (maior densidade) do que a outra em uma profundidade específica, a camada mais compactada possui maior massa de solo.

A massa de solo nos perfis pode ser obtida por:

$$
M_{\text {solo }}=D_{s} \cdot l \cdot 10000 \mathrm{~m}^{2} h a^{-1}
$$

Onde:

$$
\begin{aligned}
& M_{\text {solo }}=\text { Massa de solo por unidade de área }\left(\mathrm{Mg} \mathrm{ha}^{-1}\right) \\
& D_{\mathrm{s}}=\text { Densidade do solo em } \mathrm{Mg} \mathrm{m}^{-3} \\
& \mathrm{l}=\text { Espessura da camada em metros (m) }
\end{aligned}
$$

Considerando-se que diferentes tipos de uso do solo podem levar a alterações na densidade do solo nas áreas estudadas e assumindo que a compactação do solo é mais significante nas camadas superficiais, o cálculo dos ECs utilizando uma camada fixa acaba por acarretar em uma comparação de diferentes quantidades de solo.

Com base na literatura (SISTI et al., 2004; ELLERT; BETTANY, 1995) e do Protocolo da Rede PECUS os ECs precisam ser corrigidos para cada sistema avaliado usandose como referência a massa de solo equivalente sob vegetação nativa, ou seja, a compactação do solo na mata nativa é assumida como referência.

Os ECs foram corrigidos para cada sistema avaliado usando-se como referência a massa de solo equivalente sob vegetação nativa (Mata Atlântica), ou seja, utilizando o cálculo de massa equivalente. Para essa correção utilizou-se o cálculo de massa equivalente segundo metodologia proposta por Ellert e Bettany (1995) e, posteriormente, enfatizada por Sisti e colaboradores (2004).

A figura 9 mostra um exemplo de como é feita essa correção levando em consideração a massa de solo equivalente para a primeira camada amostrada. Supondo uma área nativa e 
uma pastagem em estudo onde são amostrados dois perfis de solo, de 0-10 cm e de $10-20 \mathrm{~cm}$. Temos que para o perfil de $0-10 \mathrm{~cm} \mathrm{M}_{\text {solo }}$ da mata nativa é de $800 \mathrm{Mg} \mathrm{ha}^{-1}$.

O EC estimado para a área de pastagem, utilizando apenas a equação 7 resultaria em $24 \mathrm{Mg} \mathrm{ha}^{-1}$. Porém para normalizar o EC da área de pastagem pela $\mathrm{M}_{\text {solo }}$ da mata nativa, teríamos que recalcular o EC para a área de pastagem assumindo a mesma $\mathbf{M}_{\text {solo }}$ para ambas as áreas. Como a $\mathrm{D}_{\mathrm{s}}$ na mata nativa é menor, a espessura da camada de solo da área de pastagem deve ser recalculada a partir da equação 8, resultando numa nova espessura de 5,3 cm e um EC corrigido de 12,8 $\mathrm{Mg} \mathrm{ha}^{-1}$. Para que as estimativas de ECs não sejam mal interpretadas, é necessário que se faça essa correção considerando a nova espessura da camada.

Figura 9 - ECs de uma área de pastagem comparado à mata nativa

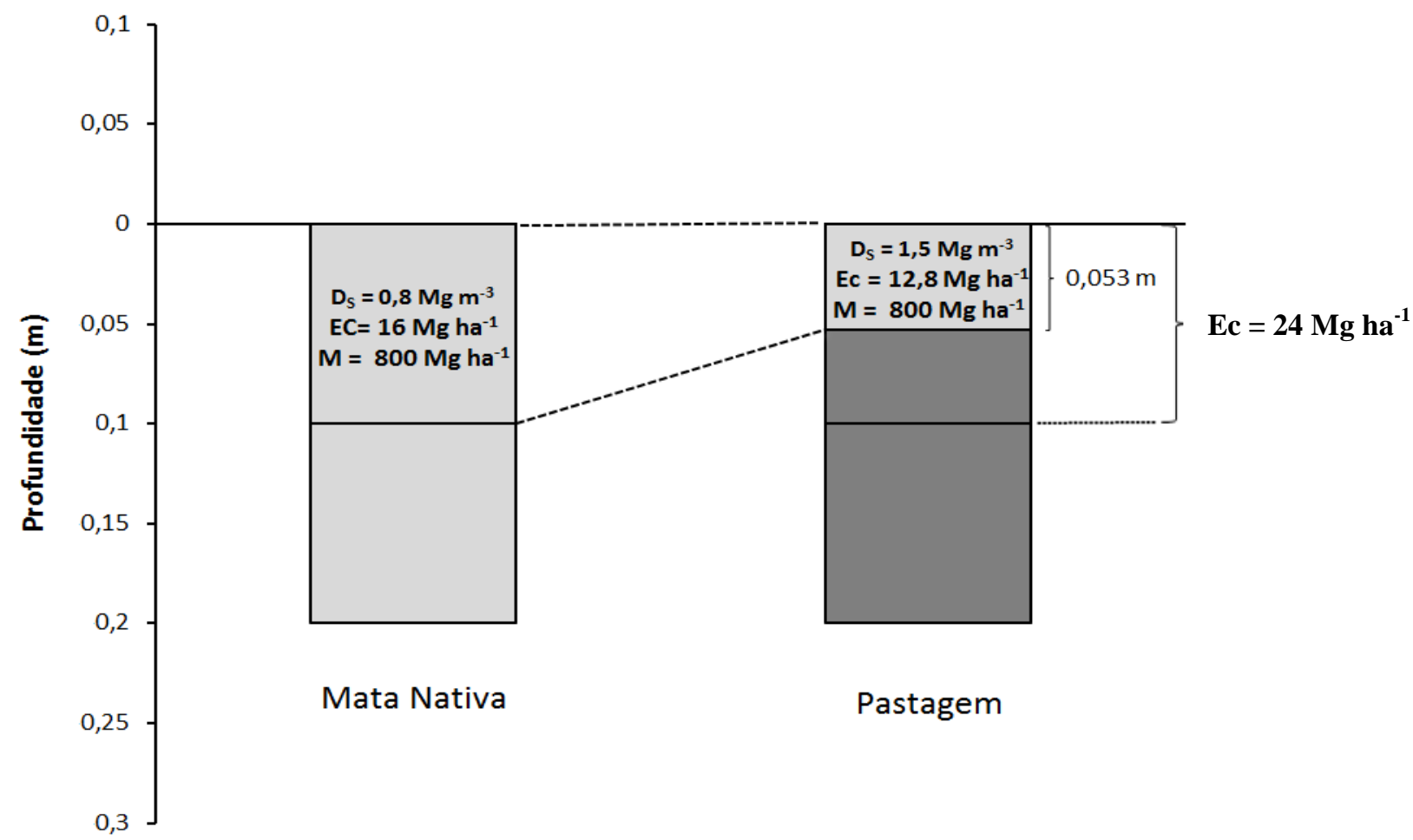

Fonte: Autoria própria

Sisti e colaboradores (2004) reuniram as equações para a correção por massa equivalente em apenas uma expressão (equação 9) para a correção de todo o perfil amostrado, considerando a massa equivalente da área de referência.

Após determinar os ECs em cada uma das camadas (equação 7), a equação 9 corrigirá em função da massa do solo da referência: 
$C s=\sum_{i=1}^{n-1} C t i+\left[M t n-\left(\sum_{i=1}^{n} M t i-\sum_{i=1}^{n} M s i\right)\right] * C t n$

Eq. 9

onde:

Cs = EC total, em $\mathrm{Mg} \mathrm{ha}^{-1}$, corrigido em função da massa de solo de uma área de referência;

$\sum_{i=1}^{n-1} C t$ = somatório dos ECs do solo da primeira à penúltima camada amostrada no tratamento considerado $\left(\mathrm{Mg} \mathrm{ha}^{-1}\right)$;

$\mathrm{Mtn}=$ massa do solo por área da última camada amostrada no tratamento $\left(\mathrm{Mg} \mathrm{ha}^{-1}\right)$;

$\sum_{i=1}^{n} M t i=$ somatório da massa total do solo amostrado sob o tratamento $\left(\mathrm{Mg} \mathrm{ha}^{-1}\right)$;

$\sum_{i=1}^{n} M s i=$ somatório da massa total do solo amostrado na área de referência $\left(\mathrm{Mg} \mathrm{ha}^{-1}\right)$;

$\mathrm{Ctn}=$ teor de $\mathrm{C}$ do solo na última camada amostrada $\left(\mathrm{Mg} \mathrm{C} \mathrm{Mg}^{-1}\right.$ de solo $)$.

\subsubsection{Correção dos ECs pelos teores de argila do solo}

Sabe-se que os ECs são proporcionais aos teores de argila do solo, portanto quanto mais elevado o teor de argila maior será a tendência de o solo estocar carbono (PINHEIRO et al. 2010).

Logo, além da correção do EC pela massa equivalente, sugeriu-se nesse trabalho utilizar também a correção por teores de argila enunciada por Moraes e colaboradores (1996), a qual é descrita pela equação abaixo.

$\mathrm{EC}=\mathrm{EC}_{0}$. Argila (referência) / Argila

Eq. 10

Onde:

$\mathrm{EC}=\mathrm{EC}$ total, em $\mathrm{Mg} \mathrm{ha}^{-1}$, corrigido em função do teor de argila

$\mathrm{EC}_{0}=\mathrm{EC}$ inicial a ser corrigido, $\mathrm{em} \mathrm{Mg} \mathrm{ha}^{-1}$

Argila $($ referência $)=$ Teor de argila da área de referência (mata nativa)

Argila $=$ Teor de argila da camada a ser corrigida . 


\subsubsection{LIFS - Laser induced fluorescence spectroscopy}

Foi utilizado um sistema portátil de LIFS, projetado para compactar todo o aparato de detecção e análise de MOS e permitir a utilização do equipamento fora das condições do laboratório (figura 10). Esse equipamento foi utilizado para a avaliação da qualidade da MOS.

Figura 10 - Sistema de LIFS portátil com excitação em 405 nm: (1) chave de energia laser; (2) caixa de controle laser; (3) cabo óptico; (4) sonda.

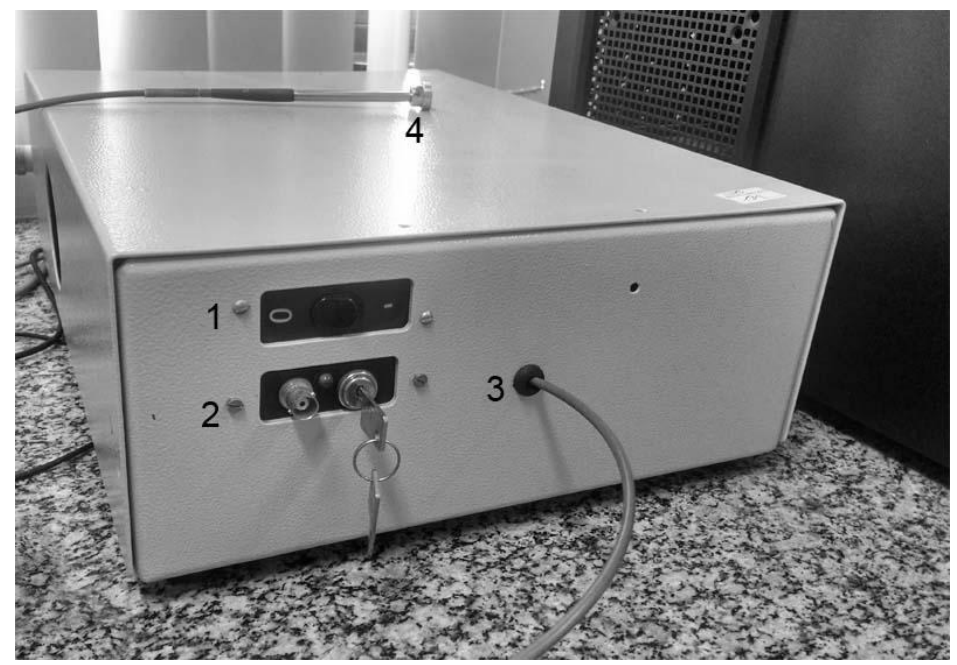

Fonte: Autoria própria

O sistema utiliza um laser de diodo emitindo em $405 \mathrm{~nm}$, com potência máxima de $50 \mathrm{~mW}$, acoplado a um cabo óptico composto por seis fibras ópticas que excitam a amostra e uma fibra óptica central que coleta o sinal de fluorescência do solo. Um desenho esquemático do equipamento utilizado é mostrado a seguir na figura 11.

Figura 11 - Esquema do equipamento LIFS portátil.

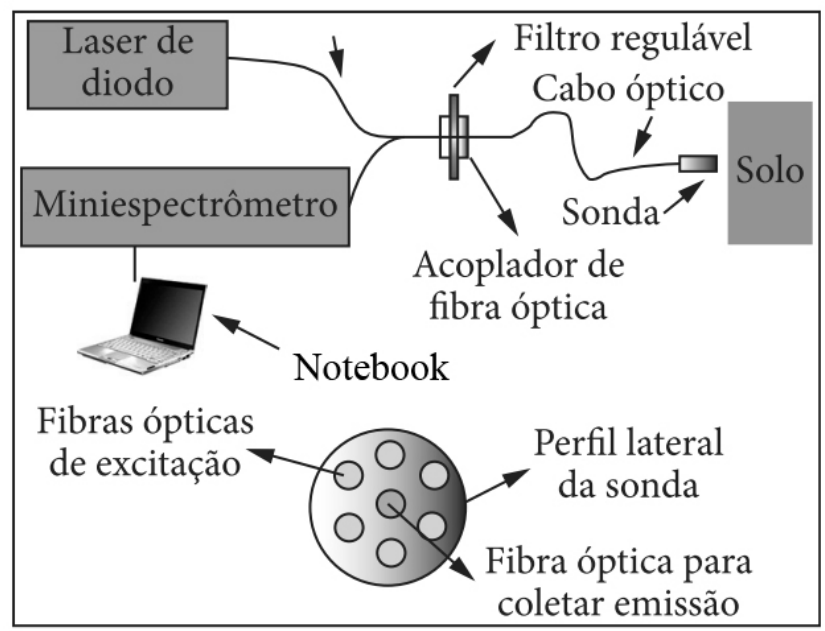

Fonte: MILORI et al., 2011a (adaptado) 
Cada amostra foi analisada com cinco repetições para a obtenção do índice de humificação médio. A janela espectral foi de 475 a $800 \mathrm{~nm}$, com intensidade de 0-4000, tempo de integração $500 \mathrm{~ms}$, box car igual a 4 e número de média igual a 5 .

A figura 12 mostra o momento da análise por LIFS de uma pastilha de solo, bem como a ponteira onde estão contidas as fibras de emissão e aquisição, apresentados no esquema acima (figura 11).

Figura 12 - Momento da análise por LIFS.

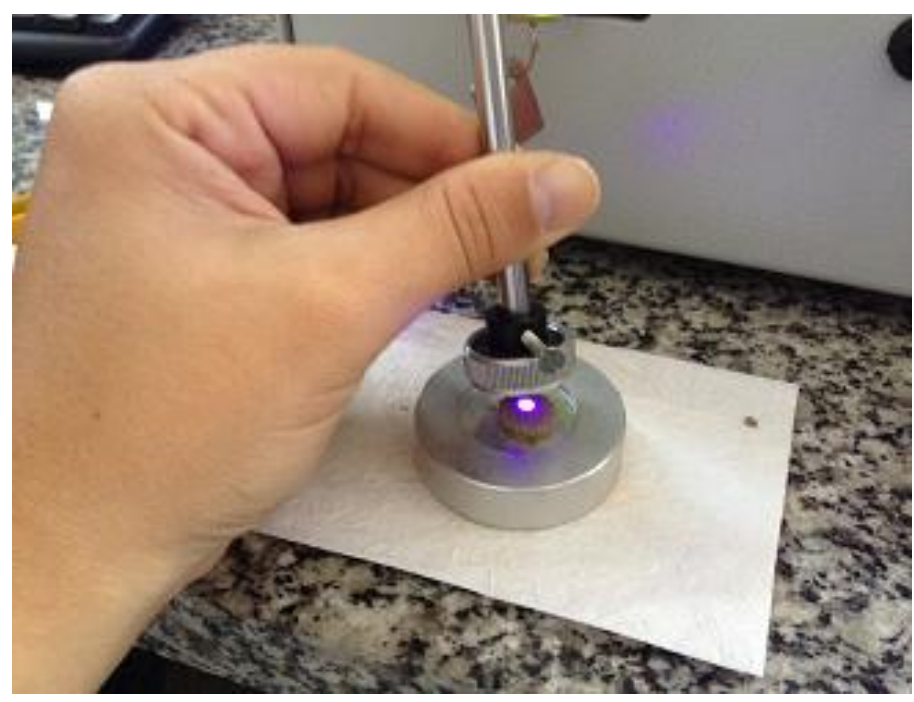

Fonte: Autoria própria

Na figura 13 é apresentado um espectro de LIFS (FIL) típico de uma amostra de solo.

Figura 13 - Espectro de LIFS típico para amostras de solos.

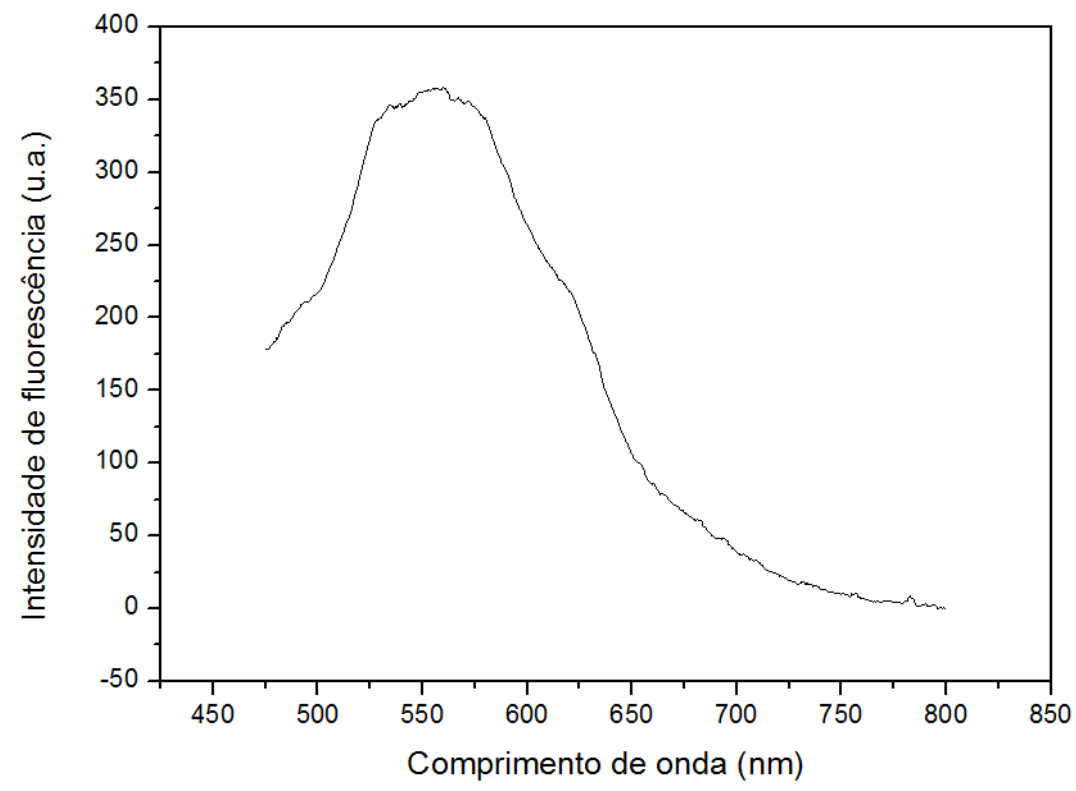

Fonte: Autoria própria 
Milori et al. (2002) trabalhando com fluorescência tradicional e com ácidos húmicos dissolvidos, observaram que o comprimento de onda na região do azul $(465 \mathrm{~nm})$ foi mais eficiente para excitar estruturas cuja condensação aumenta durante o processo de humificação. Portanto, neste trabalho citado os autores mostraram que a área total sob o espectro de emissão de fluorescência com excitação em $465 \mathrm{~nm}\left(\mathrm{~A}_{465}\right)$ é proporcional ao grau de humificação.

O H $\mathrm{FIL}_{\text {p }}$ proposto por Milori e colaboradores (2006) baseado no índice de humificação citado anteriormente de Milori e colaboradores (2002) é definido conforme a equação 11 abaixo, onde $A_{f}$ corresponde a área de fluorescência sob o espectro e $C_{t}$ é o teor de carbono total, que no estudo foi determinado via análise elementar (CHNS).

A partir da normalização da área de fluorescência pelo teor de carbono da amostra é enunciado o grau de humificação da $\mathrm{MO}$ ou $\mathrm{H}_{\mathrm{FIL}}$.

$$
H_{F I L}=\frac{A_{f}}{C_{t}}
$$

O equipamento desenvolvido em duas versões, de bancada e portátil, vem sendo utilizado por cientistas de solo tanto para análises de manejo de solo para fins agrícolas, quanto para estudos ambientais de sequestro de carbono pelo solo visando mitigação de efeito estufa e controle de parâmetros que afetem as mudanças climáticas globais (PEREZ et al., 2006; SEGNINI, et al., 2010).

\subsubsection{Quantificação de emissão de $\mathrm{CO}_{2}$ (Respiração do solo)}

Para a determinação da emissão de $\mathrm{CO}_{2}$ que o solo gera, existem vários métodos analíticos apresentados na literatura. Um deles é o método de câmaras estáticas, onde é colocado um recipiente de plástico contendo uma solução de $\mathrm{NaOH}$ a qual é responsável pela captação do $\mathrm{CO}_{2}$ evoluído do solo. Posteriormente, a solução de $\mathrm{NaOH}$ é titulada com $\mathrm{HCl}$ e fenolftaleína para a determinação indireta da concentração do $\mathrm{CO}_{2}$ (GIACOMINI; AITA, 2008; AITA et al., 2006). Porém nesse método são embutidos erros sistemáticos e aleatórios, como na concentração exata da solução de $\mathrm{NaOH}$ que é utilizada para a captação do $\mathrm{CO}_{2}$ evoluído, o volume do titulante que é utilizado, entre outros. 
Também é possível a determinação da emissão de $\mathrm{CO}_{2}$ do solo por câmaras fechadas onde amostras de ar são incubadas. Posteriormente as amostras de ar são coletadas utilizando seringas e são analisadas por cromatografia gasosa (COSTA et al., 2006).

Outro método é através de espectroscopia de absorção óptica na região espectral do infravermelho (infrared gas analyze ou IRGA). Um sistema portátil da marca LI-COR, modelo LI-8100 é capaz de realizar determinações de fluxo de $\mathrm{CO}_{2}$ no interior da câmara através da absorção no infravermelho que é característica desta molécula. Trata-se de uma câmara fechada com volume interno de $854,2 \mathrm{~cm}^{3}$ e área circular de contato com o solo de $83,7 \mathrm{~cm}^{2}$ (GARCIA et al., 1997; PANOSSO et al., 2009).

São utilizados colares (anéis) de PVC com diâmetro de aproximadamente quatro polegadas e sete a oito $\mathrm{cm}$ de altura, semelhantes a luvas de PVC utilizadas em esgoto doméstico. Os colares são cravados no solo com $3 \mathrm{~cm}$ de profundidade e o restante do anel (4 a $5 \mathrm{~cm}$ ) serve para acoplar a câmara ao colar de PVC. Abaixo, na figura 14 é mostrada a câmara de leitura acoplada ao colar cravado ao solo.

Figura 14 - Câmara de leitura acoplada ao colar cravado ao solo

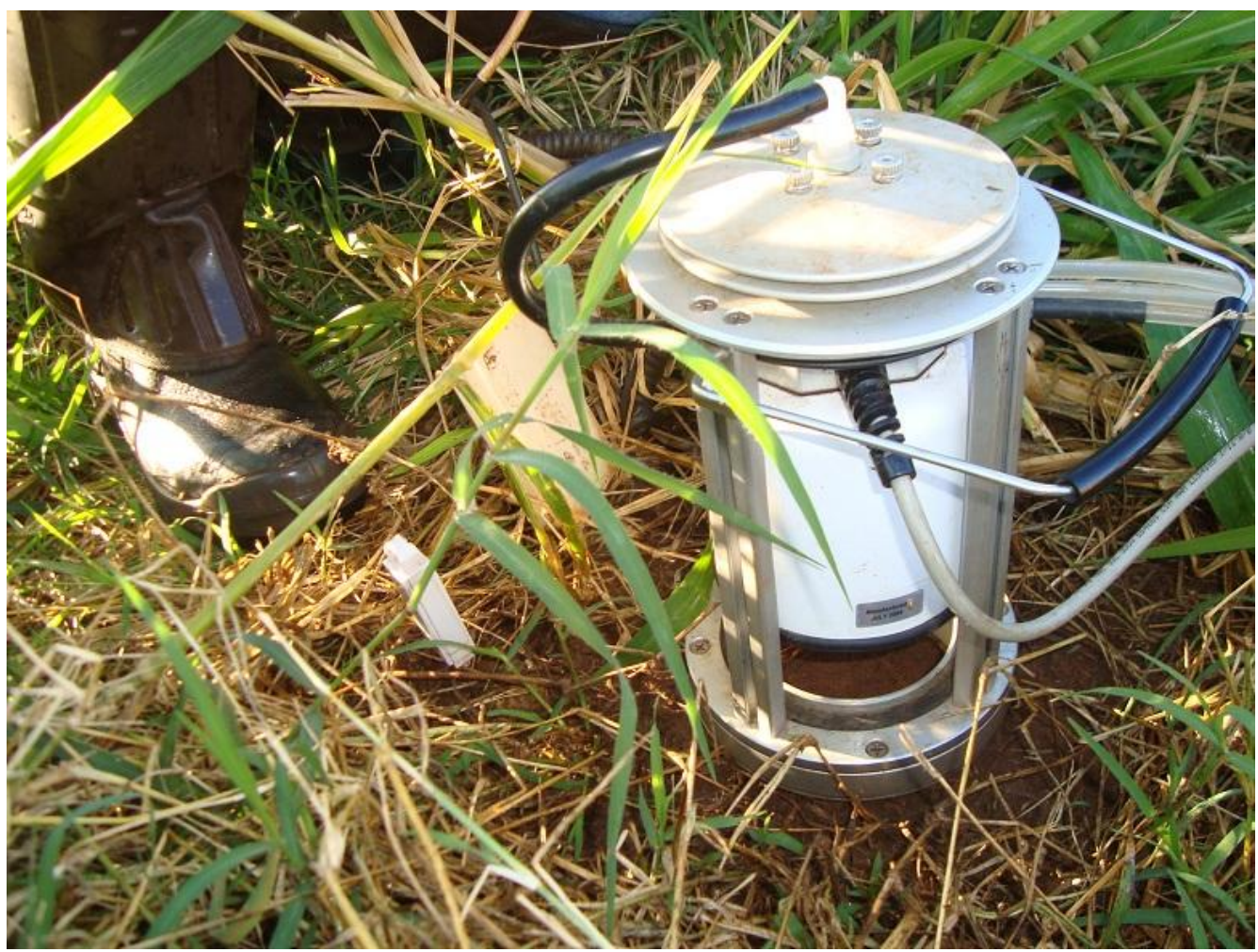

Fonte: Autoria própria

Uma vez que a câmara é fechada, a concentração de $\mathrm{CO}_{2}$ (em ppm) dentro da câmara é determinada a cada 1,0 segundo, totalizando 1,0 minuto de análise em cada coordenada do 
campo experimental. No final de toda a análise do ponto, o equipamento gera uma curva de fluxo de $\mathrm{CO}_{2}$, que pode ser ajustada a uma reta ou um crescimento exponencial (figura 15). O fluxo de $\mathrm{CO}_{2}$ é medido na unidade de mmol. $\mathrm{m}^{-2} \mathrm{~s}^{-1}$.

Figura 15 - Exemplo de regressão linear para as medidas de concentração de $\mathrm{CO}_{2}$ dentro da câmara de medição.

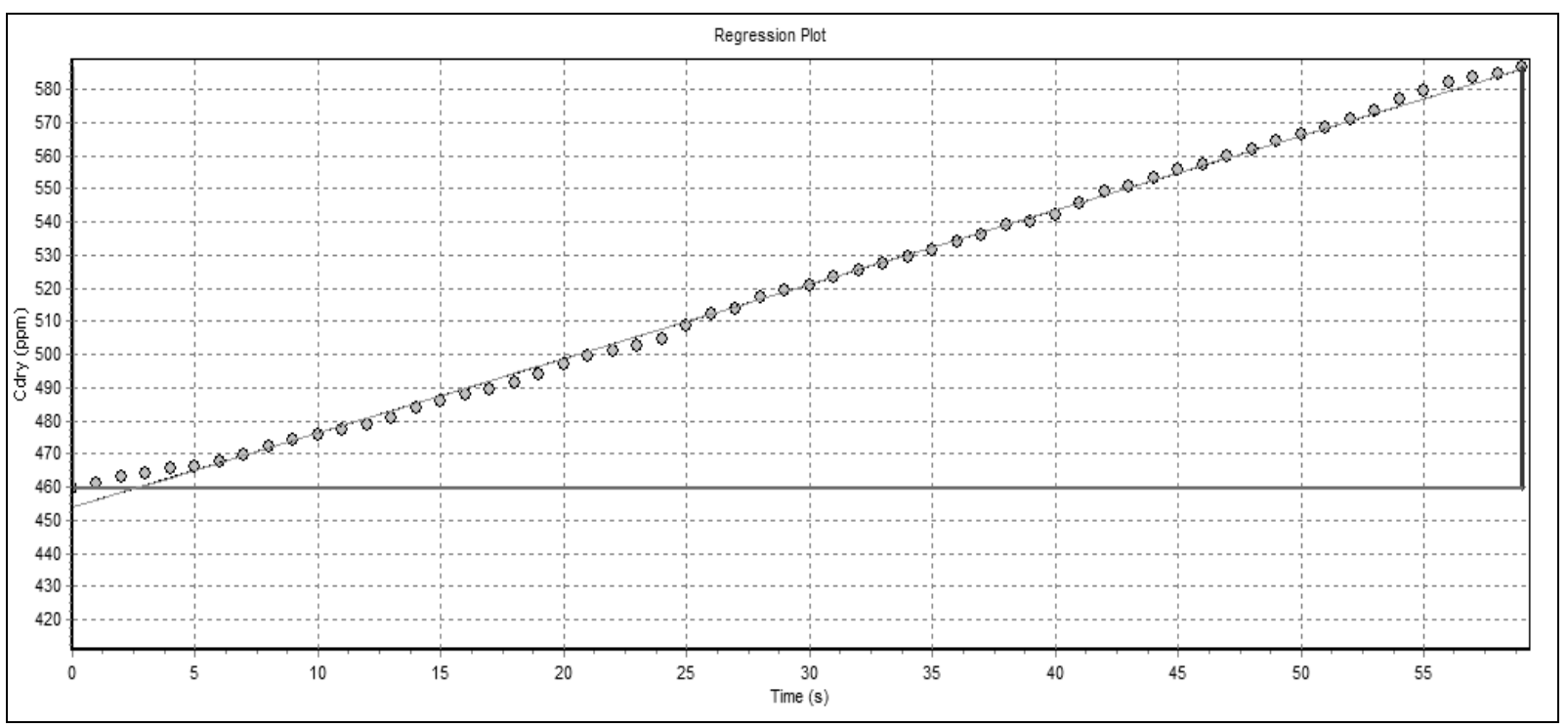

Fonte: Autoria própria

Para a coleta das amostras foram abertas 6 trincheiras em cada manejo em estudo. Nessa etapa do trabalho, optou-se por distribuir 6 pontos a mais que o número de trincheiras, ou seja, 12 pontos amostrais por área em questão.

Foram cravados 12 anéis de PVC em diferentes piquetes das áreas de estudo, sendo que 6 anéis cravados em piquetes utilizados na coleta das amostras e os outros 6 anéis nos demais piquetes. Essa distribuição objetivou a cobertura de uma maior área amostral

As coletas de gases ocorreram durante 4 semanas, no período de 10 de abril a 01 de maio de 2013, totalizando 8 dias de medidas. Esse período de medidas foi escolhido por ser o período logo após a adubação da área em recuperação, objetivando obter-se dados após essa perturbação do sistema.

Juntamente com as medidas de fluxo de $\mathrm{CO}_{2}$, também foram feitas medidas de umidade utilizando um sistema de TDR (Time Domain Reflectometry) e temperatura do solo com um termômetro comum (haste de $10 \mathrm{~cm}$ ). O aparelho de TDR é constituído de uma sonda, apresentando duas hastes de 0,12 m que são inseridas perpendicularmente ao solo, próximos aos colares de PVC. O seu princípio de funcionamento consiste em medir o tempo 
de percurso de um pulso eletromagnético no espaço compreendido entre as duas extremidades das hastes, sendo o tempo de percurso relacionado com a constante dielétrica média do meio no qual a sonda-guia é inserida.

Os equipamentos utilizados tais como anéis de PVC, LI-COR 8100, termômetro e TDR são mostrados na figura 16 e pertencem a UNESP/FCAV - Campus Jaboticabal.

Figura 16 - Equipamento LI-COR 8100 utilizado para as análises de fluxo de $\mathrm{CO}_{2}$ do solo nas áreas em estudo.

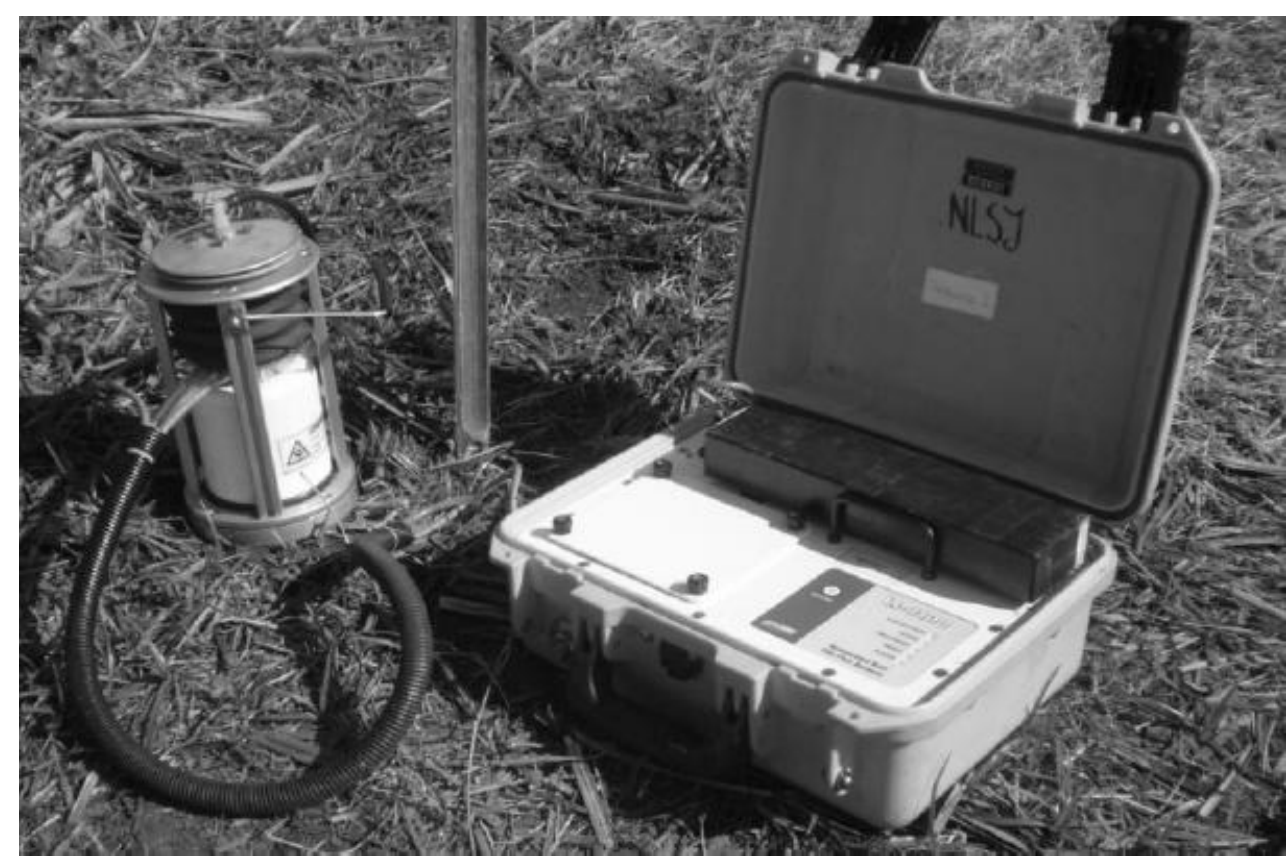

Fonte: (SILVA-OLAYA, 2010).

\subsubsection{LIBS - Laser Induced Breakdown Spectroscopy}

A espectroscopia LIBS foi utilizada na determinação de carbono em solos como técnica alternativa à análise elementar.

Tanto para as medidas espectroscópicas de LIBS quanto a de LIFS, as amostras de solos, previamente moídas, foram prensadas em pastilhas, a aproximadamente 8 toneladas, com dimensões de $1 \mathrm{~cm}$ de diâmetro, $2 \mathrm{~mm}$ de espessura e $0,5 \mathrm{~g}$ de massa, a fim de facilitar a colocação das mesmas no sistema utilizado para a análise, padronizando a forma física das amostras. Abaixo, na figura 17, é apresentado um comparativo entre uma pastilha de solo e uma moeda de $\mathrm{R} \$ 1,00$. 
Figura 17 - Comparação entre uma moeda e uma pastilha de solo prensado.

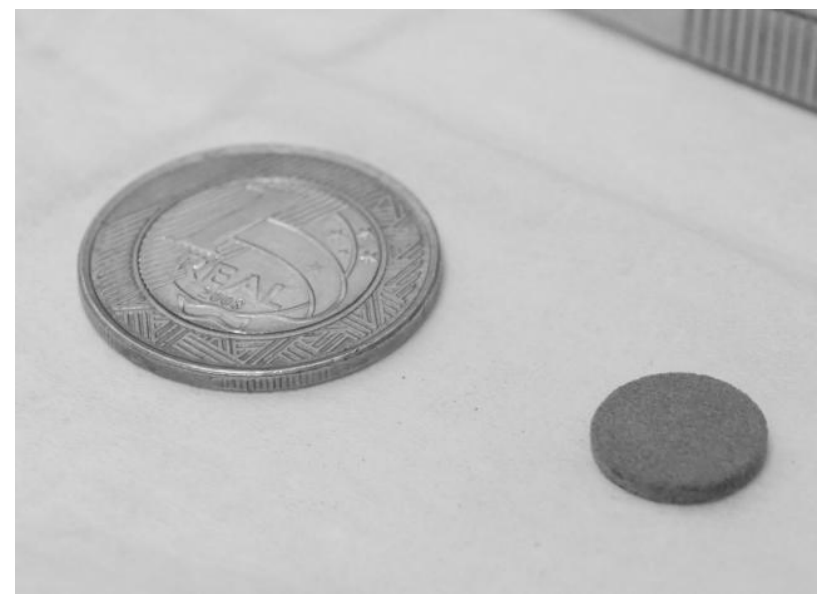

Fonte: Autoria própria

As amostras foram submetidas a um sistema LIBS da Ocean Optics, modelo LIBS2500plus (figura 18) equipado com um laser de Nd:YAG pulsado (Q-switched) de $50 \mathrm{~mJ}$ com duração de pulso de $20 \mathrm{~ns}$, diâmetro do feixe do laser (laser spot) de 0,5 mm aproximadamente, taxa de repetição de até $500 \mathrm{~Hz}$; detector CCD (Charge-Coupled Device) de 14.336 pixels; cobertura da faixa espectral de 188-980 nm e resolução óptica próxima de $0,1 \mathrm{~nm}$, com tempo de atraso (delay time) de $2 \mu$ s entre o pulso do laser e a aquisição do espectro.

Figura 18 - Sistema LIBS de bancada da Ocean Optics, modelo LIBS 2500 plus: (1) fonte de energia; (2) laser; (3) câmara de ablação; (4) conjunto de espectrômetros.

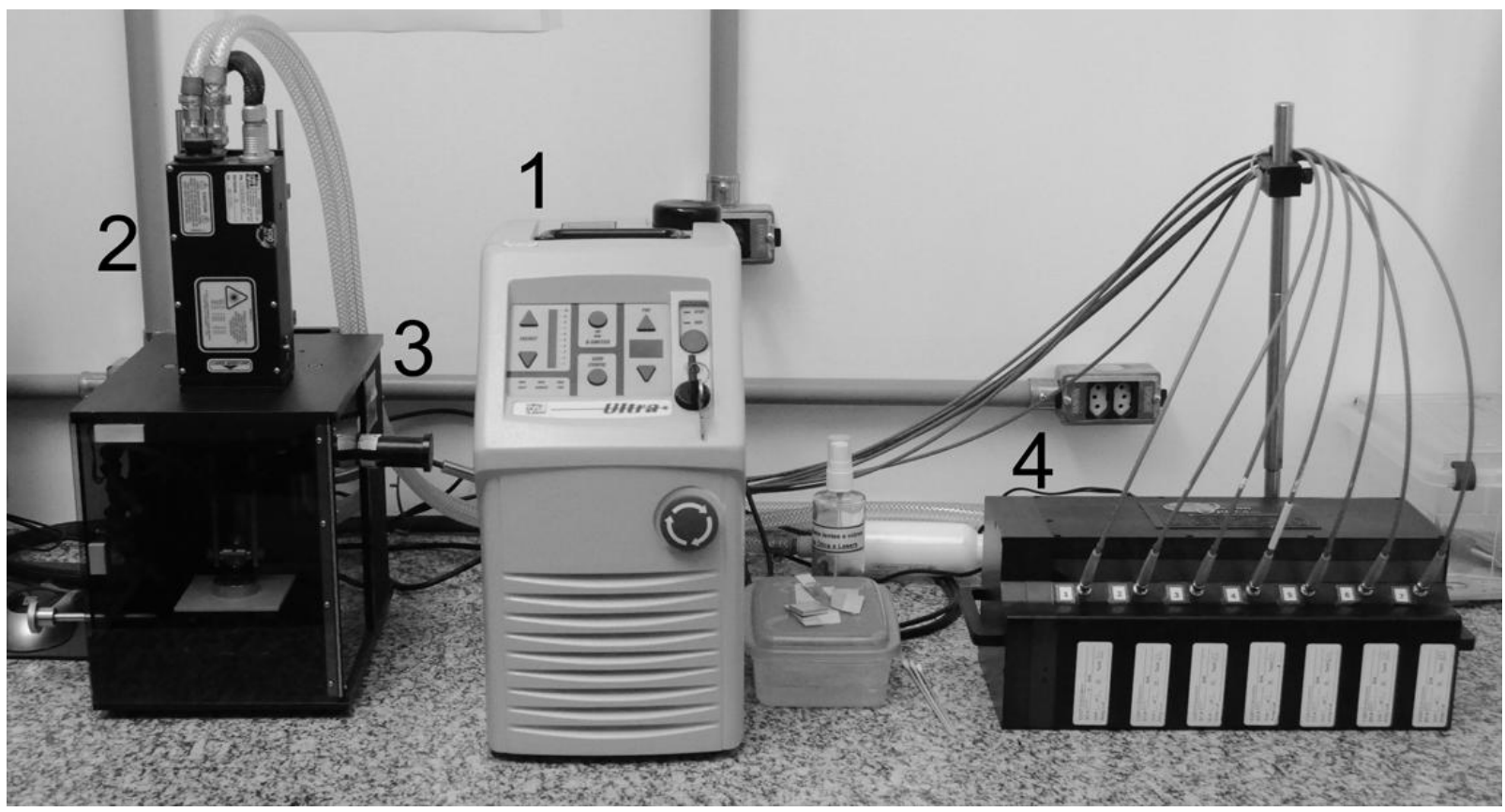

Fonte: Autoria própria 
Para cada espectro adquirido foram dados 3 tiros acumulados (um tiro de limpeza da superfície e outros dois gerando uma média para a aquisição do espectro). Para as análises foram utilizadas 2 pastilhas para cada amostra, sendo adquiridos 20 espectros por face, totalizando 60 espectros por amostra. Reservou-se uma face sem tiros caso houve-se a necessidade de futuras análises.

\subsection{Análise estatística}

Para a comparação dos resultados dos ECs e das emissões de $\mathrm{CO}_{2}$, os dados foram submetidos à análise de variância (ANOVA) com um fator. A comparação das populações foi feita a partir da análise da dispersão presente no conjunto dos dados. Antes de aplicar a comparação das médias pelo teste Tukey é necessário a observância dos seguintes pressupostos:

- o conjunto de dados apresenta $n$ grupos de observações, sendo os grupos independentes entre si;

- cada grupo de observação deve provir de uma população com distribuição normal;

- a variância das populações $n$ deve ser a mesma (homogeneidade das variâncias).

O teste Tukey foi aplicado com nível de significância de 5\% (p<0,05) para comparação das médias dos sistemas de pastagem avaliados.

Nos espectros obtidos por LIBS, foi utilizado o teste de Grubbs (teste de valor extremo) para a retirada de espectros anômalos. Para essa remoção foi considerada a intensidade na linha de emissão do carbono (193,03 nm). 


\section{CAPÍTULO 4}

RESULTADOS E DISCUSSÕES

Nesse capítulo serão apresentados os resultados e as análises realizadas neste trabalho. A apresentação está dividida em duas partes: a primeira contém as análises agroambientais, ou seja, sobre a ciclagem de carbono nos sistemas de pastagem em estudo; a segunda parte é dedicada a testes com novas ferramentas de análise de solos com potencial para o desenvolvimento de instrumentação para medidas em campo.

\subsection{Avaliação do ciclo do carbono}

Para as avaliações da ciclagem do carbono foram estimados os estoques de carbono no solo de cada sistema de pastagem e a emissão de $\mathrm{CO}_{2}$.

Para o cálculo dos ECs foram medidas a densidade e a porcentagem de carbono do solo via análise elementar (CHNS). A espectroscopia LIFS foi utilizada para a avaliação da estabilidade da matéria orgânica presente no solo do experimento. Por fim, utilizou-se um sistema portátil da marca LI-COR, modelo LI-8100 que monitora as variações da concentração de $\mathrm{CO}_{2}$ no interior da câmara.

\subsubsection{Análise granulométrica}

Através do método da pipeta obteve-se os dados granulométricos das amostras. Abaixo a tabela 1 mostra os teores $(\mathrm{g} / \mathrm{kg})$ de areia, silte e argila para cada profundidade e cada trincheira coletada nas três áreas. 
Tabela 1 - Dados granulométricos das amostras coletadas das áreas A3, A4 e MT.

\begin{tabular}{|c|c|c|c|c|c|c|c|c|c|}
\hline \multirow{4}{*}{$\begin{array}{c}\text { Trincheira } \\
\text { Profundidade }(\mathrm{cm})\end{array}$} & \multirow{2}{*}{\multicolumn{9}{|c|}{ A3 - Granulometria (g/kg) }} \\
\hline & & & & & & & & & \\
\hline & \multicolumn{3}{|c|}{ T1 } & \multicolumn{3}{|c|}{$\mathrm{T2}$} & \multicolumn{3}{|c|}{ T3 } \\
\hline & Areia & Argila & Silte & Areia & Argila & Silte & Areia & Argila & Silte \\
\hline 0 a 5 & 388 & 501 & 111 & 200 & 596 & 204 & 325 & 511 & 164 \\
\hline 5 a 10 & 414 & 507 & 79 & 208 & 584 & 208 & 307 & 547 & 146 \\
\hline 10 a 20 & 422 & 526 & 52 & 176 & 623 & 201 & 384 & 592 & 24 \\
\hline 20 a 30 & 415 & 530 & 55 & 162 & 653 & 185 & 311 & 546 & 143 \\
\hline 30 a 40 & 359 & 581 & 60 & 172 & 668 & 160 & 323 & 564 & 113 \\
\hline 40 a 60 & 364 & 578 & 58 & 154 & 652 & 194 & 329 & 619 & 52 \\
\hline 60 a 80 & 368 & 535 & 97 & 183 & 663 & 154 & 285 & 558 & 157 \\
\hline 80 a 100 & 371 & 497 & 132 & 266 & 662 & 72 & 258 & 582 & 160 \\
\hline Trincheira & & $\mathrm{T4}$ & & & T5 & & & T6 & \\
\hline 0 a 5 & 533 & 449 & 18 & 233 & 514 & 253 & 288 & 467 & 245 \\
\hline 5 a 10 & 543 & 300 & 157 & 266 & 533 & 201 & 328 & 460 & 212 \\
\hline 10 a 20 & 481 & 441 & 78 & 183 & 517 & 300 & 341 & 428 & 231 \\
\hline 20 a 30 & 502 & 433 & 65 & 249 & 545 & 206 & 291 & 525 & 184 \\
\hline 30 a 40 & 490 & 436 & 74 & 248 & 550 & 202 & 329 & 480 & 191 \\
\hline 40 a 60 & 437 & 482 & 81 & 240 & 557 & 203 & 323 & 498 & 179 \\
\hline 60 a 80 & 486 & 451 & 63 & 247 & 537 & 216 & 326 & 542 & 132 \\
\hline \multirow[t]{2}{*}{80 a 100} & 382 & 448 & 170 & 254 & 597 & 149 & 303 & 540 & 157 \\
\hline & \multicolumn{9}{|c|}{ A4 - Granulometria (g/kg) } \\
\hline Trincheira & \multicolumn{3}{|c|}{ T1 } & \multicolumn{3}{|c|}{ T2 } & \multicolumn{3}{|c|}{ T3 } \\
\hline 0 a 5 & 818 & 70 & 112 & 755 & 200 & 45 & 798 & 73 & 129 \\
\hline 5 a 10 & 909 & 66 & 25 & 777 & 166 & 57 & 770 & 131 & 99 \\
\hline 10 a 20 & 838 & 115 & 47 & 759 & 162 & 79 & 645 & 320 & 35 \\
\hline 20 a 30 & 811 & 127 & 62 & 724 & 189 & 87 & 820 & 141 & 39 \\
\hline 30 a 40 & 825 & 114 & 61 & 732 & 170 & 98 & 804 & 133 & 63 \\
\hline 40 a 60 & 755 & 188 & 57 & 713 & 155 & 132 & 737 & 191 & 72 \\
\hline 60 a 80 & 803 & 142 & 55 & 707 & 159 & 134 & 716 & 202 & 82 \\
\hline 80 a 100 & 793 & 157 & 50 & 726 & 115 & 159 & 777 & 163 & 60 \\
\hline Trincheira & & $\mathrm{T4}$ & & & T5 & & & T6 & \\
\hline 0 a 5 & 742 & 177 & 81 & 850 & 51 & 99 & 683 & 252 & 65 \\
\hline 5 a 10 & 749 & 199 & 52 & 857 & 48 & 95 & 765 & 168 & 67 \\
\hline 10 a 20 & 752 & 195 & 53 & 860 & 120 & 20 & 822 & 125 & 53 \\
\hline 20 a 30 & 704 & 238 & 58 & 846 & 72 & 82 & 621 & 331 & 48 \\
\hline 30 a 40 & 705 & 256 & 39 & 777 & 213 & 10 & 750 & 191 & 59 \\
\hline 40 a 60 & 674 & 283 & 43 & 823 & 82 & 95 & 759 & 181 & 60 \\
\hline 60 a 80 & 657 & 307 & 36 & 798 & 51 & 151 & 765 & 174 & 61 \\
\hline \multirow[t]{2}{*}{80 a 100} & 728 & 223 & 49 & 840 & 84 & 76 & 805 & 115 & 80 \\
\hline & \multicolumn{9}{|c|}{ MT - Granulometria (g/kg) } \\
\hline Trincheira & \multicolumn{3}{|c|}{$\overline{\mathrm{T} 1}$} & \multicolumn{3}{|c|}{ T2 } & \multicolumn{3}{|c|}{ T3 } \\
\hline 0 a 5 & 566 & 348 & 86 & 448 & 332 & 220 & 576 & 362 & 62 \\
\hline 5 a 10 & 645 & 307 & 48 & 534 & 338 & 128 & 441 & 467 & 92 \\
\hline 10 a 20 & 625 & 320 & 55 & 482 & 366 & 152 & 435 & 486 & 79 \\
\hline 20 a 30 & 623 & 323 & 54 & 454 & 403 & 143 & 465 & 461 & 74 \\
\hline 30 a 40 & 570 & 391 & 39 & 433 & 432 & 135 & 593 & 339 & 68 \\
\hline 40 a 60 & 545 & 332 & 123 & 570 & 367 & 63 & 556 & 396 & 48 \\
\hline 60 a 80 & 488 & 388 & 124 & 572 & 325 & 103 & 519 & 424 & 57 \\
\hline 80 a 100 & 501 & 427 & 72 & 565 & 358 & 77 & 561 & 387 & 52 \\
\hline Trincheira & & $\mathrm{T4}$ & & & T5 & & & T6 & \\
\hline 0 a 5 & 597 & 316 & 87 & 639 & 261 & 100 & 634 & 274 & 92 \\
\hline 5 a 10 & 599 & 341 & 60 & 641 & 267 & 92 & 660 & 229 & 111 \\
\hline 10 a 20 & 610 & 325 & 65 & 625 & 267 & 108 & 653 & 263 & 84 \\
\hline 20 a 30 & 595 & 319 & 86 & 620 & 343 & 37 & 625 & 291 & 84 \\
\hline 30 a 40 & 588 & 353 & 59 & 610 & 354 & 36 & 600 & 337 & 63 \\
\hline 40 a 60 & 550 & 384 & 66 & 620 & 298 & 82 & 584 & 311 & 105 \\
\hline 60 a 80 & 564 & 372 & 64 & 578 & 352 & 70 & 567 & 374 & 59 \\
\hline 80 a 100 & 567 & 364 & 69 & 600 & 329 & 71 & 583 & 361 & 56 \\
\hline
\end{tabular}

A3 - em recuperação, A4 - degradada, MT - Mata Atlântica. Fonte: Autoria própria. 
A partir desse método pôde-se determinar a composição textural dos solos e constatouse que as áreas em estudo apresentam texturas distintas, ou seja, teores diferentes de argila, silte e areia. A A3 apresentou características argilosas, A4 possui um solo mais arenoso e a MT apresentou teores médios de argila e areia.

Para melhor visualização da classificação textural, é apresentado na figura 19 o triangulo textural de classificação de solos segundo o Departamento de Agricultura dos Estados Unidos (USDA). Nele foram inseridos os pontos correspondentes às amostras em estudo conforme seus teores de argila, silte e areia.

A classificação brasileira de solos segue a classificação do USDA, porém com menos subdivisões entre as classes principais que são: muito argilosa, argilosa, siltosa, média e arenosa.

Figura 19 - Classificação dos solos das áreas de manejo segundo o USDA

\section{Classificação de solos}

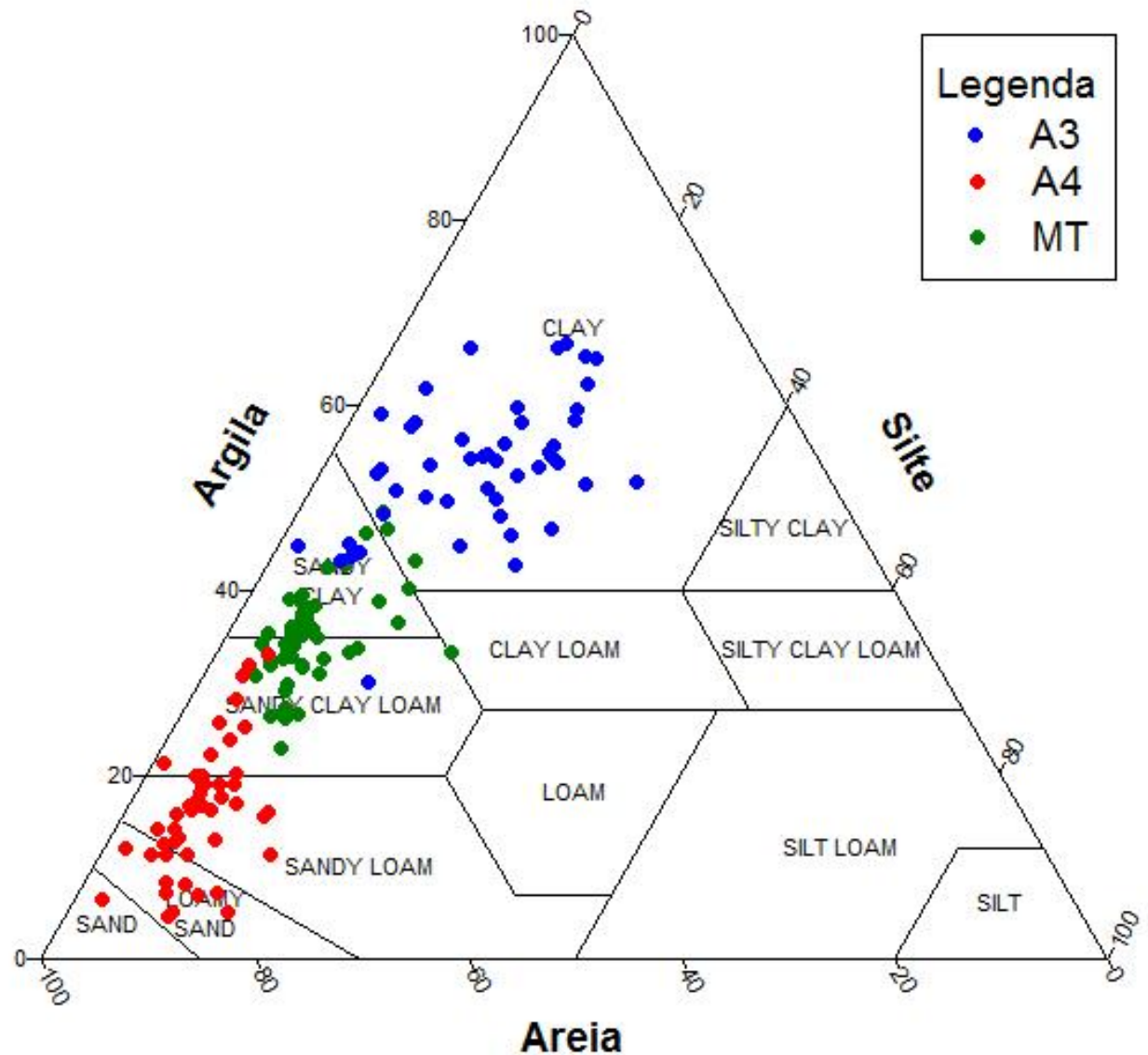

Fonte: Autoria própria 
Através do triângulo textural é possível visualizar que os solos dos manejos pertencem a grupos texturais distintos.

\subsubsection{Densidade do solo}

A densidade do solo é uma propriedade variável e depende da estrutura e compactação do solo. Alguns fatores tais como teor de água (chuvas/irrigação) e lotação animal estão relacionados com essa propriedade. O solo mais úmido tende a sofrer maior compactação promovida pelo pisoteio animal. O material constituinte do solo tem grande influência sobre o valor da densidade, assim como os sistemas de uso e manejo e tipo de cobertura vegetal (BICALHO, 2011).

Segundo Silva e colaboradores (2003) a intensidade de compactação é maior em solos com elevado teor de água. O teor de água no solo também tem relação direta com o desenvolvimento radicular.

A densidade do solo, a distribuição de tamanho dos poros e a resistência à penetração de raízes são algumas das propriedades físicas alteradas pela compactação do solo.

Os valores médios para a densidade dos solos analisados são apresentados na Tabela 2.

Tabela 2 - Valores de densidades médias do solo $\left(\mathrm{g} \mathrm{cm}^{-3}\right)$ determinados nas diferentes profundidades considerando as seis replicatas do campo (trincheiras) (média \pm desvio padrão).

\begin{tabular}{cccc}
\hline & \multicolumn{3}{c}{ Densidade do solo $\left(\mathbf{g ~ c m}^{-3}\right)$} \\
\cline { 2 - 4 } Profundidade $(\mathbf{c m})$ & $\mathbf{A 3}$ & $\mathbf{A 4}$ & MT \\
\hline 0 a 5 & $1,1( \pm 0,1) \mathrm{a}$ & $1,3( \pm 0,1) \mathrm{b}$ & $1,06( \pm 0,07) \mathrm{a}$ \\
5 a 10 & $1,1( \pm 0,1) \mathrm{a}$ & $1,4( \pm 0,1) \mathrm{b}$ & $1,14( \pm 0,10) \mathrm{a}$ \\
10 a 20 & $1,1( \pm 0,1) \mathrm{a}$ & $1,4( \pm 0,1) \mathrm{b}$ & $1,16( \pm 0,11) \mathrm{a}$ \\
20 a 30 & $1,1( \pm 0,1) \mathrm{a}$ & $1,4( \pm 0,1) \mathrm{b}$ & $1,1( \pm 0,1) \mathrm{a}$ \\
30 a 40 & $1,04( \pm 0,01) \mathrm{a}$ & $1,4( \pm 0,1) \mathrm{b}$ & $0,92( \pm 0,03) \mathrm{c}$ \\
40 a 60 & $1,1( \pm 0,1) \mathrm{a}$ & $1,3( \pm 0,1) \mathrm{b}$ & $1,16( \pm 0,04) \mathrm{c}$ \\
60 a 80 & $1,0( \pm 0,1) \mathrm{a}$ & $1,3( \pm 0,1) \mathrm{b}$ & $1,16( \pm 0,02) \mathrm{c}$ \\
80 a 100 & $1,04( \pm 0,04) \mathrm{a}$ & $1,3( \pm 0,1) \mathrm{b}$ & $1,13( \pm 0,11) \mathrm{a}$ \\
\hline
\end{tabular}

$\overline{a, b, c}$ - Médias seguidas de letras iguais não diferem estatisticamente pelo Teste de Tukey (p>0,05).

A3 - em recuperação, A4 - degradada, MT - Mata Atlântica. Fonte: Autoria própria.

Considerando todos os sistemas, não há grande variação da densidade do solo ao longo do perfil.

Segundo alguns autores (SILVA; IMHOFF; CORSI, 2003) a influência das raízes das plantas de cobertura na estrutura do solo leva a redução da densidade do solo. Esse fato pode 
ser melhor evidenciado no sistema A3, área em recuperação por conta do manejo estabelecido, tais como fertilizações e correções realizadas. Essas fertilizações favorecem o crescimento da vegetação, Brachiaria decumbens, bem como os sistemas radiculares abundantes os quais exercem influência na estrutura do solo.

Segundo Ramos (2009), baixos valores de densidade de solo em ambientes com alto teor de MOS são esperados, pois a matéria orgânica favorece a menor densidade do solo. O autor também afirma que baixos valores de densidade são observados em vegetação de mata nativa.

Em A4, pastagem degradada, o sistema também é mantido com Brachiaria decumbens, porém com maior exposição do solo por conta do manejo, a vegetação apresentase com o mínimo desenvolvimento, ou seja, uma gramínea rala e com pequeno sistema radicular. O pouco desenvolvimento das raízes acarreta o aumento da compactação solo.

Através do teste de Tukey que é representado pelas letras iguais na tabela 2, podemos dizer que a densidade do solo da pastagem em recuperação é estatisticamente igual a densidade do solo na mata nativa em praticamente todo o perfil.

Araujo, Tormena e Silva (2004) evidenciam que, comparativamente ao solo sob mata nativa, a degradação da estrutura do solo impõe limitações ao crescimento das plantas por causa da redução na água disponível, pela restrição de aeração e pela elevação da resistência do solo à penetração.

Segundo Goedert, Schermack e Freitas (2002) ainda há falta de consenso entre pesquisadores sobre o nível crítico da densidade do solo, não apresentando um valor acima do qual o solo é considerado compactado. Assim, características originais de cada solo e as práticas de manejo empregadas, destacam-se dentre vários outros fatores, sobre o estado de compactação do solo.

\subsubsection{Quantificação do teor de carbono no solo}

Os valores médios obtidos para cada área de pastagem e para a mata nativa são apresentados na tabela 3. São mostrados também os desvios padrão considerando as seis replicatas de campo. Também optou-se por trabalhar com os valores médios dos resultados de carbono.

Os teores de carbono apresentados foram utilizados para os cálculos dos ECs das áreas estudadas, incluindo as correções por massa equivalente. 
Tabela 3 - Teores médios de carbono em porcentagem determinados por análise elementar considerando as seis replicatas do campo (média \pm desvio padrão)

\begin{tabular}{cccc}
\hline & \multicolumn{3}{c}{ \% Carbono $(\mathbf{m} / \mathbf{m})$} \\
\cline { 2 - 4 } Profundidade $(\mathbf{c m})$ & A3 & A4 & MT \\
\hline 0 a 5 & $2,6( \pm 0,3) \mathrm{a}$ & $1,5( \pm 0,3) \mathrm{b}$ & $2,4( \pm 0,5) \mathrm{b}$ \\
5 a 10 & $2,2( \pm 0,4) \mathrm{a}$ & $1,18( \pm 0,04) \mathrm{b}$ & $1,8( \pm 0,3) \mathrm{a}$ \\
10 a 20 & $1,7( \pm 0,2) \mathrm{a}$ & $1,1( \pm 0,1) \mathrm{b}$ & $1,3( \pm 0,1) \mathrm{c}$ \\
20 a 30 & $1,4( \pm 0,3) \mathrm{a}$ & $0,9( \pm 0,2) \mathrm{b}$ & $1,1( \pm 0,1) \mathrm{a}$ \\
30 a 40 & $1,2( \pm 0,1) \mathrm{a}$ & $0,9( \pm 0,1) \mathrm{b}$ & $0,92( \pm 0,03) \mathrm{b}$ \\
40 a 60 & $1,1( \pm 0,1) \mathrm{a}$ & $0,7( \pm 0,1) \mathrm{b}$ & $0,85( \pm 0,13) \mathrm{b}$ \\
60 a 80 & $0,0( \pm 0,1) \mathrm{a}$ & $0,7( \pm 0,1) \mathrm{b}$ & $0,8( \pm 0,1) \mathrm{b}$ \\
80 a 100 & $0,8( \pm 0,1) \mathrm{a}$ & $0,6( \pm 0,1) \mathrm{b}$ & $0,7( \pm 0,2) \mathrm{b}$ \\
\hline
\end{tabular}

a,b,c - Médias seguidas de letras iguais não diferem estatisticamente pelo Teste de Tukey (p>0,05). A3 - em recuperação, A4 - degradada, MT - Mata Atlântica. Fonte: Autoria própria.

Para todas as áreas em questão foram encontrados os maiores valores de carbono na superfície e à medida que a profundidade aumenta os teores decrescem, tendência essa comumente verificada em Latossolos. Essa tendência ocorre em camadas superiores por haver entrada contínua de material fresco oriundo da vegetação e dos animais.

O sistema de pastagem A3 apresentou os maiores valores de carbono no solo, superando os valores da Mata Nativa. De acordo com Rezende e colaboradores (1999), as pastagens bem manejadas apresentam um grande potencial para retirar $\mathrm{CO}_{2}$ da atmosfera e enriquecer o solo com MOS. Como citado anteriormente, esses autores mostraram que após a retirada da vegetação nativa e criação do sistema de pastagem, o EC foi reposto e ultrapassou valores dos ECs da vegetação nativa.

Segundo Kluthcouski e colaboradores (2006), os teores de MOS nas pastagens de Brachiaria também podem ser maiores que os dos Cerrados virgens. As avaliações apresentadas por Segnini (2007) mostram a mesma tendência considerando área de Cerradão e pastagens de Brachiaria decumbens bem manejadas. Fearnside e Barbosa (1998) também mostraram que o carbono do solo é afetado pelo sistema de pastagem, onde pastagens degradadas perdem substancial quantidade de carbono do solo. Essas situações são frequentemente afetadas pelas diminuições das gramíneas de cobertura já que há menor entrada de carbono orgânico pelas raízes.

Na Tabela 3 também é possível observar que os maiores desvios-padrão foram obtidos nas primeiras profundidades, ao considerar a média referente aos teores de carbono calculados 
para as seis replicatas no campo. Esse fato é explicado pela maior entrada de material orgânico na parte superficial do solo.

Considerando que sistemas de pastagens são áreas ambientais altamente heterogêneas, nas quais o aporte do material orgânico, o pisoteio animal, a compactação do solo, a presença desigual da cobertura vegetal, a taxa de loteamento animal, gradientes de fertilidade, o relevo e a umidade são fatores que influenciam os teores de carbono do solo. Esses fatores fazem com que a comparação dos resultados de carbono por médias apresentem elevadas variações nos desvios entre as replicatas de campo.

\subsubsection{Estimativa do Estoque de Carbono nas áreas de pastagem}

O IPCC enfatiza a importância da estimativa dos ECs na camada de 0-30 cm separadamente, camada essa onde ocorrem as principais mudanças nos ECs em relação aos diferentes manejos e usos do solo (penetração dos implementos agrícolas).

Já a recomendação da rede PECUS é que a avaliação dos ECs seja feita em camadas mais profundas, ou seja, até pelo menos 1 metro de profundidade quando se trata de áreas experimentais com vegetações tropicais onde o sistema radicular dessas gramíneas é profundo (BATJES, 2010). Boddey e colaboradores (2010) mostraram que ainda existem poucos trabalhos na literatura sobre ECs que avaliam profundidades até 1 metro.

A partir dos teores de carbono apresentados no tópico anterior e a equação 7 , foram calculados os ECs e são apresentados na tabela 4. Os ECs foram calculados para cada trincheira das áreas de estudo de $0-30 \mathrm{~cm}$ e de $30-100 \mathrm{~cm}$ de profundidade e posteriormente calculada a média das trincheiras (EC médio da área). 
Tabela 4 - ECs calculados para as áreas em estudo de $0-30 \mathrm{~cm}$ e de $30-100 \mathrm{~cm}$ para cada trincheira coletada

\begin{tabular}{|c|c|c|c|c|c|c|}
\hline \multirow[b]{2}{*}{ Trincheira } & \multicolumn{2}{|c|}{ EC $0-30 \mathrm{~cm}$} & \multicolumn{2}{|c|}{ EC $30-100 \mathrm{~cm}$} & \multicolumn{2}{|c|}{ EC $0-100 \mathrm{~cm}$} \\
\hline & $\begin{array}{l}\text { Média } \\
\left(\mathrm{Mg} \mathrm{ha}^{-1}\right)\end{array}$ & $\begin{array}{l}\text { Desvio } \\
\text { padrão }\end{array}$ & $\begin{array}{c}\text { Média } \\
\left(\mathrm{Mg} \mathrm{ha}^{-1}\right)\end{array}$ & $\begin{array}{l}\text { Desvio } \\
\text { padrão }\end{array}$ & $\begin{array}{c}\text { Média } \\
\left(\mathrm{Mg} \mathrm{ha}^{-1}\right)\end{array}$ & $\begin{array}{l}\text { Desvio } \\
\text { padrão }\end{array}$ \\
\hline A3T1 & 51,31 & & 67,94 & & 119,25 & \\
\hline АЗТ 2 & 72,37 & & 81,63 & & 154,00 & \\
\hline АЗТЗ & 67,56 & & 70,93 & & 138,49 & \\
\hline АЗТ4 & 62,31 & & 68,54 & & 130,85 & \\
\hline A3T5 & 51,25 & & 74,71 & & 125,96 & \\
\hline А3T6 & 71,93 & & 74,81 & & 146,74 & \\
\hline ÁREA 3 & 63 & 10 & 73 & 5 & 136 & 13 \\
\hline A4T1 & 34,42 & & 53,74 & & 88,16 & \\
\hline A4T2 & 46,42 & & 66,79 & & 113,20 & \\
\hline A4T3 & 50,02 & & 63,40 & & 113,42 & \\
\hline A4T4 & 50,37 & & 67,81 & & 118,18 & \\
\hline A4T5 & 48,99 & & 64,03 & & 113,03 & \\
\hline A4T6 & 45,15 & & 64,61 & & 109,76 & \\
\hline ÁREA 4 & 46 & 6 & 63 & 5 & 109 & 11 \\
\hline MTT1 & 61,28 & & 65,31 & & 126,59 & \\
\hline MTT2 & 46,18 & & 54,98 & & 101,16 & \\
\hline MTT3 & 48,43 & & 78,32 & & 126,76 & \\
\hline MTT4 & 46,92 & & 61,37 & & 108,29 & \\
\hline MTT5 & 50,06 & & 64,37 & & 114,43 & \\
\hline MTT6 & 48,92 & & 66,62 & & 115,54 & \\
\hline MATA & 50 & 6 & 65 & 8 & 115 & 10 \\
\hline
\end{tabular}

A3 - em recuperação, A4 - degradada, MT - Mata Atlântica. Fonte: Autoria própria.

Na figura 21 são apresentados os ECs médios obtidos pelo cálculo das médias entre os ECs das trincheiras de cada área em todo o perfil $(0-100 \mathrm{~cm})$. Os dados presentes na figura 20 foram obtidos da tabela 4 . 
Figura 20 - ECs dos sistemas de pastagem e mata nativa em todo o perfil.

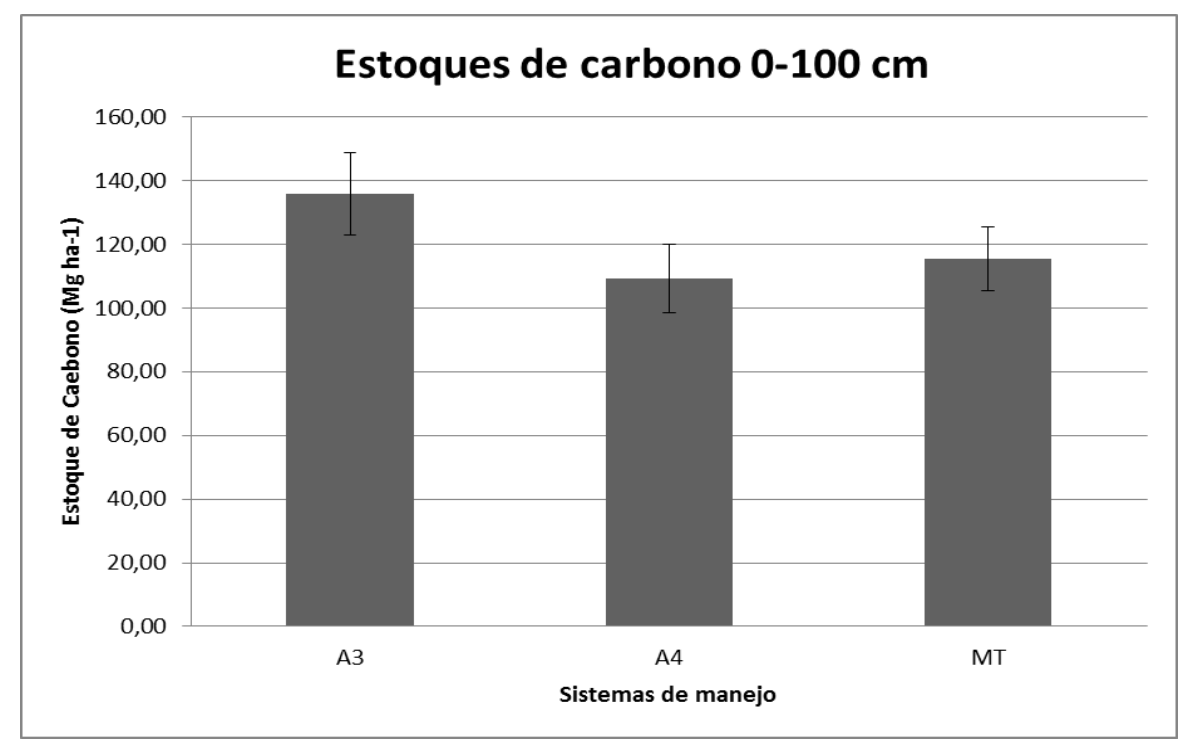

A3 - em recuperação, A4 - degradada, MT - Mata Atlântica.

Fonte: Autoria própria

Nesses resultados a A3 apresentou os maiores valores de EC com $136 \mathrm{Mg} \mathrm{ha}^{-1}$, enquanto que para a A4 estimou-se EC de $109 \mathrm{Mg} \mathrm{ha}^{-1}$ e para a MT um EC de $115 \mathrm{Mg} \mathrm{ha}^{-1}$.

Na figura 22 são apresentados os ECs considerando as camadas 0-30 cm e 30-100 cm separadamente. Os dados de EC apresentados na figura 21 foram obtidos da tabela 4.

Figura 21 - ECs dos sistemas de pastagem e mata nativa nas camadas de 0-30 cm e de $30-100 \mathrm{~cm}$

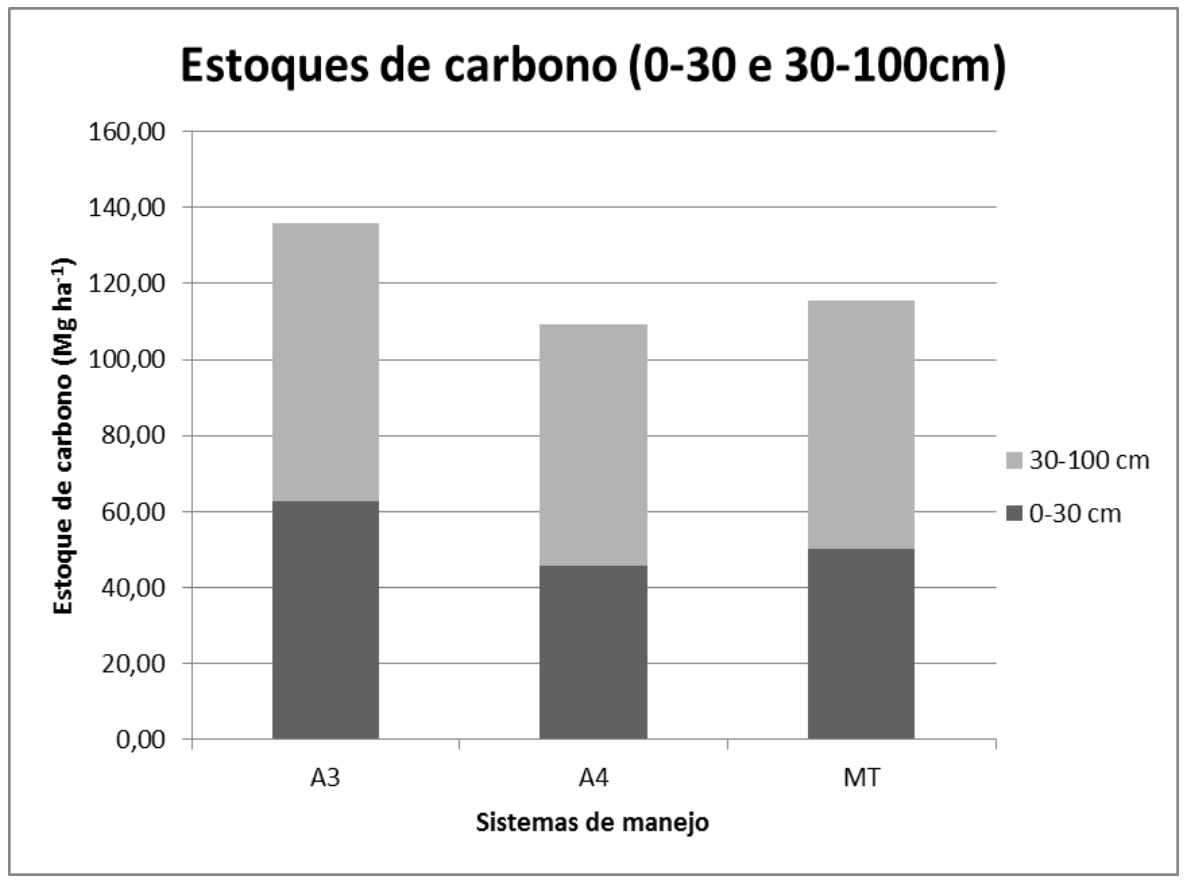

A3 - em recuperação, A4 - degradada, MT - Mata Atlântica.

Fonte: Autoria própria 


\subsubsection{Correção dos ECs por massa de solo equivalente}

Como se pretende comparar ECs de solos com densidades diferentes em função dos manejos, faz-se necessária a correção pela massa equivalente de solo como enunciado no item 3.3.3.1. Os ECs foram corrigidos em função da massa equivalente para cada sistema de manejo de pastagem conforme as equações 7 e 8 .

Os ECs de cada trincheira das áreas de pastagem foram corrigidos pela massa equivalente de cada uma das seis trincheiras da mata nativa. Abaixo, na tabela 5, são mostrados os dados de ECs calculados (sem correção) e os ECs corrigidos para todo o perfil amostrado (0-100 cm). Também são mostrados os ECs médios de cada trincheira das áreas, bem como os desvios padrão.

Tabela 5 - ECs calculados e corrigidos de 0-100 cm para cada trincheira das áreas em estudos

\begin{tabular}{|c|c|c|c|c|c|c|c|c|c|}
\hline \multirow{2}{*}{ Trincheira } & \multirow{2}{*}{$\begin{array}{c}\text { EC } \\
\text { calculado } \\
\left(\mathrm{Mg} \mathrm{ha}^{-1}\right)\end{array}$} & \multicolumn{8}{|c|}{ EC corrigido ( $M g$ ha $^{-1}$ ) em função de cada T da MT } \\
\hline & & $\mathrm{T} 1$ & $\mathrm{~T} 2$ & T3 & $\mathrm{T} 4$ & T5 & T6 & MÉDIA & SD \\
\hline A3T1 & 119,25 & 123,42 & 117,00 & 117,00 & 124,16 & 127,55 & 123,18 & 122,05 & \\
\hline A3T2 & 154,00 & 163,25 & 154,59 & 154,59 & 164,24 & 168,82 & 162,92 & 161,40 & \\
\hline A3T3 & 138,49 & 149,16 & 141,93 & 141,93 & 150,00 & 153,82 & 148,89 & 147,62 & \\
\hline A3T4 & 130,85 & 134,71 & 128,81 & 128,80 & 135,39 & 138,50 & 134,49 & 133,45 & \\
\hline A3T5 & 125,96 & 138,11 & 130,83 & 130,83 & 138,95 & 142,79 & 137,84 & 136,56 & \\
\hline A3T6 & 146,74 & 154,85 & 147,62 & 147,61 & 155,68 & 159,51 & 154,58 & 153,31 & \\
\hline ÁREA 3 & 136 & & & & & & & 142 & 14 \\
\hline$\overline{\mathrm{A} 4 \mathrm{~T} 1}$ & 88,16 & 84,52 & 80,00 & 80,00 & 85,04 & 87,43 & 84,36 & 83,56 & \\
\hline A4T2 & 113,20 & 102,65 & 96,40 & 96,40 & 103,37 & 106,67 & 102,42 & 101,32 & \\
\hline A4T3 & 113,42 & 105,42 & 100,68 & 100,68 & 105,96 & 108,46 & 105,24 & 104,41 & \\
\hline A4T4 & 118,18 & 109,50 & 103,47 & 103,46 & 110,19 & 113,37 & 109,27 & 108,21 & \\
\hline A4T5 & 113,03 & 102,36 & 97,41 & 97,41 & 102,93 & 105,55 & 102,18 & 101,31 & \\
\hline A4T6 & 109,76 & 98,09 & 93,39 & 93,39 & 98,63 & 101,11 & 97,91 & 97,09 & \\
\hline ÁREA 4 & 109 & & & & & & & 99 & 9 \\
\hline MTT1 & 126,59 & & & & & & & & \\
\hline MTT2 & 101,16 & & & & & & & & \\
\hline MTT3 & 126,76 & & & & & & & & \\
\hline MTT4 & 108,29 & & & & & & & & \\
\hline MTT5 & 114,43 & & & & & & & & \\
\hline MTT6 & 115,54 & & & & & & & & \\
\hline MATA & 115 & & & & & & & 115 & 10 \\
\hline
\end{tabular}

A3 - em recuperação, A4 - degradada, MT - Mata Atlântica. Fonte: Autoria própria. 
Os dados de ECs de cada área foram submetidos a testes estatísticos e os ECs médios para cada área são apresentados na figura 22 abaixo. Os desvios são apresentados em função das seis replicatas do campo, como apresentados na tabela 5.

Figura 22 - ECs dos sistemas de pastagem e mata nativa em todo o perfil utilizando a correção por massa equivalente.

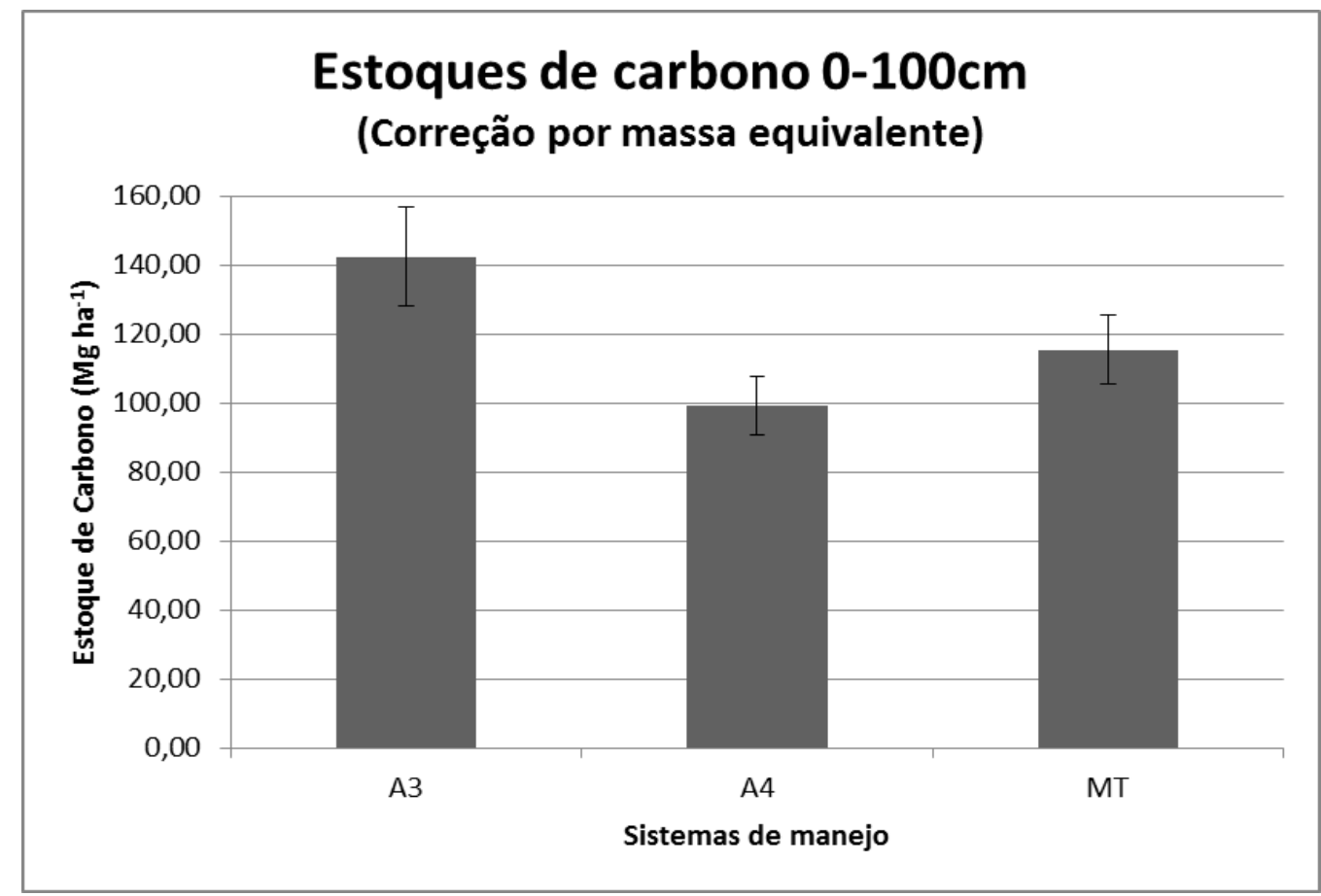

A3 - em recuperação, A4 - degradada, MT - Mata Atlântica.

Fonte: Autoria própria

Os resultados dos ECs até 1m de profundidade mostram que a A3 apresentou maior EC (142 $\mathrm{Mg} \mathrm{ha}^{-1}$ ) em comparação com os demais sistemas. Os ECs da A4 (99 Mg ha $\left.{ }^{-1}\right)$ e MT (115 $\left.\mathrm{Mg} \mathrm{ha}^{-1}\right)$ podem ser considerados estatisticamente iguais, porém são diferentes de A3.

Em relação a A3 e A4, a vegetação é a mesma, porém A4 é um sistema degradado, ou seja, mantido sem nenhum controle. Em A3 os resultados foram promissores, pois os dados apresentados indicam que pastos foram melhorados com o uso da gramínea introduzida. Com a manutenção da fertilidade adequada do solo e taxas de criação de animais cuidadosamente planejada, o carbono no solo pode ser mantido em níveis maiores daqueles das florestas que foram substituídas. Entretanto, em pastos degradados com pequena quantidade de aporte orgânico, levaram a ECs inferiores.

Alguns autores mostram a capacidade de sequestro de carbono por parte de pastos bem manejados. Segnini (2007) estimou ECs em diferentes sistemas de pastagem variando de 
174 a $223 \mathrm{Mg} \mathrm{ha}^{-1}$ após 27 anos de pastagem, enquanto que em área nativa de cerradão os ECs determinados foram de $129 \mathrm{Mg} \mathrm{ha}^{-1}$. Fisher et al. (1994) obtiveram cerca de $200 \mathrm{Mg} \mathrm{ha}^{-1}$ nas savanas colombianas, com 9 anos de experimento e, Corazza et al. (1999), $150 \mathrm{Mg} \mathrm{ha}^{-1}$, em pastagens cultivadas com Brachiaria decumbens após 23 anos de experimento, sendo todos esses valores avaliados nas mesmas profundidades.

Também foram calculados os ECs corrigidos em função da área de referência (massa equivalente), porém considerando as camadas $0-30 \mathrm{~cm}$ e $30-100 \mathrm{~cm}$ separadamente.

Abaixo, na tabela 6, são apresentados os ECs corrigidos considerando apenas a camada $0-30 \mathrm{~cm}$.

Tabela 6 - ECs calculados e corrigidos de 0-30 cm para cada trincheira das áreas em estudos

\begin{tabular}{|c|c|c|c|c|c|c|c|c|c|}
\hline \multirow{2}{*}{ Trincheira } & \multirow{2}{*}{$\begin{array}{c}\text { EC calculado 0-30 } \\
\mathrm{cm}\left(\mathrm{Mg} \mathrm{ha}^{-1}\right)\end{array}$} & \multicolumn{8}{|c|}{ EC corrigido ( $\mathrm{Mg} \mathrm{ha}^{-1}$ ) em função de cada T da MT } \\
\hline & & T1 & $\mathrm{T} 2$ & T3 & $\mathrm{T} 4$ & T5 & T6 & MÉDIA & SD \\
\hline A3T1 & 51,31 & 55,12 & 50,14 & 47,84 & 51,54 & 53,56 & 50,14 & 51,39 & \\
\hline A3T2 & 72,37 & 74,94 & 67,41 & 63,95 & 69,53 & 72,58 & 67,42 & 69,30 & \\
\hline A3T3 & 67,56 & 72,11 & 65,34 & 62,22 & 67,24 & 69,98 & 65,34 & 67,04 & \\
\hline A3T4 & 62,31 & 69,03 & 61,16 & 57,53 & 63,36 & 66,56 & 61,16 & 63,13 & \\
\hline A3T5 & 51,25 & 60,85 & 54,35 & 51,36 & 56,18 & 58,81 & 54,36 & 55,98 & \\
\hline A3T6 & 71,93 & 81,40 & 72,72 & 68,73 & 75,16 & 78,67 & 72,73 & 74,90 & \\
\hline ÁREA 3 & 63 & & & & & & & 64 & 9 \\
\hline A4T1 & 34,42 & 33,72 & 30,52 & 29,04 & 31,42 & 32,72 & 30,52 & 31,32 & \\
\hline A4T2 & 46,42 & 43,49 & 38,73 & 36,53 & 40,06 & 42,00 & 38,73 & 39,92 & \\
\hline A4T3 & 50,02 & 47,08 & 40,84 & 37,97 & 42,59 & 45,12 & 40,85 & 42,41 & \\
\hline A4T4 & 50,37 & 46,85 & 41,62 & 39,21 & 43,09 & 45,21 & 41,62 & 42,93 & \\
\hline A4T5 & 48,99 & 44,37 & 39,65 & 37,48 & 40,97 & 42,88 & 39,65 & 40,83 & \\
\hline A4T6 & 45,15 & 40,43 & 35,69 & 33,50 & 37,02 & 38,94 & 35,69 & 36,88 & \\
\hline ÁREA 4 & 46 & & & & & & & 39 & 4 \\
\hline MTT1 & 61,28 & & & & & & & 61,28 & \\
\hline MTT2 & 46,18 & & & & & & & 46,18 & \\
\hline MTT3 & 48,43 & & & & & & & 48,43 & \\
\hline MTT4 & 46,92 & & & & & & & 46,92 & \\
\hline MTT5 & 50,06 & & & & & & & 50,06 & \\
\hline MTT6 & 48,92 & & & & & & & 48,92 & \\
\hline MATA & 50 & & & & & & & 50 & 6 \\
\hline
\end{tabular}

A3 - em recuperação, A4 - degradada, MT - Mata Atlântica. Fonte: Autoria própria. 
Os resultados dos ECs de 0-30 $\mathrm{cm}$ de profundidade mostram que a A3 apresentou maior EC (64 $\left.\mathrm{Mg} \mathrm{ha}^{-1}\right)$ em comparação com os ECs da A4 (39 $\left.\mathrm{Mg} \mathrm{ha}^{-1}\right)$ e MT (50 Mg ha $\left.{ }^{-1}\right)$. As três áreas foram consideradas estatisticamente diferentes entre si para a profundidade de 0$30 \mathrm{~cm}$.

Na figura 23 são apresentados os ECs médios, considerando as seis replicatas do campo, corrigidos pela massa equivalente da mata tanto em superfície $(0-30 \mathrm{~cm})$ quanto em profundidade $(30-100 \mathrm{~cm})$, unindo os dados apresentados nas tabelas 5 e 6.

Figura 23 - ECs dos sistemas de pastagem e mata nativa nas camadas de 0-30 cm e de 30-100 cm utilizando a correção por massa equivalente.

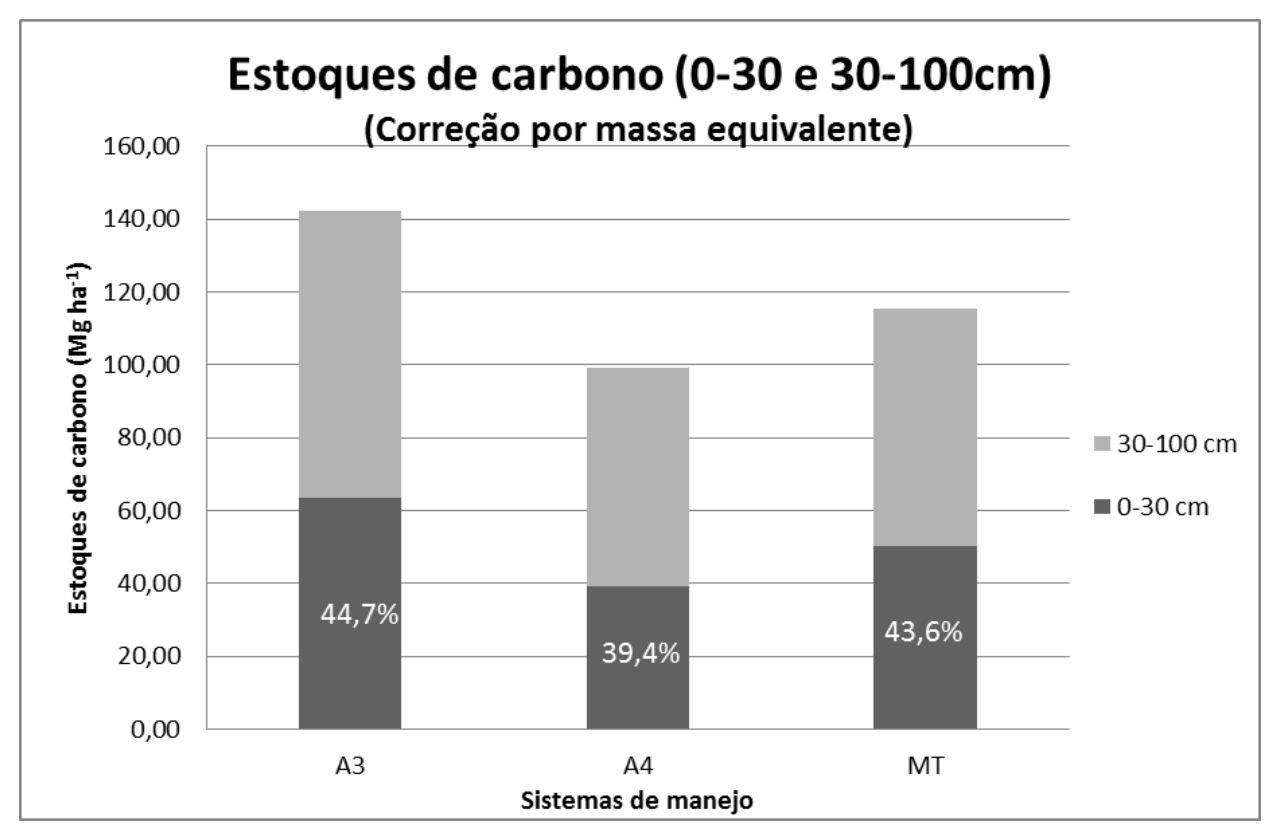

A3 - em recuperação, A4 - degradada, MT - Mata Atlântica

Fonte: Autoria própria

O dado interessante dessa avaliação foi a distribuição do EC para cada camada estudada. Os ECs calculados para a camada $0-30 \mathrm{~cm}$ representam cerca de $43 \%$ do total, enquanto que a camada $30-100 \mathrm{~cm}$ contribui com os restantes $57 \%$ dos ECs. Com essa informação, fica evidente a importância de se avaliar as camadas mais profundas do solo, principalmente quando se tratam de áreas de pastagem de Brachiaria e Panicum, forrageiras com predomínio de sistemas radiculares abundantes.

Os resultados apresentados referentes aos ECs provenientes dos sistemas de pastagem mostram que a pastagem bem manejada tende a estocar maior quantidade de carbono enquanto que a pastagem degradada, na qual não foi exercido nenhum tipo de controle, tendeu a estocar menor quantidade de carbono. 
A partir dos dados de ECs apresentados, baseados na literatura e nas justificativas apresentadas na seção 3.3.4.1, recomenda-se que a correção por massa equivalente seja aplicada às estimativas de ECs de áreas de pastagem estudadas, por conta da diferença significativa de densidade entre as áreas e os perfis. Sem a correção por massa equivalente pode-se subestimar ou sobrestimar os ECs das áreas de pastagem por conta das diferenças da densidade do solo. Aplicada essa correção é possível comparar os ECs em igualdade de massa de solo.

\subsubsection{Correção dos ECs pelos teores de argila do solo}

Investigou-se também outra forma de correção dos ECs, a correção dos ECs pelos teores de argila correspondentes a cada área. Os resultados são apresentados na abaixo na tabela 7.

Tabela 7 - ECs calculados e corrigidos pelos teores de argila de 0-100 $\mathrm{cm}$ para cada trincheira das áreas em estudos

\begin{tabular}{|c|c|c|c|}
\hline Trincheira & EC $0-100 \mathrm{~cm}\left(\mathrm{Mg} \mathrm{ha}^{-1}\right)$ & $\begin{array}{l}\text { EC Corrigido Argila } \\
\left(\mathrm{Mg} \mathrm{ha}^{-1}\right)\end{array}$ & $\begin{array}{l}\text { Desvio } \\
\text { padrão }\end{array}$ \\
\hline A3T1 & 119,25 & 78,67 & \\
\hline A3T2 & 154,00 & 84,30 & \\
\hline A3T3 & 138,49 & 84,94 & \\
\hline A3T4 & 130,85 & 105,71 & \\
\hline A3T5 & 125,96 & 81,30 & \\
\hline A3T6 & 146,74 & 104,20 & \\
\hline ÁREA 3 & 136 & 90 & 12 \\
\hline A4T1 & 88,16 & 255,75 & \\
\hline A4T2 & 113,20 & 257,24 & \\
\hline A4T3 & 113,42 & 255,17 & \\
\hline A4T4 & 118,18 & 177,09 & \\
\hline A4T5 & 113,03 & $\underline{549,20}$ & \\
\hline A4T6 & 109,76 & 229,13 & \\
\hline ÁREA 4 & 109 & 287 & 132 \\
\hline MTT1 & 126,59 & & \\
\hline MTT2 & 101,16 & & \\
\hline MTT3 & 126,76 & & \\
\hline MTT4 & 108,29 & & \\
\hline MTT5 & 114,43 & & \\
\hline MTT6 & 115,54 & & \\
\hline MATA & 115 & 115 & 10 \\
\hline
\end{tabular}

A3 - em recuperação, A4 - degradada, MT - Mata Atlântica. Fonte: Autoria própria. 
Notou-se um valor muito discrepante de EC corrigido para a A4T5 próximo de $550 \mathrm{Mg} \mathrm{ha}^{-1}$. Esse dado foi considerado anômalo e não foi utilizado para a construção do gráfico abaixo (figura 24). A trincheira T5 apresenta os menores teores de argila no solo e quando se efetua a correção pelos teores de argila da mata nativa, as estimativas de EC tendem a serem altas. A figura abaixo mostra os ECs das três áreas corrigidos pelos teores de argila dos solos da mata nativa.

Figura 24 - ECs dos sistemas de pastagem e mata nativa em todo o perfil utilizando a correção pelos teores de argila

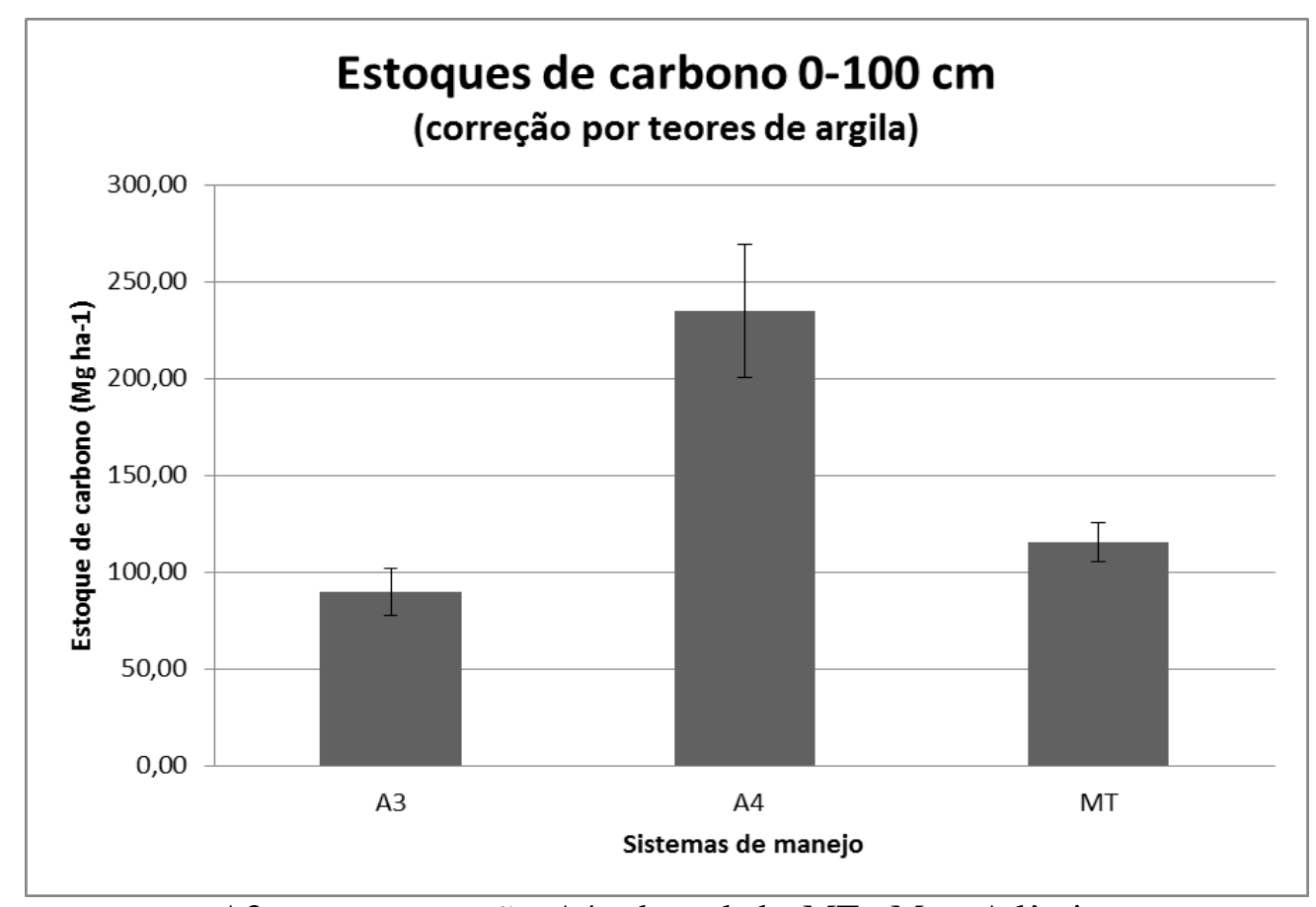

A3 - em recuperação, A4 - degradada, MT - Mata Atlântica

Fonte: Autoria própria

Os resultados não foram condizentes à realidade agronômica. Solos com texturas argilosas possuem a tendência de armazenar maior concentração de C (PINHEIRO et al. 2010). No entanto, segundo a equação 10 apresentada no tópico 3.3.4.2, quanto maior o teor de argila da camada, maior será o valor no divisor, menor será o valor de estoque final obtido, ou seja, solos com maiores teores de argila apresentariam valores de ECs menores, fato esse que não faz sentido real.

Por conta desse resultado conflitante com a realidade, não foram corrigidos os ECs separadamente de $0-30 \mathrm{~cm}$ e $30-100 \mathrm{~cm}$. 


\subsubsection{Considerações finais sobre as estimativas dos ECs.}

Para as considerações finais sobre os cálculos e estimativas dos ECs, são apresentados na tabela 8 os dados de ECs utilizando os três tipos de correções: sem correção (equação 7), com correção por massa equivalente (equação 9) e correção por teores de argila (equação 10).

Tabela 8 - ECs dos sistemas de pastagem e mata nativa em todo o perfil $(0-100 \mathrm{~cm})$ utilizando os três tipos de correções.

\begin{tabular}{cccc}
\hline & \multicolumn{3}{c}{ ECs $\left(\mathbf{M g ~ h a}{ }^{-1}\right)$} \\
\cline { 2 - 4 } Tipo de Correção & A3 & A4 & MT \\
\hline Sem correção & $136 \pm 13$ & $109 \pm 10$ & $115 \pm 10$ \\
Massa equivalente & $142 \pm 14$ & $99 \pm 9$ & $115 \pm 10$ \\
Argila & $90 \pm 12$ & $287 \pm 132$ & $115 \pm 10$ \\
\hline
\end{tabular}

A 3 - em recuperação, A4 - degradada, MT - Mata Atlântica. Fonte: Autoria própria.

$\mathrm{Na}$ figura 25 são apresentados os ECs das áreas de pastagem e da mata nativa conforme os três tipos de estimativa.

Figura 25 - ECs dos sistemas de pastagem e mata nativa em todo o perfil utilizando os três tipos de correções.

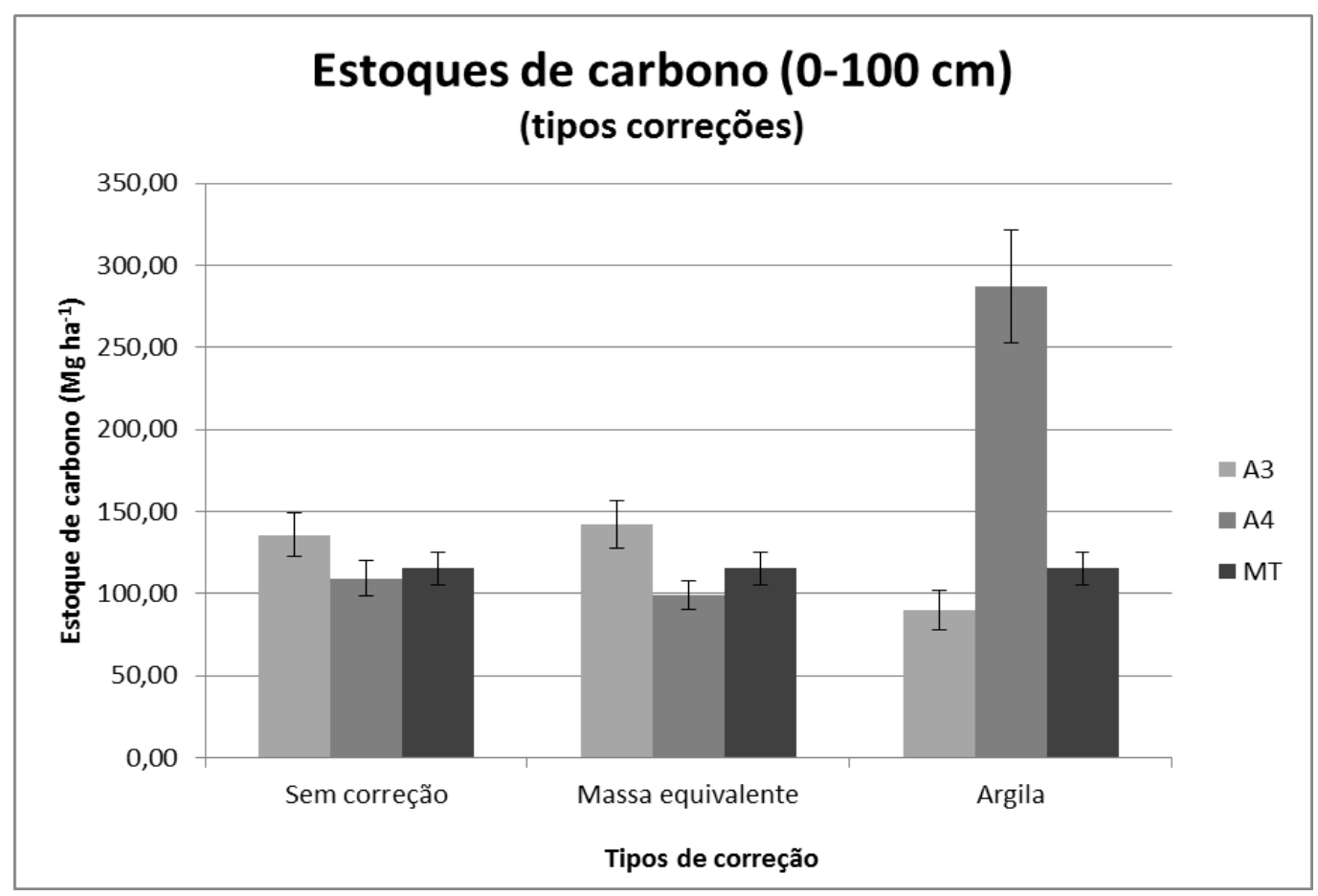

A3 - em recuperação, A4 - degradada, MT - Mata Atlântica

Fonte: Autoria própria 
Pôde-se então se concluir que a correção por massa equivalente se faz necessária por conta da comparação de solos com densidades diferentes. Para que se consiga compará-los em igualdade, a correção por massa equivalente se mostrou eficiente. Já a correção por teores de argila não apresentou coerência com os atributos físicos, químicos e agronômicos dos solos estudos, já que solos mais arenosos (A4) apresentaram os maiores teores de ECs.

\subsubsection{Avaliação da qualidade da MOS}

Para a avaliação da qualidade da MOS, utilizou-se a LIFS. Foram coletados cinco espectros por amostra em questão. A partir das áreas desses cinco espectros foi calculada uma área média.

A partir da proposta do índice de humificação proposto por Milori e colaboradores (2006), ou seja, a área média das cinco medidas experimentais de fluorescência foi normalizada pelo teor de carbono da amostra. A partir dos índices de humificação $\mathrm{H}_{\mathrm{FIL}}$ foi possível comparar os sistemas de manejo e mata em termos de estabilidade do carbono.

Na tabela 9 são apresentados os dados de $\mathrm{H}_{\mathrm{FIL}}$ para cada profundidade em cada uma das seis trincheiras de cada área em estudo. Foram calculados os índices de humificação médios $\left(\mathrm{H}_{\mathrm{FIL}}\right)$ para cada profundidade levando em consideração as replicatas do campo. 
Tabela 9 - Valores dos índices de humificação $\left(\mathrm{H}_{\mathrm{FL}}\right)$ para cada trincheira em cada profundidade das áreas em estudo.

\begin{tabular}{|c|c|c|c|c|c|c|c|c|}
\hline \multicolumn{9}{|c|}{$H_{F I L}\left(x 10^{4}\right)-A 3$} \\
\hline Trincheira & $0-5$ & $5-10$ & $10-20$ & $20-30$ & $30-40$ & $40-60$ & $60-80$ & $80-100$ \\
\hline $\mathrm{T} 1$ & 1,49 & 1,90 & 2,43 & 3,02 & 3,08 & 3,48 & 3,35 & 4,52 \\
\hline $\mathrm{T} 2$ & 1,23 & 1,42 & 1,69 & 2,16 & 2,23 & 2,37 & 2,72 & 3,00 \\
\hline T3 & 1,53 & 1,90 & 1,62 & 2,26 & 2,48 & 2,81 & 3,45 & 3,82 \\
\hline T4 & 1,68 & 2,37 & 2,36 & 2,85 & 3,43 & 4,40 & 4,76 & 5,25 \\
\hline T5 & 1,56 & 1,88 & 1,79 & 2,20 & 2,49 & 2,69 & 3,20 & 3,66 \\
\hline T6 & 1,23 & 1,22 & 1,85 & 1,91 & 2,76 & 2,97 & 3,62 & 3,88 \\
\hline Média & 1,45 & 1,78 & 1,96 & 2,40 & 2,74 & 3,12 & 3,52 & 4,02 \\
\hline SD & 0,18 & 0,40 & 0,34 & 0,43 & 0,44 & 0,72 & 0,68 & 0,77 \\
\hline \multicolumn{9}{|c|}{$H_{\mathrm{FIL}}\left(x 10^{4}\right)-\mathrm{A4}$} \\
\hline Trincheira & $0-5$ & $5-10$ & $10-20$ & $20-30$ & $30-40$ & $40-60$ & $60-80$ & $80-100$ \\
\hline T1 & 8,22 & 7,50 & 10,9 & 17,2 & 18,8 & 18,9 & 17,1 & 25,6 \\
\hline T2 & 4,54 & 6,84 & 7,84 & 8,86 & 10,1 & 13,2 & 11,0 & 10,8 \\
\hline T3 & 4,63 & 7,06 & 7,99 & 6,44 & 9,12 & 15,7 & 15,9 & 15,9 \\
\hline T4 & 4,03 & 6,70 & 8,62 & 9,04 & 9,46 & 13,2 & 14,2 & 14,0 \\
\hline T5 & 5,90 & 7,43 & 9,10 & 11,4 & 16,4 & 18,6 & 18,4 & 28,6 \\
\hline T6 & 8,59 & $\underline{9,31}$ & 11,6 & $11,8 \mathrm{E}$ & 14,6 & 16,0 & 23,7 & 27,6 \\
\hline Média & 5,98 & 7,47 & 9,33 & 10,8 & 13,1 & 16,0 & 16,7 & 20,4 \\
\hline SD & 1,98 & 0,95 & 1,55 & 3,68 & 4,08 & 2,50 & 4,28 & 7,74 \\
\hline \multicolumn{9}{|c|}{$H_{F I L}\left(x 10^{4}\right)-M T$} \\
\hline Trincheira & $0-5$ & $5-10$ & $10-20$ & $20-30$ & $30-40$ & $40-60$ & $60-80$ & $80-100$ \\
\hline T1 & 2,13 & 3,00 & 5,26 & 6,38 & 6,92 & 6,79 & 9,07 & 10,1 \\
\hline T2 & 2,62 & 3,52 & 4,20 & 4,77 & 5,61 & 6,67 & 7,38 & 9,13 \\
\hline T3 & 2,59 & 2,86 & 4,25 & 4,76 & 5,09 & 5,31 & 5,64 & $\underline{5,45}$ \\
\hline T4 & 3,54 & 3,57 & 4,88 & 5,03 & 6,48 & 8,54 & 8,29 & 8,67 \\
\hline T5 & 2,84 & 4,16 & 5,28 & 6,84 & 7,34 & 7,85 & 8,10 & 10,2 \\
\hline T6 & 2,97 & 3,65 & 4,61 & 6,33 & 7,20 & 7,36 & 8,51 & 10,5 \\
\hline Média & 2,78 & 3,46 & 4,75 & 5,68 & 6,44 & 7,09 & 7,83 & 9,00 \\
\hline SD & 0,46 & 0,47 & 0,477 & 0,93 & 0,90 & 1,11 & 1,21 & 1,87 \\
\hline
\end{tabular}

A3 - em recuperação, A4 - degradada, MT - Mata Atlântica. Fonte: Autoria própria.

$\mathrm{Na}$ figura 26 é apresentado um gráfico de barras onde são mostrados os índices de humificação médios para cada perfil amostrado bem como as barras de desvio onde foram consideradas as repetições de campo.

Para a construção do gráfico abaixo foram desconsiderados os anômalos (A4T6 5 $10 \mathrm{~cm}$, MTT3 $80-100 \mathrm{~cm}$ ) assinalados na tabela anterior, pois apresentaram dados de $\mathrm{H}_{\mathrm{FIL}}$ muito discrepantes. 
Figura 26 - Índices de humificação $\left(\mathrm{H}_{\mathrm{FIL}}\right)$ determinados por LIFS em amostras de solos, em diferentes profundidades.

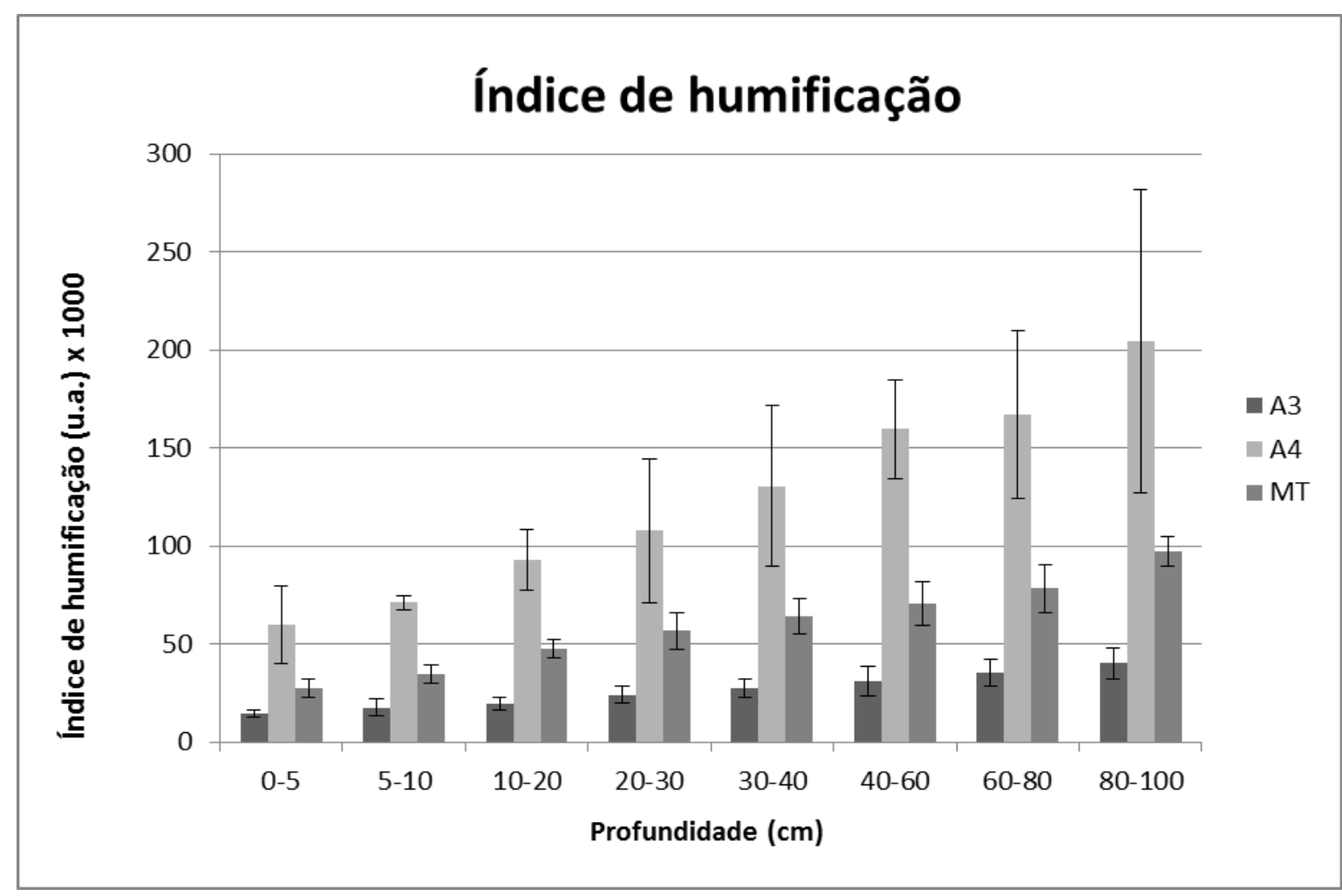

A3 - em recuperação, A4 - degradada, MT - Mata Atlântica

Fonte: Autoria própria

Os resultados de LIFS mostram tendência de aumento da humificação da MOS com o aumento da profundidade, para todos os manejos de pastagem e a mata. Na superfície, onde há material orgânico lábil acumulado, proveniente da cobertura vegetal e dos resíduos animais, o material é menos humificado, ao passo que nas camadas mais profundas de solo, o material orgânico torna-se mais humificado e estável.

$\mathrm{Na}$ área $\mathrm{A} 3$, com o maior EC calculado, evidenciados pela maior entrada de $\mathrm{MO}$ fresca (lábil) no sistema, os valores dos índices de humificação são menores que no restante dos sistemas de manejo, mesmo comparado com a mata nativa.

No Caso da A4, região em degradação, nota-se os menores teores de carbono e os maiores índices de humificação, ou seja, por mais baixa que seja essa quantidade de MOS presente, é a porção mais recalcitrante. Nesse estado a MOS é principalmente formada por compostos insaturados, contendo duplas ligações e anéis condensados.

Dependendo do manejo, o carbono lábil poderá ser facilmente perdido ou emitido para a atmosfera na forma de $\mathrm{CO}_{2}$. Pela figura 27 fica evidente que o carbono mais lábil está presente principalmente na superfície do solo. Com esses resultados pode-se constatar que 
esses sistemas estão suscetíveis a perdas caso o manejo não for adequado e principalmente devido à instabilidade do carbono quantificado.

Foram excluídos valores discrepantes e mesmo assim, em alguns casos, os valores dos desvios padrão são altos. Os elevados desvios apresentados na A4 (figura 27) em profundidade $(80-100 \mathrm{~cm})$ nos levam a crer que variabilidade espacial é responsável por essas diferenças entre as amostras, considerando a distância (de 30 a 300 m) entre as trincheiras, uma vez que as medidas instrumentais não apresentaram grandes variações entre as replicatas.

$\mathrm{Na}$ figura 27 são apresentados dois espectros médios de fluorescência de duas amostras diferentes (replicatas de campo/trincheiras diferentes) da A4, porém do mesmo perfil $(80-100 \mathrm{~cm})$ e com teores de carbono próximo. Nota-se pelos espectros a diferença entre áreas de fluorescência. Os índices de humificação também são apresentados em cada um dos espectros das amostras.

Figura 27 - Espectros médios obtidos por LIFS de diferentes repetições de campo a) trincheira T5 e b) trincheira T3, ambas da área degradada.

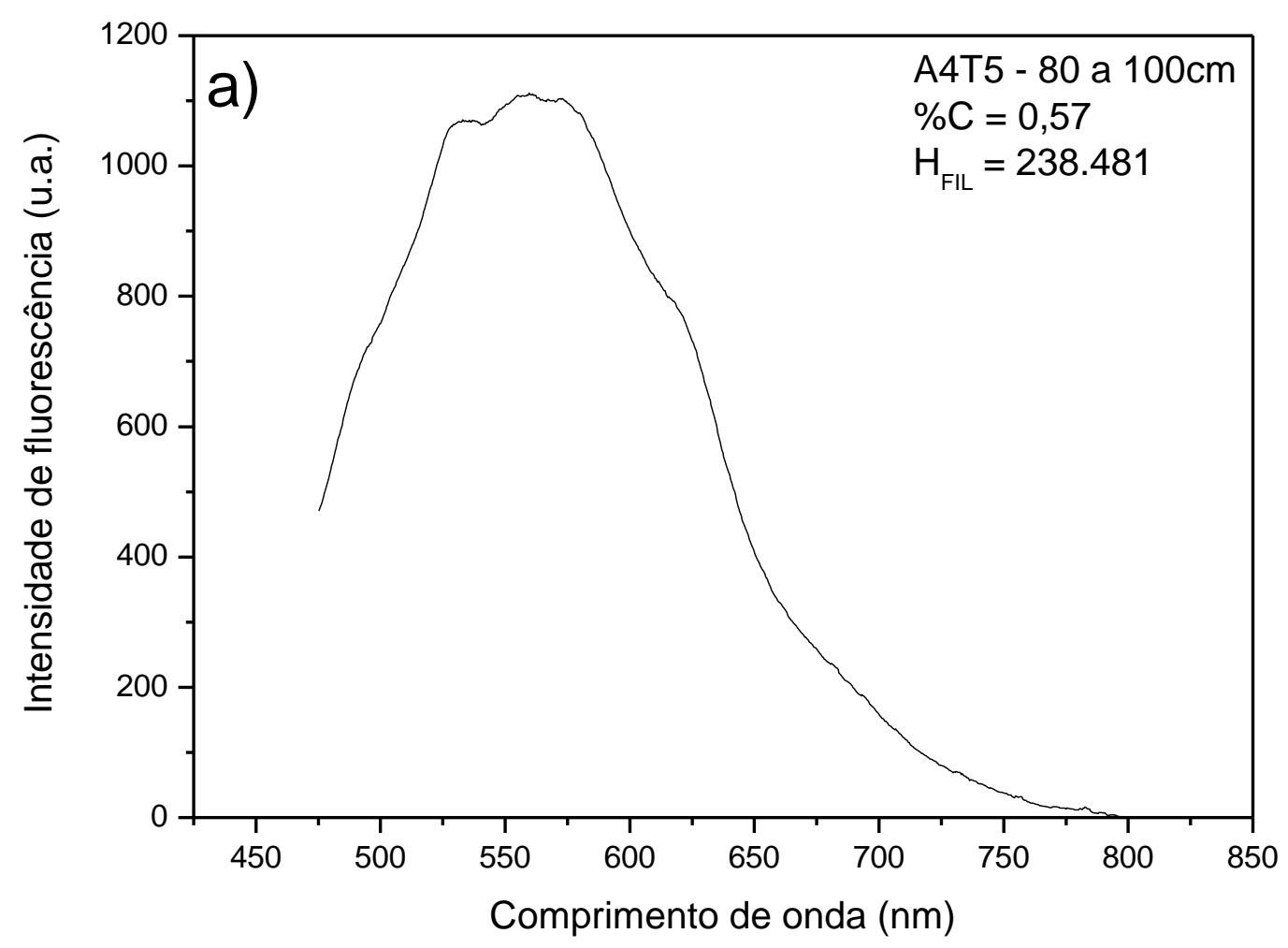




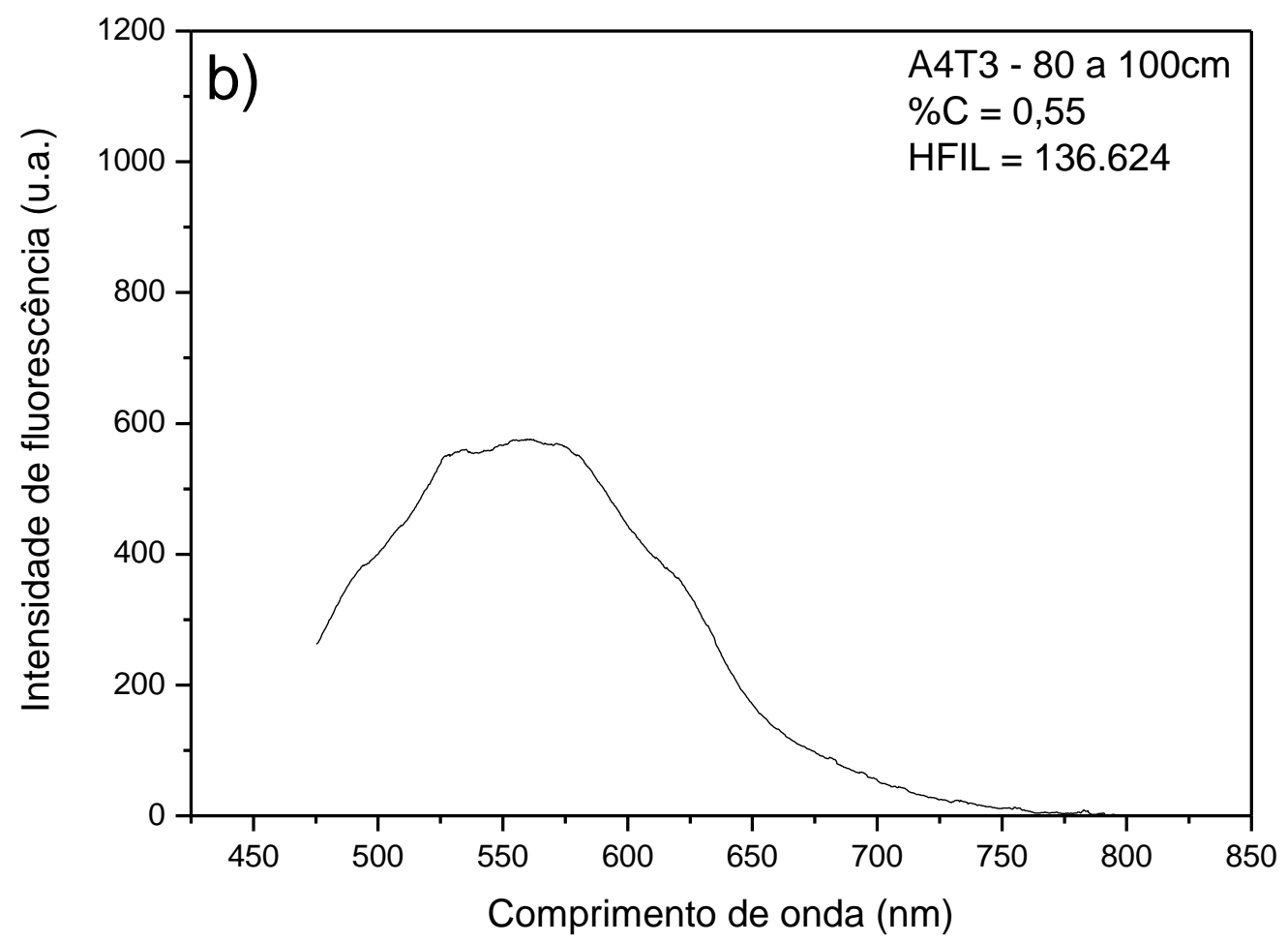

Fonte: Autoria própria

Além da variabilidade espacial, a temporal também pode ser observada em sistemas de pastagem, muito em função da instabilidade desses sistemas (SANTOS et al., 2010). Esse fator pôde ser melhor explicado nos resultados obtidos por LIFS.

\subsubsection{Quantificação de emissão de $\mathrm{CO}_{2}$ (Respiração do Solo)}

São apresentados abaixo os dados médios de respiração (figuras 28a, 28b e 28c) e temperatura do solo (figura 29) em cada um dos 8 dias de medidas. Nota-se que houve uma tendência da diminuição do fluxo de $\mathrm{CO}_{2}$ do solo com o passar dos dias, bem como a diminuição da temperatura do solo. 
Figura 28 - Fluxo médio de $\mathrm{CO}_{2}$ do solo por áreas de manejo e dias de medida. a) A3 - Em recuperação; b) A4 - Degradada; c) MT - Mata Atlântica.
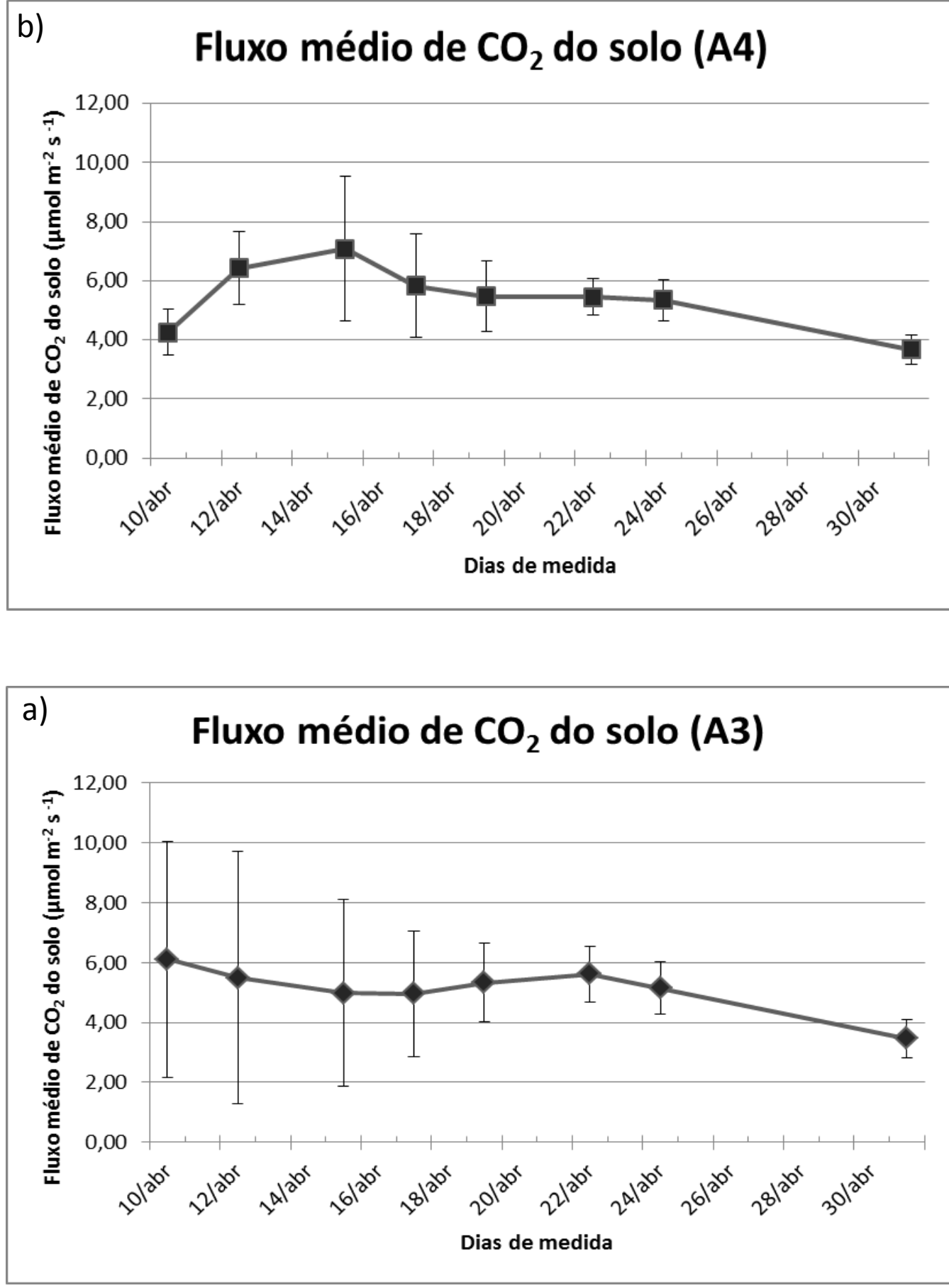


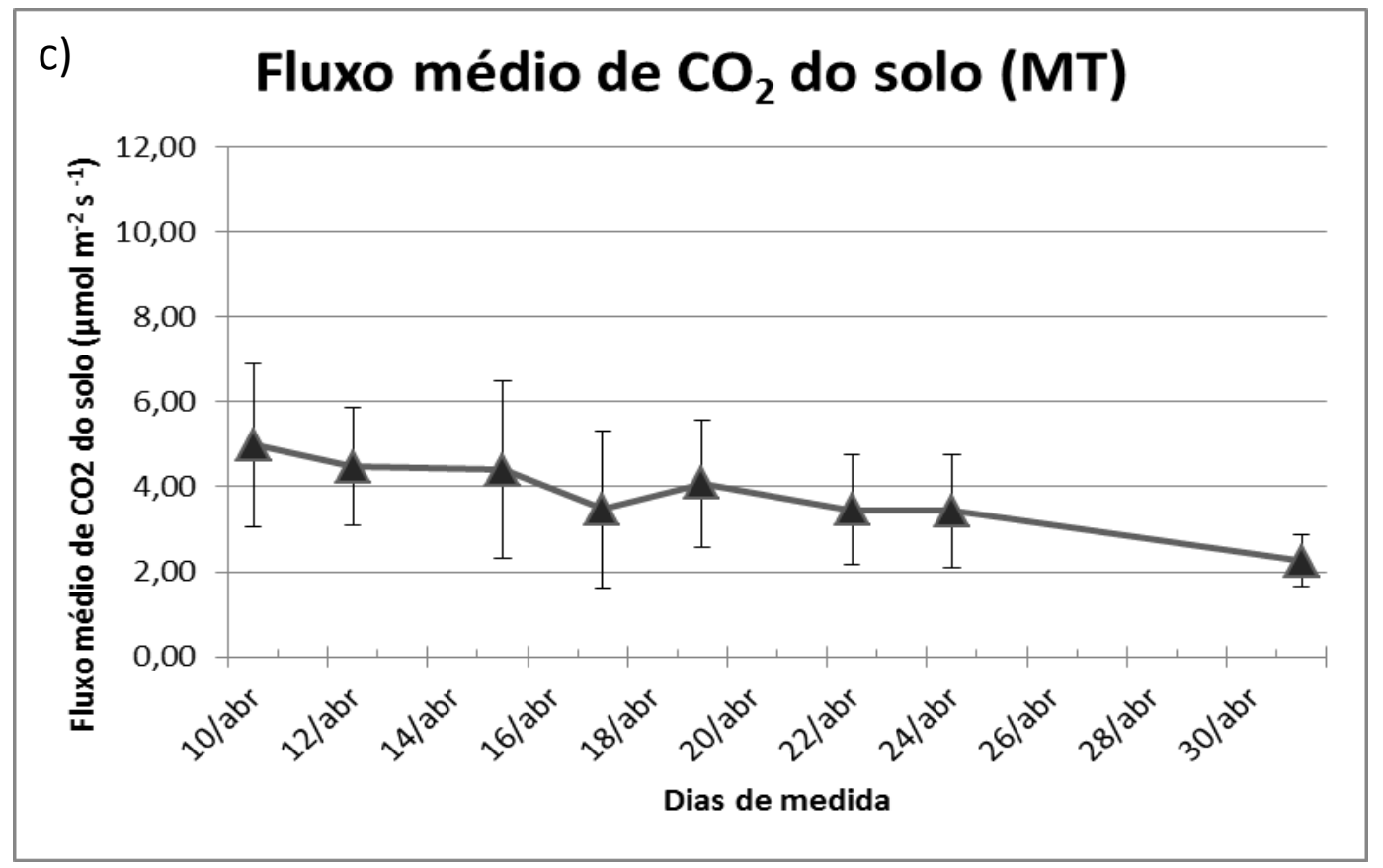

A3 - em recuperação, A4 - degradada, MT - Mata Atlântica

Fonte: Autoria própria

Figura 29 - Temperatura média do solo por áreas de manejo e dias de medida

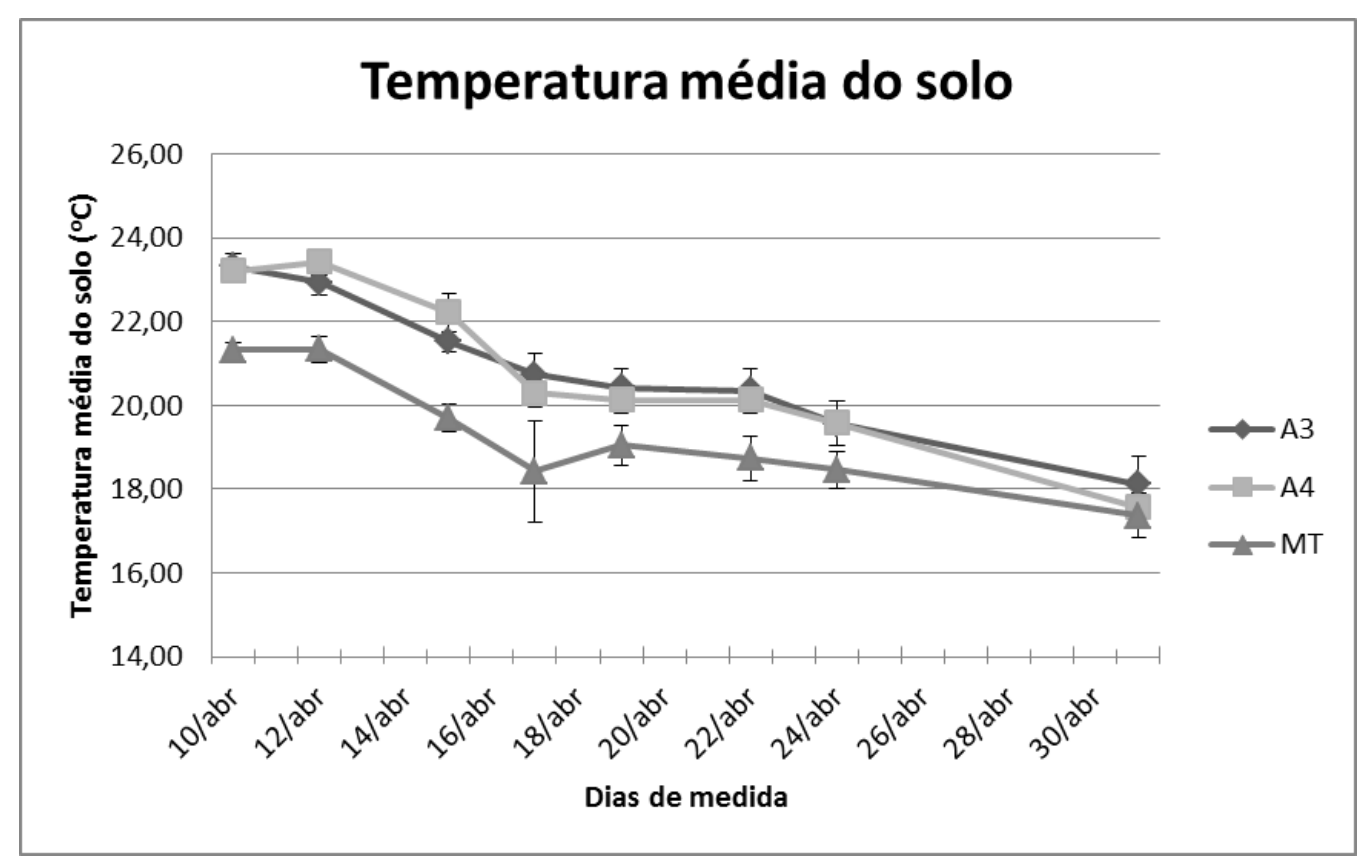

Fonte: Autoria própria

Os dados obtidos também foram submetidos ao teste de normalidade e foi feito a média de emissão de $\mathrm{CO}_{2}$ por ponto analisado. A emissão média de $\mathrm{CO}_{2}$ do solo durante o mês de medida para a área em recuperação (A3) foi de 5,0 $( \pm 2) \mathrm{mmol} \cdot \mathrm{m}^{-2} \mathrm{~s}^{-1} \mathrm{e}$ a área degradada (A4) apresentou média 5,5 $( \pm 0,7)$ mmol. $\mathrm{m}^{-2} \mathrm{~s}^{-1}$ de emissão de $\mathrm{CO}_{2}$. Já a mata 
nativa apresentou média de 4,0 $( \pm 1)$ mmol. $\mathrm{m}^{-2} \mathrm{~s}^{-1}$. Abaixo, na figura 30, são apresentados os dados de respiração média do solo.

Figura 30 - Dados das emissões médias de $\mathrm{CO}_{2}$ em cada área de manejo

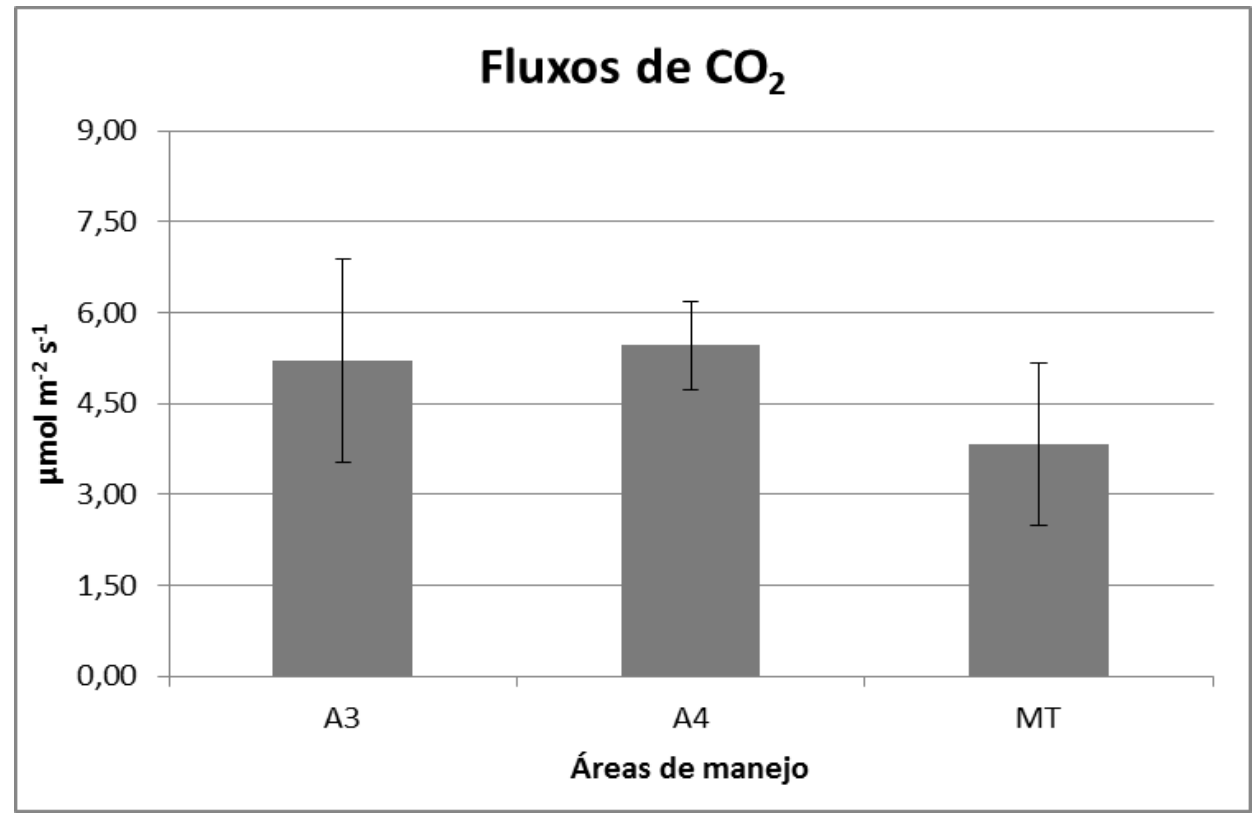

A3 - em recuperação, A4 - degradada, MT - Mata Atlântica

Fonte: Autoria própria

Para a comparação dos resultados, os dados foram submetidos à ANOVA com um fator. A partir dos dados apresentados na figura 30 e utilizando ANOVA, concluiu-se que as emissões das A3 e A4 são estatisticamente iguais, enquanto que A3 e MT são diferentes, assim como A4 e MT também possuem diferença significativa.

As taxas de emissão da área A3 podem ser atribuídas a alta atividade microbiana do solo devido a adubação realizada na área. Já os dados obtidos da área A4, em conjunto com os dados de EC e LIFS, mostram que área está perdendo carbono para atmosfera por meio de emissão de $\mathrm{CO}_{2}$. Foram registrados os menores ECs para a $\mathrm{A} 4$ e os maiores índices de humificação, mostrando que área não está sequestrando carbono.

Para a realização das medidas, procurou-se manter os sistemas em condições o mais próximo possível das condições naturais, ou seja, sem a remoção da vegetação local, cravando os anéis antes do começo do experimento para que não ocorresse emissão de $\mathrm{CO}_{2}$ por conta da pressão exercida no solo no momento de cravar os anéis.

Porém, após as análises dos dados, trabalhou-se com a hipótese de ter-se medido juntamente com a emissão do solo, o fluxo de $\mathrm{CO}_{2}$ proveniente da vegetação. Após discussões essa hipótese foi descartada por conta de todas as medidas terem sido realizadas no período da 
manhã, entre 7 e 11 horas, período este em que a vegetação realiza fotossíntese, com a absorção de $\mathrm{CO}_{2}$ atmosférico e liberação de $\mathrm{O}_{2}$.

Outro fato observado foi a tendência do solo argiloso (A3) reter mais água (umidade) do que os solos com textura mais arenosa (A4 e MT). Esse fato está relacionado diretamente ao fluxo de $\mathrm{CO}_{2}$, já que a atividade microbiana necessita de uma umidade ideal para favorecer a cinética das reações bioquímicas. Foi constatado um descréscimo tanto na temperatura quanto na umidade com o passar dos dias de medida, influenciando assim a taxa de emissão de $\mathrm{CO}_{2}$ para a atmosfera.

\subsection{Novas técnicas para a quantificação de carbono no solo}

Neste estudo utilizou-se a técnica LIBS para a obtenção de modelos de quantificação do carbono. Na figura 31 é mostrado um espectro característico de solos obtido por LIBS. A seta representa uma das regiões onde a linha de emissão do carbono está presente $(193,03 \mathrm{~nm})$.

Figura 31 - Espectro típico de solo obtido por LIBS, destacando (seta) a região do pico de carbono $(193,03 \mathrm{~nm})$.

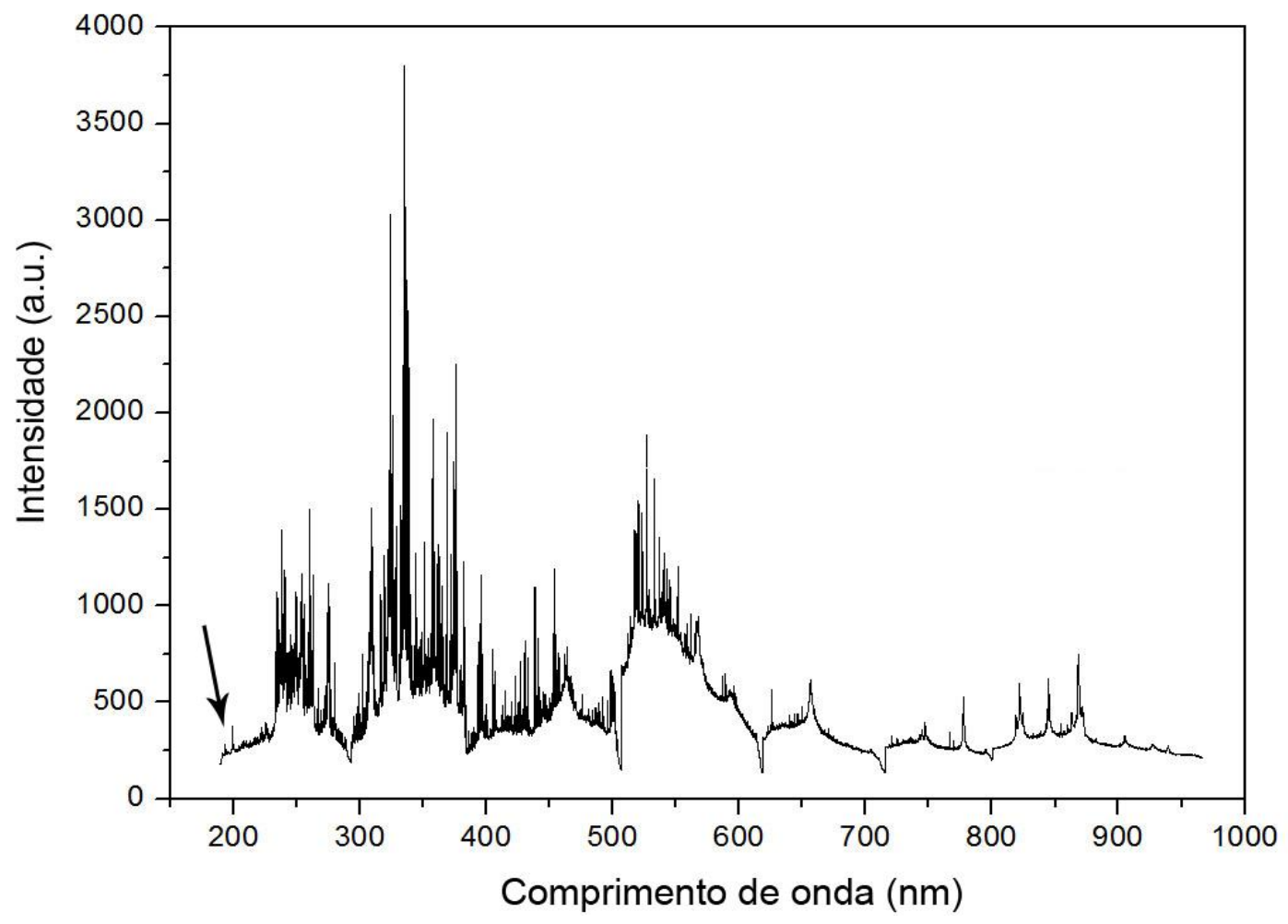

Fonte: Autoria própria 
No espectro LIBS poucas linhas de emissão de carbono são intensas e apresentam altas probabilidades de transição e no caso da matriz de solo as linhas mais intensas sofrem interferências espectrais causadas pela emissão concomitante de elementos comumente presentes em solos brasileiros.

Esse é o caso típico da linha C(I) em 193,03 nm que sofre interferência espectral de Al (II) (iônico) em 193,04 nm, Al (I) (atômico) em 193,16 nm e 193,58 nm. Essas linhas de emissão do alumínio não são bem resolvidas (separadas) por conta da resolução do espectrômetro $(\sim 0,1 \mathrm{~nm})$.

Outro elemento também encontrado em altas concentrações em solos tropicais é o ferro. No espectro LIBS, a linha de carbono em 247,86 nm tem forte interferência de ferro em várias linhas nessa região.

Em consulta ao banco de dados do NIST (National Institute of Standards and Technology, 2013), obtiveram-se as informações das linhas de emissão correspondente aos elementos presentes nos solos.

Na figura 32 são apresentados dados das linhas de emissão do carbono mais utilizadas $(193,03 \mathrm{~nm}$ e $247,86 \mathrm{~nm})$, interferidas por alumínio e ferro, bem como as intensidades relativas e as probabilidades de transição.

Figura 32 - Site do NIST (National Institute of Standards and Technology) onde são mostradas as possíveis linhas de emissão do Carbono, Alumínio e Ferro.

\begin{tabular}{|c|c|c|c|c|c|c|c|c|c|c|c|}
\hline \multirow{2}{*}{$\begin{array}{l}\text { Íon } \\
\text { C I }\end{array}$} & \multirow{2}{*}{$\begin{array}{c}\begin{array}{c}\text { Comp. de } \\
\text { onda (nm) }\end{array} \\
193,027\end{array}$} & \multirow{2}{*}{$\begin{array}{c}\begin{array}{c}\text { Intens. } \\
\text { Rel. }\end{array} \\
1000\end{array}$} & \multirow{2}{*}{$\frac{A\left(s^{-1}\right)}{3,39 E+08}$} & \multirow{2}{*}{$\begin{array}{c}\begin{array}{c}\text { Energia do } \\
\text { estado inferior } \\
\text { (cm }\end{array} \\
10192,63\end{array}$} & \multirow{2}{*}{$\begin{array}{c}\begin{array}{c}\text { Energia do } \\
\text { estado superior } \\
\left(\mathbf{c m}^{-1}\right)\end{array} \\
61981,82\end{array}$} & \multicolumn{2}{|c|}{ Nível Inferior } & \multicolumn{3}{|c|}{ Nível Superior } & \\
\hline & & & & & & $2 s^{2} 2 p^{2}$ & ${ }^{1} \mathrm{D}$ & 2 & $2 s^{2} 2 p 3 s$ & ${ }^{1} \mathrm{P}^{\circ}$ & 1 \\
\hline Al II & 193,041 & 125 & $1,08 \mathrm{E}+09$ & 59852,02 & 111637,33 & $3 s 3 p$ & ${ }^{1} \mathrm{P}^{\circ}$ & 1 & $3 p^{2}$ & ${ }^{1} \mathrm{~S}$ & 0 \\
\hline Al I & 193,163 & 1000 & $1,79 \mathrm{E}+09$ & 0,00 & 51752,7 & $3 s^{2} 3 p$ & ${ }^{2} \mathrm{P}^{\circ}$ & $1 / 2$ & $3 s 3 p^{2}$ & ${ }^{2} S$ & $1 / 2$ \\
\hline Al I & 193,582 & 1200 & $3,56 \mathrm{E}+09$ & 112,06 & 51752,7 & $3 s^{2} 3 p$ & ${ }^{2} \mathrm{P}^{\circ}$ & $3 / 2$ & $3 s 3 p^{2}$ & ${ }^{2} \mathrm{~S}$ & $1 / 2$ \\
\hline $\mathrm{Fe}$ II & 247,811 & 14000 & $3,10 \mathrm{E}+07$ & 26932,73 & 67273,83 & $3 d^{6}\left({ }^{3} \mathrm{P} 2\right) 4 s$ & $\mathrm{~b}^{2} \mathrm{P}$ & $1 / 2$ & $3 d^{6}\left({ }^{3} \mathrm{~F} 2\right) 4 p$ & $y^{2} D^{\circ}$ & $3 / 2$ \\
\hline Fe II & 247,818 & 700 & $1,70 \mathrm{E}+06$ & 64040,89 & 104380,94 & $3 d^{6}\left({ }^{3} \mathrm{~F} 2\right) 4 p$ & $y^{4} G^{0}$ & $7 / 2$ & $3 d^{6}\left({ }^{5} \mathrm{D}\right) 5 d$ & ${ }^{6} \mathrm{~F}$ & \\
\hline $\mathrm{Fe}$ II & 247,821 & 7000 & $5,60 \mathrm{E}+06$ & 21812,04 & 62151,55 & $3 d^{6}\left({ }^{3} \mathrm{P} 2\right) 4 s$ & $b^{4} P$ & $3 / 2$ & $3 d^{6}\left({ }^{3} \mathrm{~F} 2\right) 4 p$ & $y^{4} F^{\circ}$ & $5 / 2$ \\
\hline Fe II & 247,845 & 4000 & $3,10 \mathrm{E}+06$ & 21251,58 & 61587,20 & $3 d^{6}\left({ }^{3} \mathrm{H}\right) 4 s$ & $a^{4} \mathrm{H}$ & $13 / 2$ & $3 d^{6}\left({ }^{3} \mathrm{H}\right) 4 p$ & $z^{4} \mathrm{I}^{\circ}$ & $11 / 2$ \\
\hline C I & 247,856 & 800 & $2,80 \mathrm{E}+07$ & 21648,01 & 61981,82 & $2 s^{2} 2 p^{2}$ & ${ }^{1} \mathrm{~S}$ & 0 & $2 s^{2} 2 p 3 s$ & ${ }^{1} \mathrm{p}^{\circ}$ & 1 \\
\hline Fe II & 247,857 & 110000 & $9,10 \mathrm{E}+07$ & 22939,35 & 63272,98 & $3 d^{6}\left({ }^{3} \mathrm{~F} 2\right) 4 s$ & $b^{4} F$ & $5 / 2$ & $3 d^{6}\left({ }^{3} \mathrm{~F} 2\right) 4 p$ & $x^{4} D^{\circ}$ & $5 / 2$ \\
\hline Fe II & 247,914 & 1200 & $1,20 \mathrm{E}+07$ & 66522,31 & 106846,64 & $3 d^{6}\left({ }^{3} \mathrm{G}\right) 4 p$ & $x^{4} F^{0}$ & $5 / 2$ & $3 d^{6}\left({ }^{5} \mathrm{D}\right) 5 d$ & ${ }^{4} \mathrm{~F}$ & $3 / 2$ \\
\hline Fe II & 247,923 & 4000 & $3,60 \mathrm{E}+07$ & 38164,22 & 78487,14 & $3 d^{6}\left({ }^{1} \mathrm{D} 2\right) 4 s$ & $c^{2} D$ & $5 / 2$ & $3 d^{6}\left({ }^{1} \mathrm{D} 2\right) 4 p$ & $\mathrm{w}^{2} \mathrm{D}^{\circ}$ & $3 / 2$ \\
\hline $\mathrm{Fe}$ II & 247,929 & 3100 & $1,90 \mathrm{E}+06$ & 26055,41 & 66377,31 & $3 d^{6}\left({ }^{3} \mathrm{G}\right) 4 s$ & $a^{4} G$ & $5 / 2$ & $3 d^{6}\left({ }^{3} \mathrm{G}\right) 4 p$ & $x^{4} F^{0}$ & $7 / 2$ \\
\hline Fe II & 247,938 & 6000 & $9,00 \mathrm{E}+06$ & 42658,24 & 82978,71 & $3 d^{6}\left({ }^{5} \mathrm{D}\right) 4 p$ & $\mathrm{z}^{6} \mathrm{p}^{0}$ & $7 / 2$ & $3 d^{6}\left({ }^{5} \mathrm{D}\right) 4 d$ & $e^{6} \mathrm{~F}$ & $9 / 2$ \\
\hline $\mathrm{Fe} I$ & 247,948 & 650 & $2,10 \mathrm{E}+07$ & 7985,78 & 48304,64 & $3 d^{7}\left({ }^{4} \mathrm{~F}\right) 4 s$ & $\mathrm{a}^{5} \mathrm{~F}$ & 2 & $3 d^{7}\left({ }^{4} \mathrm{P}\right) 4 p$ & $\mathrm{x}^{3} \mathrm{P}^{\circ}$ & 2 \\
\hline $\mathrm{Fe} I$ & 247,963 & 129 & $7,06 \mathrm{E}+05$ & 7376,76 & 47693,23 & $3 d^{7}\left({ }^{4} \mathrm{~F}\right) 4 s$ & $a^{5} \mathrm{~F}$ & 4 & $3 d^{6}\left({ }^{3} \mathrm{G}\right) 4 s 4 p\left({ }^{3} \mathrm{P}^{\circ}\right)$ & $w^{5} G^{\circ}$ & 3 \\
\hline $\mathrm{Fe} I$ & 247,978 & 7600 & $1,74 \mathrm{E}+08$ & 704,007 & 41018,051 & $3 d^{6} 4 s^{2}$ & $a^{5} \mathrm{D}$ & 2 & $3 d^{6}\left({ }^{5} \mathrm{D}\right) 4 s 4 p\left({ }^{1} \mathrm{P}^{\circ}\right)$ & $x^{5} F^{\circ}$ & 2 \\
\hline Fe II & 247,985 & 900 & $8,00 \mathrm{E}+06$ & 62689,87 & 103002,66 & $3 d^{6}\left({ }^{3} \mathrm{P} 2\right) 4 p$ & $\mathrm{y}^{4} \mathrm{D}^{\circ}$ & $5 / 2$ & $3 d^{6}\left({ }^{3} \mathrm{P} 2\right) 4 d$ & ${ }^{4} \mathrm{D}$ & $5 / 2$ \\
\hline
\end{tabular}

Fonte: Autoria própria 
Nota-se a presença de várias linhas de $\mathrm{Fe}$ (I) e Fe (II) na região da linha do C(I) em 247,86 nm com alta probabilidade de transição e alta intensidade. Essa interferência dificultaria o trabalho desde o pré-tratamento espectral, tal como correção de linha de base até a tentativa de separação (resolução) dessas linhas.

Logo, para evitar essa interferência e trabalhar com a linha de maior intensidade, optou-se pela linha de emissão do carbono no comprimento de onda de 193,03 nm. Definida a linha de C(I) em 193,03 nm para se trabalhar, escolheu-se a melhor região de trabalho. A região de trabalho foi selecionada de 190 a $203 \mathrm{~nm}$.

Na figura 33 é mostrado um espectro de solos obtido por LIBS onde é destacada a região de interesse abrangendo as linhas de emissão do carbono (193,03 nm) e do alumínio $(193,58 \mathrm{~nm})$.

Figura 33 - Linha de emissão de C (193,03 nm) parcialmente interferida por Al (193,58 nm)

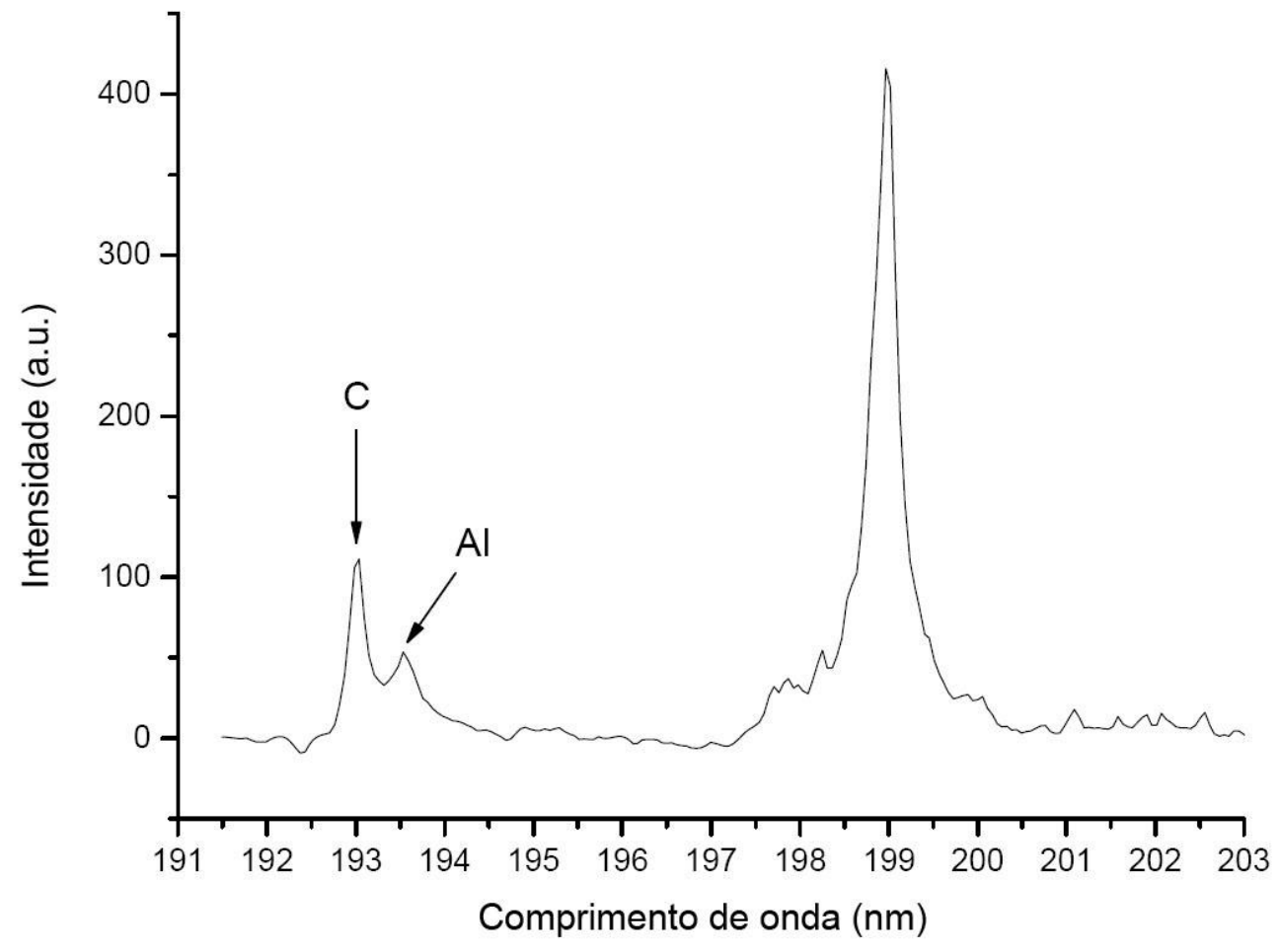

Fonte: Autoria própria

Para essa faixa espectral foi aplicado um procedimento de correção dos espectros (prétratamento) de cada uma das 60 medidas para cada amostra. O procedimento consistiu em subtrair de toda faixa espectral de trabalho as intensidades médias do intervalo de 191,82 192,54 nm (intervalo livre de linhas de emissão ou zona de ruído), de forma que todos os espectros iniciassem em zero de intensidade. 
Esse procedimento foi denominado de correção de offset (figura 34a e 34b). Essa correção torna-se necessária, pois os espectros LIBS tendem a apresentar variação significativa do sinal de fundo. Essas variações provocam deslocamentos de intensidade para espectros de uma mesma amostra e diferentes amplitudes de ruído.

Figura 34 - Espectros LIBS (a) antes da correção do offset e (b) após a correção (região de $191,82-192,54 \mathrm{~nm})$.
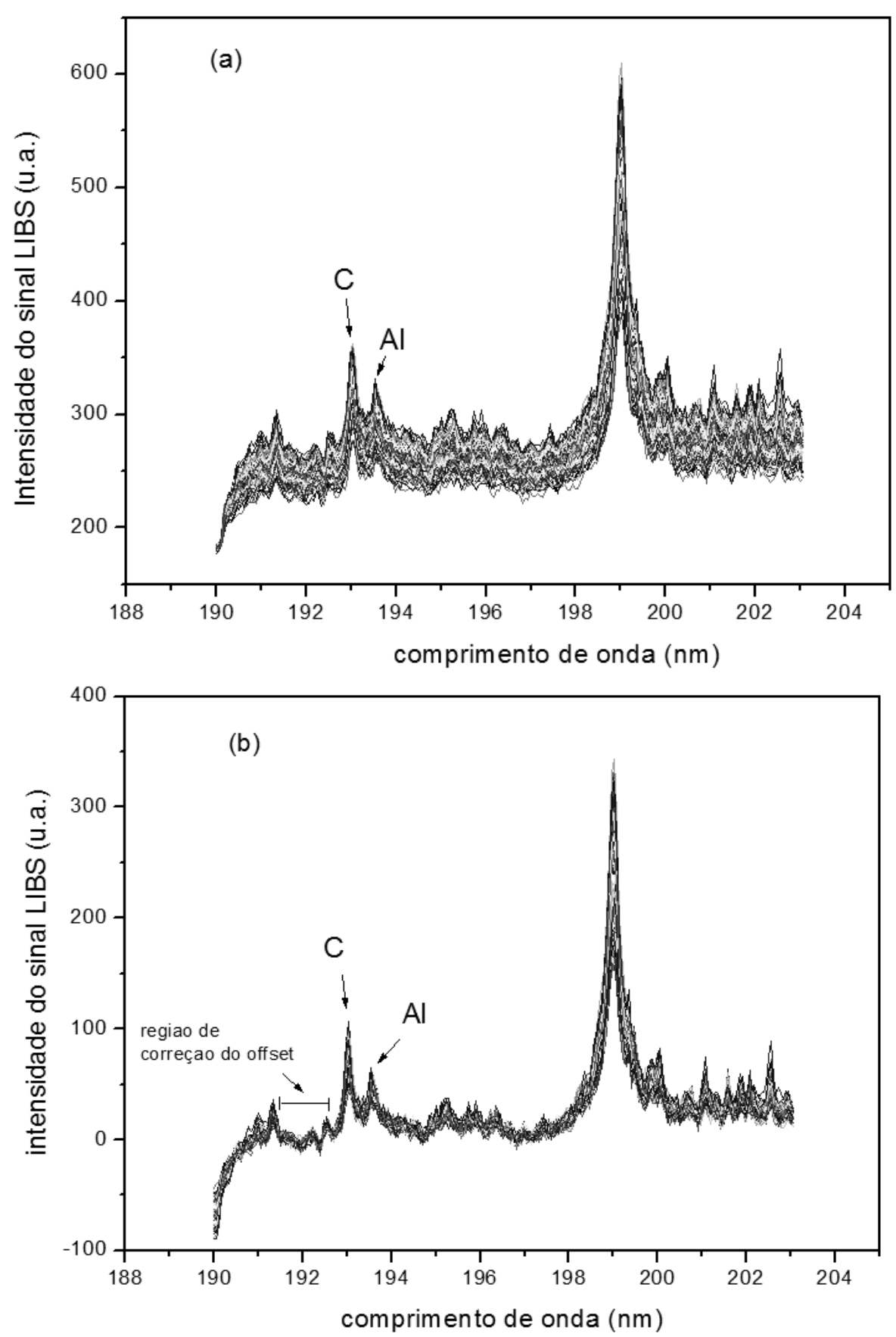

Fonte: Autoria própria 
Para a distinção das linhas presentes na região espectral em que se encontra a linha 193,03 nm referente ao carbono, Nicolodelli e colaboradores (2014) executaram um experimento onde foram obtidos os espectros LIBS em dois materiais diferentes. O primeiro material utilizado foi uma pastilha de grafite e o segundo material usado foi uma placa de alumínio. A partir dos espectros obtidos comparou-se os mesmos com um espectro de uma amostra de solo obtido por LIBS.

Abaixo, na figura 35 são mostrados três espectros sobrepostos, o primeiro representado pela linha tracejada mostra uma amostra de grafite, o segundo representado com a linha em cinza mostra uma amostra de alumínio e o terceiro espectro representado pela linha cheia mostra uma amostra de solo do conjunto amostral. Nela é possível observar como as linhas de alumínio interferem na linha de emissão do carbono.

As linhas de alumínio são de Al (II) em 193,04 nm, Al (I) em 193,58 nm.

Figura 35 - Linha de emissão do carbono (193,03 nm) interferida pelos picos de Alumínio (em $193,04 \mathrm{~nm}$ e $193,58 \mathrm{~nm})$

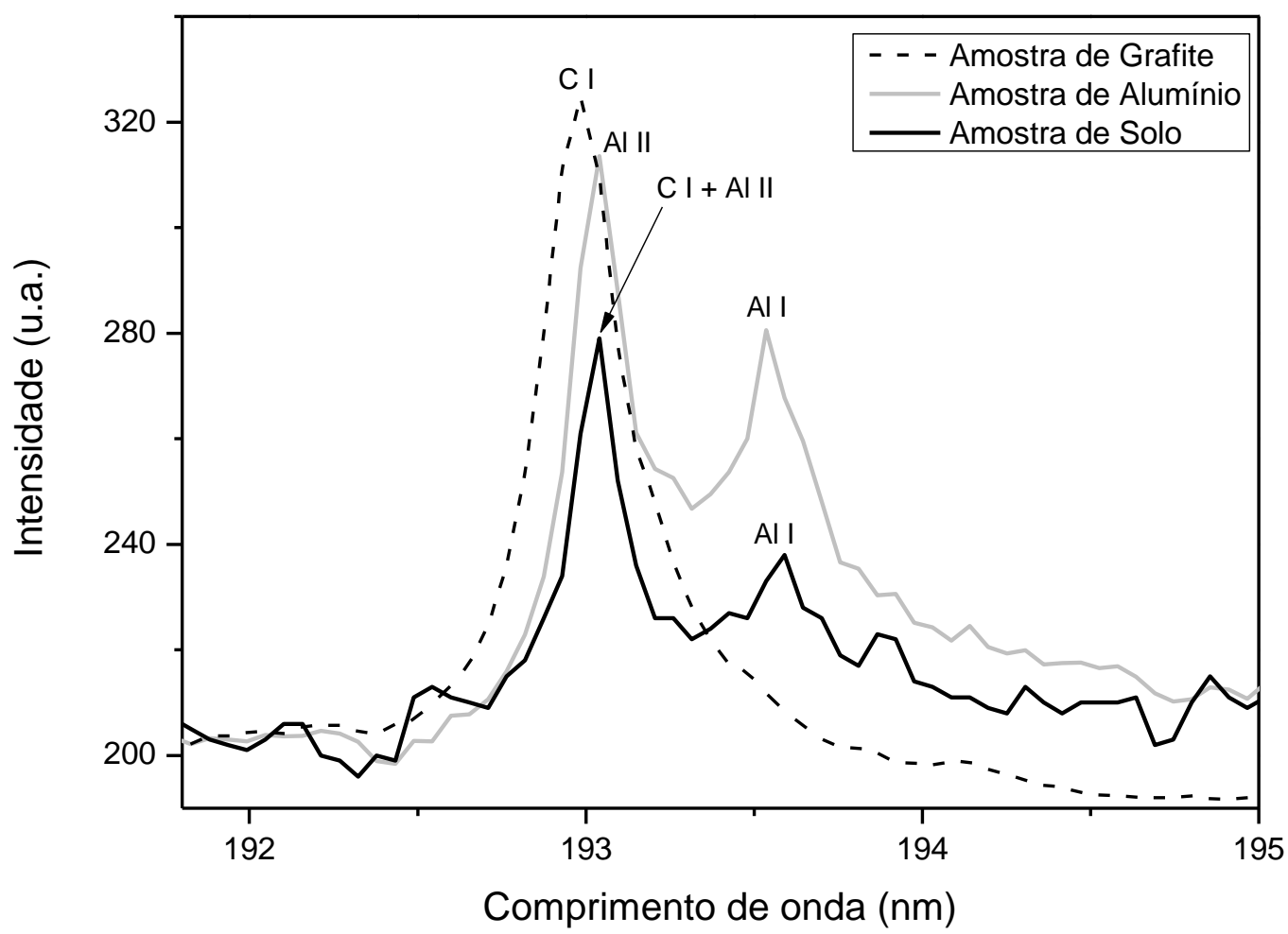

Fonte: NICOLODELLI et al., 2014 (adaptado) 
Baseado nos dados obtidos pela pesquisa ao banco de dados do NIST e de acordo com Nicolodelli e colaboradores (2014), conclui-se que as emissões de Al (I) trata-se de um dupleto em 193,16 nm e 193,58 nm. Logo, realizou-se uma correção utilizando a intensidade da linha de emissão do Al (I) em 193,58 nm para normalizar da intensidade da linha de emissão do C(I) em 193,03 nm.

Para a construção do modelo de calibração utilizando amostras de solos do experimento foram relacionados os valores das razões entre as intensidades dos picos de carbono em 193,03 nm e do pico de alumínio em 193,58 nm $\left(\mathrm{I}_{193,03} / \mathrm{I}_{193,58}\right)$.

Chegou-se a essa ideia, pois a linha de alumínio em 193,04 nm contribui para o aumento da intensidade da linha de emissão do carbono. As razões entre as duas intensidades foram então correlacionadas com os valores de carbono previamente determinados por análise elementar (CHNS).

Inicialmente construiu-se um modelo linear utilizando $65 \%$ de todo o conjunto amostral para a curva de calibração e o restante para a curva de validação, ou seja, ignorou-se o fato das amostras apresentarem diferenças texturais. Esse modelo apresentou coeficiente de correlação de 0,87 .

A curva de calibração foi ajustada pelo método dos mínimos quadrados utilizando as concentrações de carbono determinadas por CHNS como variáveis independentes e as intensidades das linhas de carbono em 193,03 nm, tomadas após a normalização dos espectros com as linhas de $\mathrm{Al}$ em 193,58 nm $\left(\mathrm{I}_{193,03} / \mathrm{I}_{193,58}\right)$.

A curva de calibração para o modelo contendo todo o conjunto amostral (sem distinção textural) é apresentado na figura 36. 
Figura 36 - Curva de calibração utilizando todo o conjunto amostral

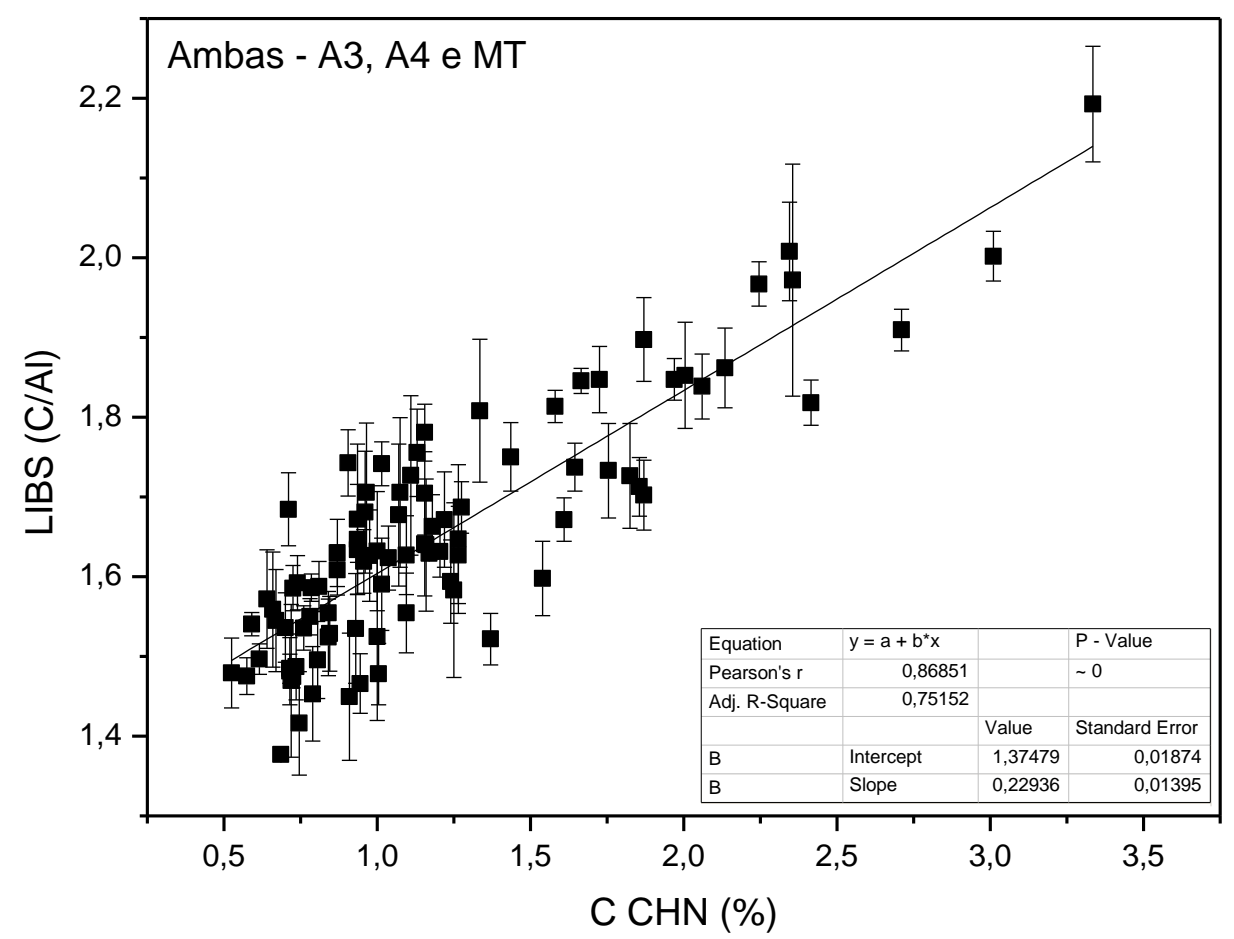

Fonte: Autoria própria

O modelo apresentou $\mathrm{p}$-valor $(\alpha=0,05)$ próximo de zero mostrando a significância da curva. É apresentado na figura 37 o histograma dos resíduos (distribuição de frequências) e na figura 38 o gráfico da distribuição dos resíduos.

Figura 37 - Histograma dos resíduos

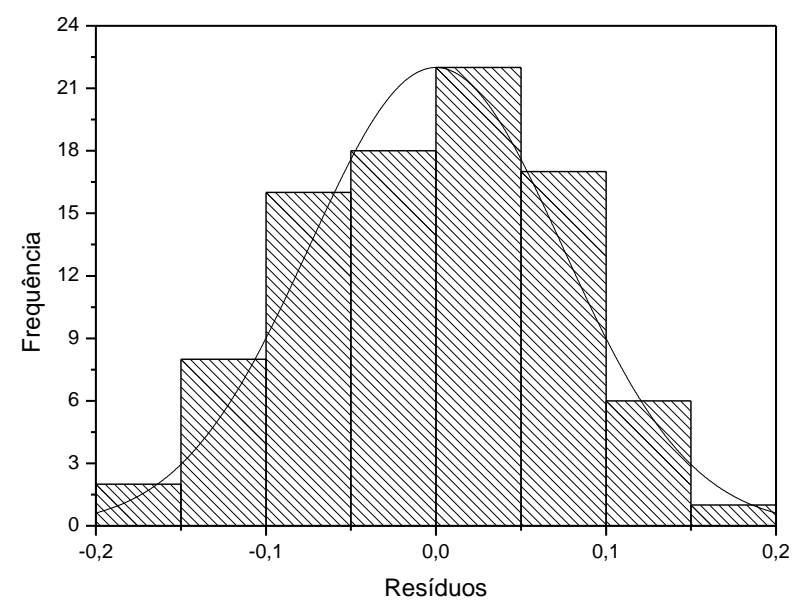

Fonte: Autoria própria 
Figura 38 - Gráfico dos resíduos da curva de calibração

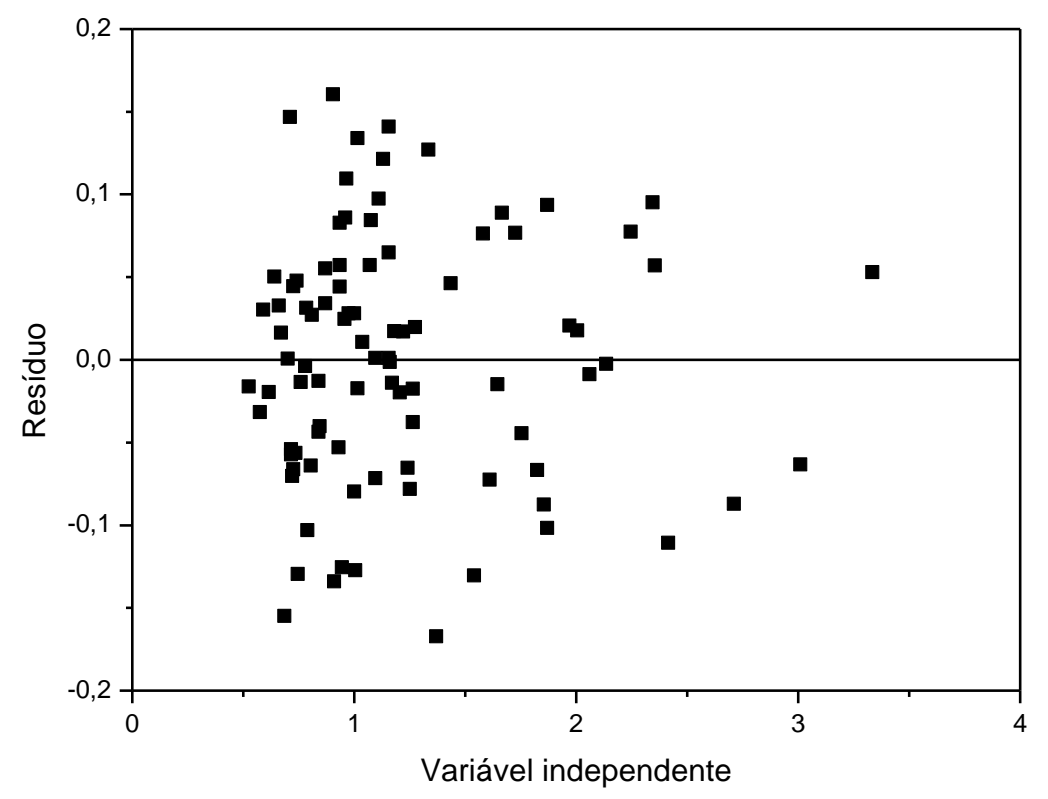

Fonte: Autoria própria

Os resíduos apresentaram distribuição normal e a partir do gráfico de distribuição dos resíduos foi possível verificar a homocedasticidade e ausência de amostras atípicas, ou seja, o comportamento constante dos resíduos ao longo de toda a faixa da variável independente (\% obtida por CHNS).

O LIBS ainda possui alguns pontos que precisam ser levados em consideração como a forte interferência da matriz na análise, principalmente quando o objeto de estudo é uma amostra tão heterogênea como o solo.

A partir do resultado prévio, utilizando todo o conjunto amostral para a construção do modelo, optou-se por construir modelos de calibração para cada tipo de textura do experimento em questão. Logo, foram construídos modelos levando em conta as semelhanças entre as texturas das áreas, ou seja, A4 e MT, gerando o modelo para texturas arenosas e A3 gerando o modelo para texturas argilosas, levando em consideração os teores médios de argila por área de manejo.

As quantidades médias de argila das áreas são apresentadas na figura 39 abaixo. 
Figura 39 - Quantidade média de argila em cada área em questão.

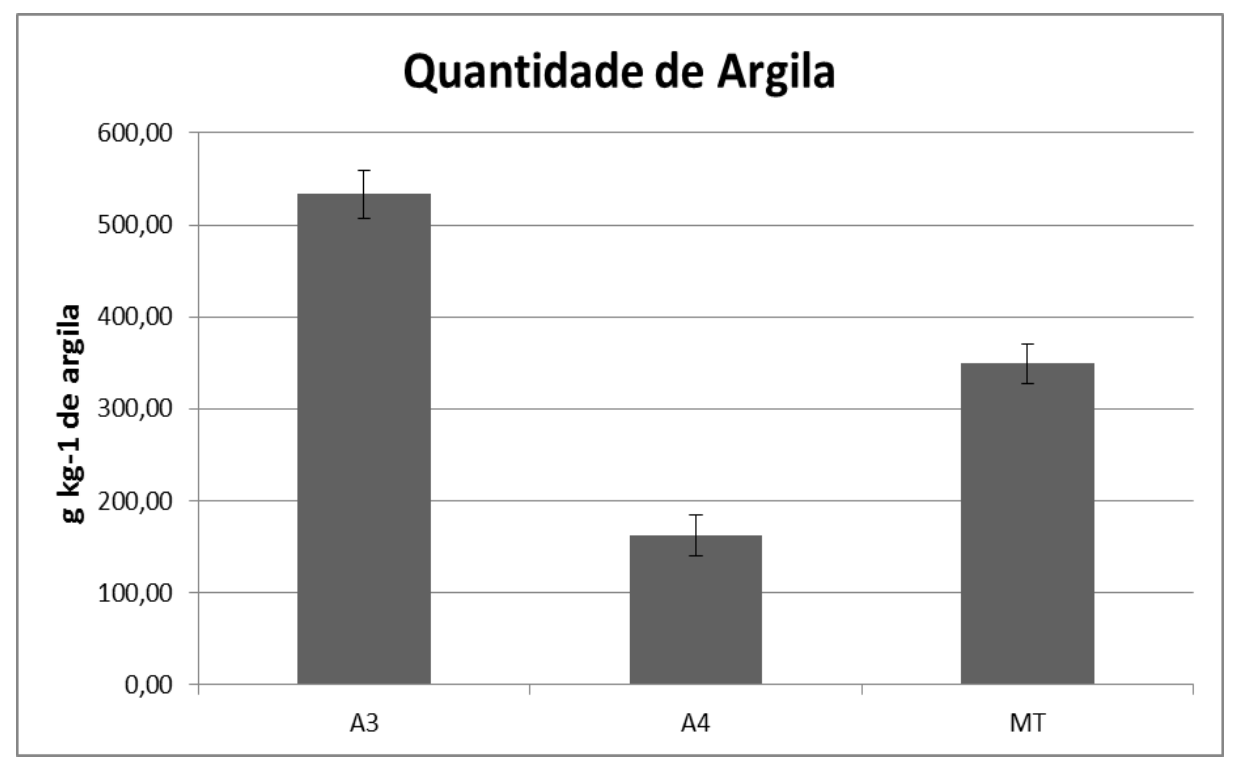

A3 - em recuperação, A4 - degradada, MT - Mata Atlântica.

Fonte: Autoria própria

As curvas de calibração ajustadas pelo método dos mínimos quadrados para os dois modelos (textura argilosa, arenosa) são apresentadas nas figuras 40a e 40b. A Tabela 10 mostra as equações das curvas de calibração e o coeficiente de correlação R (Pearson) para cada modelo construído. 
Figura 40 - Curvas de Calibração para os 2 modelos distintos (a) Modelo argiloso e (b) Modelo arenoso
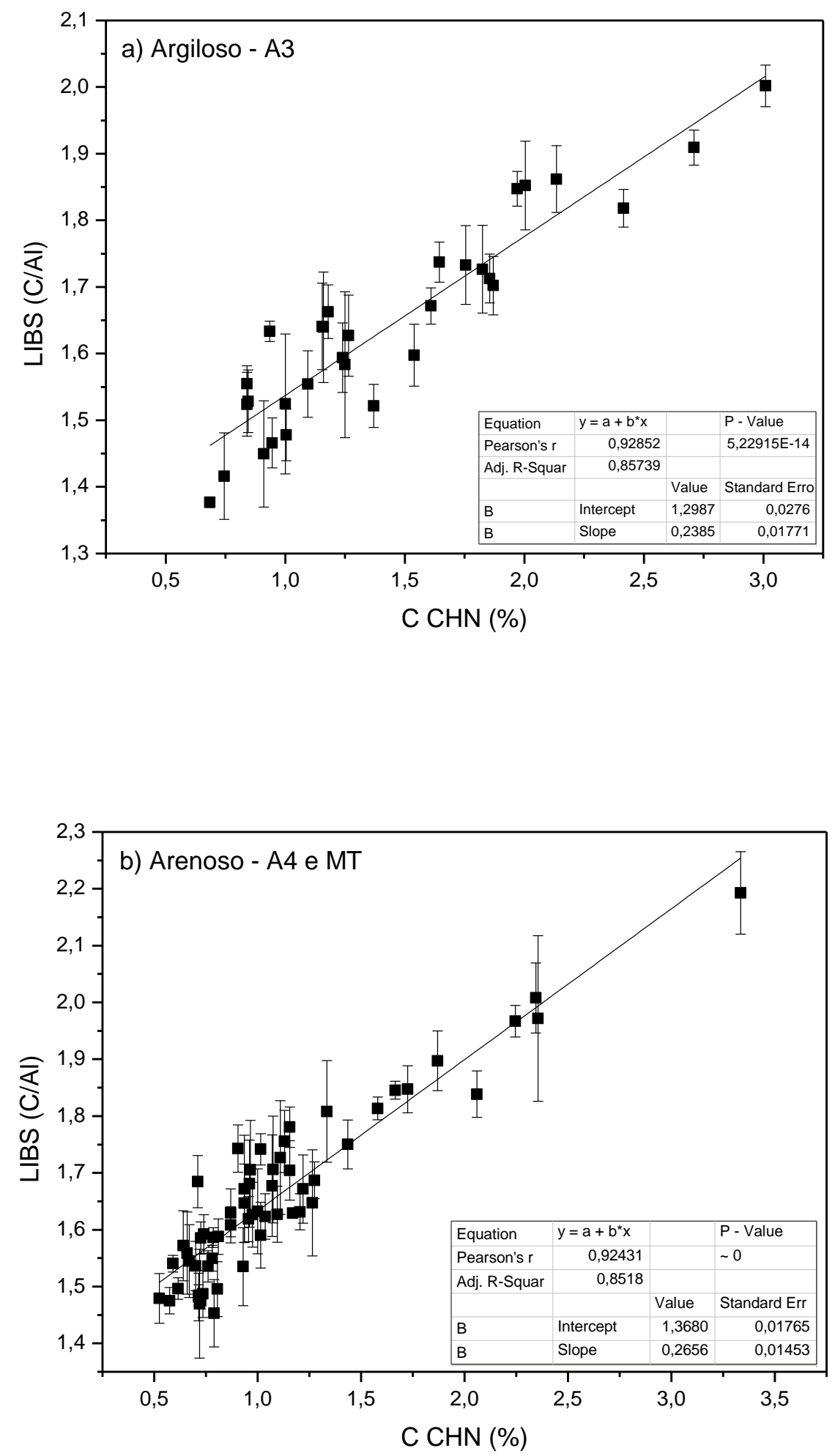

Fonte: Autoria própria 
Tabela 10 - Equações das curvas de calibração e coeficiente de correlação R para determinação de carbono em solos por LIBS em diferentes áreas de pastagem e mata nativa.

\begin{tabular}{cccc}
\hline Textura & Áreas & Equações & R \\
\hline Argilosa & A3 & $\mathrm{y}=(1,30 \pm 0,03)+(0,24 \pm 0,02) \mathrm{x}$ & 0,93 \\
Arenosa & A4 e MT & $\mathrm{y}=(1,37 \pm 0,02)+(0,26 \pm 0,01) \mathrm{x}$ & 0,92 \\
Ambas & A3, A4 e MT & $\mathrm{y}=(1,37 \pm 0,02)+(0,23 \pm 0,01) \mathrm{x}$ & 0,87 \\
\hline
\end{tabular}

A3 - em recuperação, A4 - degradada, MT - Mata Atlântica. Fonte: Autoria própria.

Assim como a curva obtida anteriormente para todo o conjunto amostral, para ambas os modelos texturais (argiloso e arenoso) os resíduos apresentaram distribuição normal dos dados e distribuição homogênea dos resíduos (homocedasticidade), bem como p-valores próximos a zero $(\alpha=0,05)$. Notou-se um leve aumento no coeficiente de correlação com a separação das amostras por textura.

Os modelos foram validados utilizando as amostras que não foram utilizadas para a construção das curvas de calibração.

Na figura 41a, 41b e 41c são mostrados os gráficos de validação correlacionando os valores preditos de carbono por LIBS e os valores de referência por CHNS, bem como o erro médio absoluto relativo (EMAR) de cada modelo. Os EMAR foram calculados a partir da equação abaixo:

$E M A R=\left(\% C_{C H N S}-\% C_{\text {predito }}\right) .100 / \% C_{C H N S}$

Onde:

$\% \mathrm{C}_{\mathrm{CHNS}}=$ teor de carbono $(\%)$ determinado por análise elementar

$\% \mathrm{C}_{\text {predito }}=$ teor de carbono $(\%)$ estimado pelo modelo do LIBS 
Figura 41 - Curvas de validação dos modelos de LIBS separados por diferentes texturas, a) Todas as amostras; b) Modelo argiloso e c) Modelo Arenoso. São apresentados também os valores de correlação (R) e os EMAR em \% para cada situação avaliada.
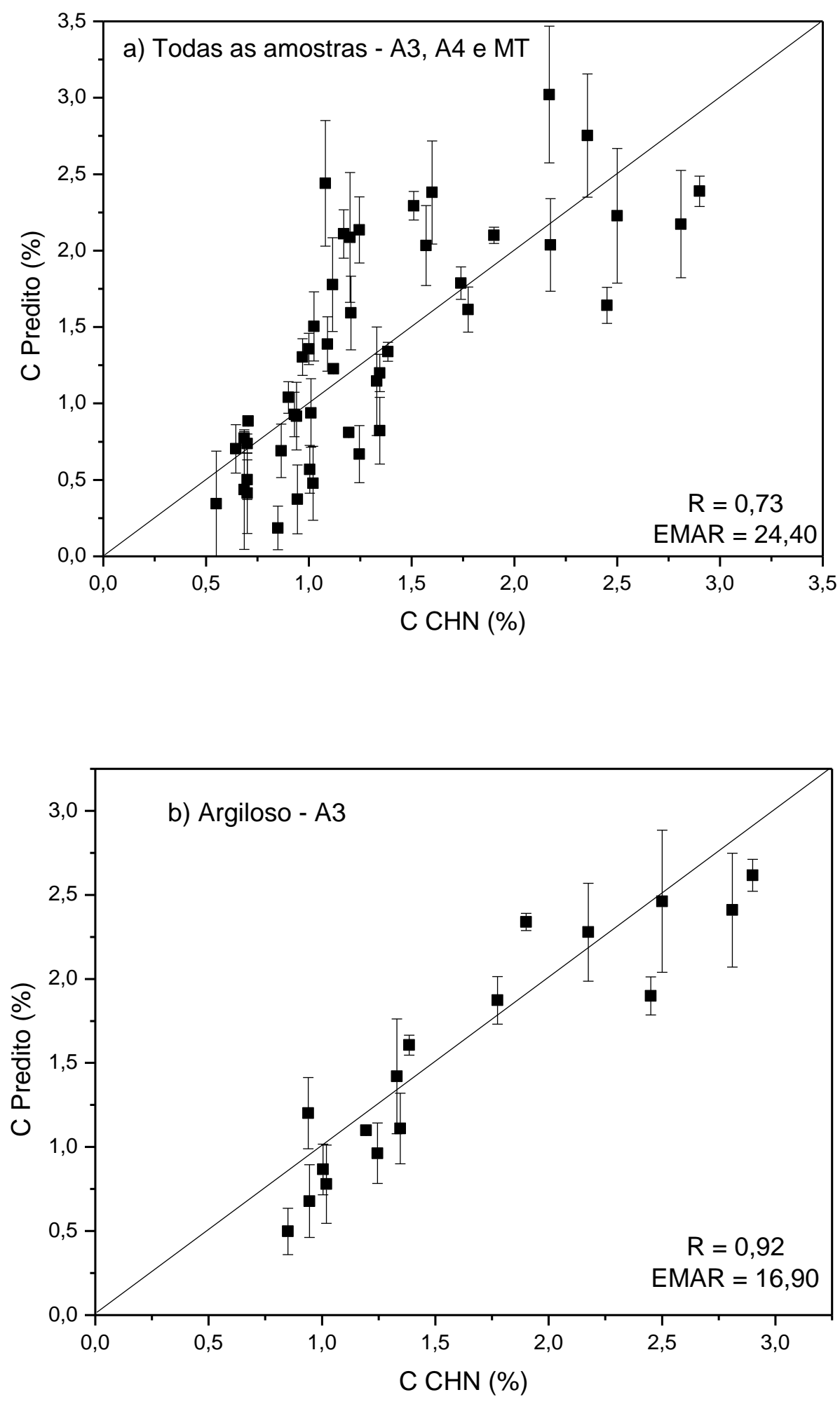


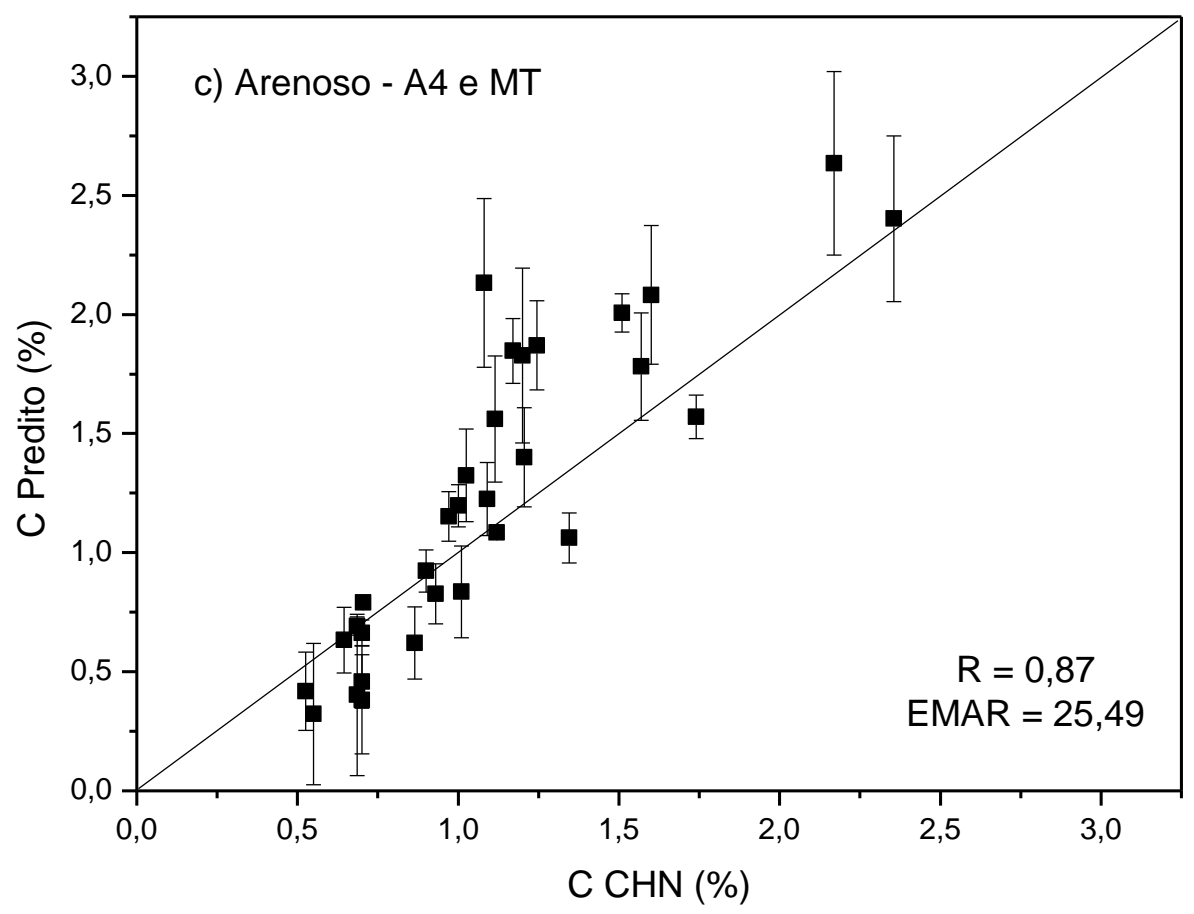

Fonte: Autoria própria

O limite de detecção (LOD) de uma curva analítica segundo a União Internacional de Química Pura e Aplicada (IUPAC) é definido por $\mathrm{LOD}=3 \sigma_{\mathrm{B}} / \mathrm{S}$, onde $\sigma_{\mathrm{B}}$ é desvio padrão das medidas do branco (ausência do analito de interesse) e S é o coeficiente angular da curva de calibração. Porém, no caso desse trabalho no qual foram utilizadas amostras sólidas de solo para a construção dos modelos, onde não existe uma amostra em que não tenha sido determinado carbono, essa metodologia de utilizar-se o LOD proposto pela IUPAC se tornou inviável (NOMURA et al., 2008).

Os LODs foram estimados baseados na definição da IUPAC, porém utilizou-se $\sigma$ sendo o desvio padrão das medidas da amostra com menor concentração de carbono e $S$ é o coeficiente angular da curva de calibração (TREVIZAN et al., 2009). Essa determinação é importante, pois mostra qual será a menor concentração que pode ser detectada pelo modelo. Os LOD para as metodologias propostas foram de $0,13 \%$ para o modelo de textura argilosa e $0,65 \%$ para o modelo de textura arenosa. 
Fatores intrínsecos à técnica, à matriz analisada, a qual influencia diretamente na formação do plasma, e relacionados à resolução do equipamento são os principais motivos dos desvios.

Considerando a heterogeneidade natural das amostras e a resolução espectral do equipamento usado, a boa correlação entre os dados e o erro relativamente baixo mostram o grande potencial da utilização de sistemas LIBS para medidas quantitativas de carbono para solos tropicais. 


\section{CAPÍTULO 5} CONCLUSÕES

Confrontando os três métodos de estimativa de ECs, ou seja, sem correção alguma, com correção por massa equivalente e com correção por argila, concluiu-se que a correção por massa equivalente mostrou-se mais coerente, unindo a metodologia matemática com a realidade agronômica e física do solo. Se a correção por massa equivalente não for feita, pode-se subestimar os ECs em função do aumento da densidade superficial do solo devido à compactação do solo causada pelo pisoteio animal.

Através dessa correção, concluiu-se pelos dados obtidos de ECs que a pastagem A3 $\left(142,40 \mathrm{Mg} \mathrm{ha}^{-1}\right)$, a qual se encontra em estágio de recuperação, apresentou os maiores ECs, sendo assim sumidouro ativo de carbono da atmosfera, mitigando efeitos dos GEE. Foram observados os maiores ECs para este sistema, comparado à área de pasto degradado (A4 99,31 $\left.\mathrm{Mg} \mathrm{ha}^{-1}\right)$ e mesmo à mata nativa $\left(115,46 \mathrm{Mg} \mathrm{ha}^{-1}\right)$, tanto em superfície quanto em profundidade, evidenciando o que vários autores dizem sobre o poder das pastagens de Brachiaria. Essa espécie de pastagem possui sistema radicular vigoroso quando bem manejada, o que leva ao acúmulo de MOS mesmo em camadas mais profundas.

Tomando como base os resultados obtidos com este trabalho, pode-se fazer uma estimativa do impacto da recuperação das pastagens degradadas no Brasil. Atualmente, o Brasil dispõe de mais de 200 Mha de área destinada a pastagem sendo que cerca $50 \%$ das pastagens se encontram em estado de degradação, apresentando balanço negativo na dinâmica do carbono, ou seja, os sistemas estão emitindo mais carbono para atmosfera do que sequestrando. Se estas áreas fossem recuperadas através do manejo proposto na área A3, poderia ser removido da atmosfera em torno de 4,3 Pg de carbono em aproximadamente 15 anos. Embora pareça pouco, pois é da ordem de $1 \%$ da quantidade de $\mathrm{C}$ presente na atmosfera, pode representar uma contribuição importante para a sustentabilidade deste sistema produtivo. É claro que a estimativa feita é bastante grosseira, pois não leva em conta os diferentes tipos de solos, os diferentes tipos de clima, as diferentes gramíneas utilizadas em pastagens, entre outros parâmentros físicos, químicos e agronômicos. Entretanto, trata-se de um simples exercício para estimar a ordem de grandeza que se trabalha quando se utiliza a agricultura como aliada em questões ambientais relacionadas às MCGs.

A taxas de emissão de $\mathrm{CO}_{2}$ para a área em recuperação apresentaram valores médios próximos às taxas de emissão da $\mathrm{A} 4$, ou seja, por mais que a $\mathrm{A} 3$ esteja emitindo $\mathrm{CO}_{2}$ por 
conta da atividade microbiana, esta área está estocando expressivamente mais carbono que o sistema degradado.

Os índices de humificação da matéria orgânica do solo $\left(\mathrm{H}_{\mathrm{FIL}}\right)$ mostraram um cenário interessante e um tanto alarmante para o manejo da pastagem em recuperação A3. O carbono lá estocado, mesmo em profundidade, possui um grau de humificação menor em todas as camadas do perfil quando comparado com a pastagem degradada e a mata nativa. Este fato nos remete a fragilidade deste sistema a manejos inadequados. Como o carbono estocado é bastante lábil, rapidamente o carbono pode ser exposto à degradação e voltar para a atmosfera.

Finalmente, a técnica LIBS foi utilizada na avaliação quantitativa do carbono, proporcionando resultados interessantes para as áreas em questão. Foi possível estimar o teor de carbono nas amostras com relativa precisão e baixo erro de predição (em média 20\%). Modelos matemáticos de calibração foram construídos, dividindo as amostras em dois modelos distintos segundo a textura média das amostras, com melhorias no coeficiente de correlação de Pearson para ambos os modelos, comparando-se com o modelo utilizando todas as amostras. Este fato pode estar relacionado ao efeito de matriz na formação do plasma no momento do pulso do laser, ou seja, diferentes tipos de matrizes geram diferentes formações, evoluções e temperaturas de plasmas.

Os resultados obtidos com os métodos espectroscópicos, tanto com LIBS quanto com LIFS, mostram assim a possibilidade de aplicações in situ, com equipamentos portáteis, mais baratos, demandando menor tempo de preparo de amostras e análise. Desta forma espera-se que essas técnicas fotônicas sejam efetivamente aplicadas a campo oferecendo informações que possam auxiliar nas decisões que tornem a agricultura e a pecuária mais sustentável. 
CAPÍTULO 6

REFERÊNCIAS BIBLIOGRÁFICAS

AITA, C.; CHIAPINOTTO, I. C.; GIACOMINI, S. J.; HÜBNER, A. P.; MARQUES, M. G. Decomposição de palha de aveia preta e dejetos de suínos em solo sob plantio direto. Revista Brasileira de Ciência do Solo, v. 30, p. 149-161, 2006.

ALVES, B. J. R; BODDEY, R. M.; CABALLERO, S. S. U. Pastagens produtivas: lucro para o produtor e para o meio ambiente. Embrapa Agrobiologia. Seropédica, 2003. Disponível em: <http://www.cnpab.embrapa.br/publicacoes/artigos/artigo_pastagens_produtivas> Acesso em: 10 fev. 2014.

ARAÚJO, A. S. F.; SANTOS, V. B.; MONTEIRO, R. T. R. Responses of soil microbial biomass and activity for practices of organic and conventional farming systems in Piauí state, Brazil. European Journal of Soil Biology, v. 44, n. 2, p. 225-230, 2008.

ARAUJO, M. A.; TORMENA, C. A.; SILVA, A. P. Propriedades físicas de um Latossolo Vermelho distrófico cultivado e sob mata nativa. Revista Brasileira de Ciência do Solo, v. 28, p. 337-345, 2004.

BATJES, N.H. A global framework of soil organic carbon stocks under native vegetation for use with the sample assessment option of the Carbon Benefits Project System. Wageningen: Carbon Benefits Project (CBP) and ISRIC: World Soil Information. Report 2010/10. Disponível em <http://www.isric.org/isric/webdocs/docs//ISRIC_Report_2010_10.pdf?q=isric/Webdocs/Doc s/ISRIC_Report_2010_10.pdf>. Acesso em: 11 fev. 2014

BAYER, C.; MARTIN-NETO, L.; MIELNICZUK, J.; DIECKOW, J.; AMADO, T. J. C. C and $\mathrm{N}$ stocks and the role of molecular recalcitrance and organomineral interaction in stabilizing soil organic matter in a subtropical Acrisol managed under no-tillage. Geoderma, v. 133, n. 3-4, p. 258-268, 2006 b.

BAYER, C.; MARTIN-NETO, L.; MIELNICZUK, J.; PAVINATO, A.; DIECKOW, J. Carbon sequestration in two Brazilian Cerrado soils under no-till. Soil \& Tillage Research, v. 86 , n. 2, p. 237-245, 2006a.

BAYER, C.; MARTIN-NETO, L.; MIELNICZUK, J.; SAAB, S. D.; MILORI, D. M. P.; BAGNATO, V. S. Tillage and cropping system effects on soil humic acid characteristics as determined by electron spin resonance and fluorescence spectroscopies. Geoderma, v. 105, n. 1-2, p. 81-92, $2002 b$. 
BAYER, C.; MIELNICZUK, J.; MARTIN-NETO, L.; ERNANI, P. R. Stocks and humification degree of organic matter fractions as affected by no-tillage on a subtropical soil. Plant and Soil, v. 238, n. 1, p. 133-140, 2002a.

BICALHO, I.M. Um estudo da densidade do solo em diferentes sistemas de uso e manejo. Enciclopédia Biosfera, v.7, n.12, p.1-9, 2011. Disponível em: $<$ http://www.conhecer.org.br/enciclop/2011a/agrarias/um\%20estudo\%20da\%20densidade.pdf $>$ Acesso em: 11 fev. 2014.

BODDEY, R. M.; ALVES, B. J. R.; OLIVEIRA, O. C.; URQUIAGA, S. Potencial para acumulação e sequestro de carbono em pastagens de Brachiaria. In: LIMA, M. A.;CABRAL, O. M. R. e MIGUEZ, J. D. G. (Ed.). Mudanças climáticas globais e a agropecuária brasileira. Jaguariúna: Embrapa Meio Ambiente, 2001. p.213-229.

BODDEY, R. M.; JANTALIA, C. P.; CONCEICAO, P. C.; ZANATTA, J. A.; BAYER, C.; MIELNICZUK, J.; DIECKOW, J.; DOS SANTOS, H. P.; DENARDIN, J. E.; AITA, C.; GIACOMINI, S. J.; ALVES, B. J. R.; URQUIAGA, S. Carbon accumulation at depth in Ferralsols under zero-till subtropical agriculture. Global Change Biology, v. 16, n. 2, p. 784$795,2010$.

BOLINDER, M. A.; ANGERS, D. A.; GIROUX, M.; LAVERDIERE, M. R. Estimating C inputs retained as soil organic matter from corn (Zea Mays L.). Plant and Soil, v. 215, n. 1, p. 85-91, 1999.

CENTRO DE CIÊNCIA DO SISTEMA TERRESTRE (CCST). Contribuição do grupo de trabalho I ao quarto relatório de avaliação do painel intergovernamental sobre mudança do clima - sumário para os formuladores de políticas. Genebra, 2007. Disponível em: <http://www.ccst.inpe.br/wp-content/themes/ccst/pdf/IPCCWGI.pdf >. Acesso em: 10 fev. 2014

CERRI, C. C.; CERRI, C. E. P. Agricultura e aquecimento global. Boletim da Sociedade Brasileira de Ciência do Solo, v. 32, n.1, p. 40-44, 2007.

CIAIS, P.; REICHSTEIN, M.; VIOVY, N.; GRANIER, A.; OGEE, J.; ALLARD, V.; AUBINET, M.; BUCHMANN, N.; BERNHOFER, C.; CARRARA, A.; CHEVALLIER, F.; DE NOBLET, N.; FRIEND, A. D.; FRIEDLINGSTEIN, P.; GRUNWALD, T.; HEINESCH, B.; KERONEN, P.; KNOHL, A.; KRINNER, G.; LOUSTAU, D.; MANCA, G.; MATTEUCCI, G.; MIGLIETTA, F.; OURCIVAL, J. M.; PAPALE, D.; PILEGAARD, K.; RAMBAL, S.; SEUFERT, G.; SOUSSANA, J. F.; SANZ, M. J.; SCHULZE, E. D.; VESALA, T.; VALENTINI, R. Europe-wide reduction in primary productivity caused by the heat and drought in 2003. Nature, v. 437, n. 7058, p. 529-533, 2005. 
CLIMATE CHANGE. Working Group I Contribution to the IPCC Fifth Assessment Report. Zähringerstrasse, 2013. Disponível em:

<http://www.climatechange2013.org/images/report/WG1AR5_ALL_FINAL.pdf>. Acesso em: 19 fev. 2014

CORAZZA, E. J.; SILVA, J. E.; RESCK, D. V. S.; GOMES, A. C. Comportamento de diferentes sistemas de manejo como fonte ou depósito de carbono em relação à vegetação de cerrado. Revista Brasileira de Ciência do Solo, v. 23, p. 425-432, 1999.

COSTA, F. D. S.; GOMES, J.; BAYER, C.; MIELNICZUK, J. Métodos para avaliação das emissões de gases do efeito estufa no sistema solo-atmosfera. Ciência Rural, v. 36, p. 693$700,2006$.

DA SILVA, R. M.; MILORI, D.; FERREIRA, E. C.; FERREIRA, E. J.; KRUG, F. J.; MARTIN-NETO, L. Total carbon measurement in whole tropical soil sample.

Spectrochimica Acta Part B-Atomic Spectroscopy, v. 63, n. 10, p. 1221-1224, 2008.

ELLERT, B. H.; BETTANY, J. R. Calculation of organic matter and nutrients stored in soils under contrasting management regimes. Canadian Journal of Soil Science, v. 75, n. 4, p. 529-538, 1995.

EMPRESA BRASILEIRA DE PESQUISA AGROPECUÁRIA (EMBRAPA). Manual de métodos de análise de solo. 2.ed. Rio de Janeiro: Centro Nacional de Pesquisa de Solos, 1997. 212p.

EMPRESA BRASILEIRA DE PESQUISA AGROPECUÁRIA (EMBRAPA). Rede Pecus. São Carlos, 2011. Disponível em: <http://www.cppse.embrapa.br/redepecus>. Acesso em: 10 fev. 2013.

FEARNSIDE, P. M.; BARBOSA, R. I. Soil carbon changes from conversion of forest to pasture in Brazilian Amazonia. Forest Ecology and Management, v. 108, n. 1-2, p. 147-166, 1998.

FERREIRA, E. C.; MENEZES, E. A.; MATOS, W. O.; MILORI, D. M. B. P.; NOGUEIRA, A. R. A.; MARTIN-NETO, L. Determination of Ca in breakfast cereals by laser induced breakdown spectroscopy. Food Control, v. 21, n. 10, p. 1327-1330, 2010.

FISHER, M. J.; RAO, I. M.; AYARZA, M. A.; LASCANO, C. E.; SANZ, J. I.; THOMAS, R. J.; VERA, R. R. Carbon storage by introduced deep-rooted grasses in the south-american savannas. Nature, v. 371, n. 6494, p. 236-238, 1994. 
GARCIA, R. L.; DEMETRIADES-SHAH, T. H.; WELLES, J. L.; MCDERMITT, D. K.; NORMAN, J. M. Measurements of soils $\mathbf{C O}_{2}$ flux. LI-COR Env Technical Resources Library, 1997. Disponível em: <http://envsupport.licor.com/docs/AppNote119.pdf>. Acesso em: 10 fev. 2014.

GIACOMINI, S. J.; AITA, C. Emissão de dióxido de carbono após aplicação de dejetos líquidos e cama sobreposta de suínos. Pesquisa Agropecuária Brasileira, v. 43, p. 107-114, 2008.

GOEDERT, W. J.; SCHERMACK, M. J.; FREITAS, F. C. Estado de compactação do solo em áreas cultivadas no sistema de plantio direto. Pesquisa Agropecuária Brasileira, v. 37, p. 223-227, 2002. <http://seer.sct.embrapa.br/index.php/pab/article/view/6331/3388>. Acesso em: 11 fev. 2014.

HILLEL, D.; HOSENZWEIG, C. Soil and carbon climate change. CSA NEWS, v. 54, p. 311, 2009. Disponível em:

<http://pubs.giss.nasa.gov/docs/2009/2009_Hillel_Rosenzweig_1.pdf >. Acesso em: 10 fev. 2012

INSTITUTO DE ESTUDOS DO COMÉRCIO E NEGOCIAÇÕES INTERNACIONAIS (ICONE). Modeling LUC due to sugarcane expansion by M. Moreira. 2012. Disponível em: <http://www.ornl.gov/sci/ees/cbes/forums/CBES_MMOREIRA_tech.pdf> Acesso em: 10 fev. 2014

INTERGOVERNMENTAL PANEL ON CLIMATE CHANGE (IPCC). Organization. Oslo, 1988. Disponível em: <http://www.ipcc.ch/organization/organization.shtml>. Acesso em: 10 fev. 2014.

JANTALIA, C. P.; TARRÉ, R. M.; MACEDO, R. O.; ALVES, B. J. R.; URQUIAGA, S.; BODDEY, R. M. Acumulação de carbono no solo em pastagens de Brachiaria. In: ALVES, B. J. R. U., S.; AITA, C.; BODDEY, R. M.; JANTALIA, C. P.; CAMARGO, F. O. (Ed.). Manejo de sistemas agrícolas: Impacto no seqüestro de $\mathrm{C}$ e nas emissões de gases de efeito estufa. Porto Alegre: Genesis, 2006. p.157-170.

KLUTHCOUSKI, J. A., H.; COBUCI, T.; STONE, L. F.; THUNG, M. D. T.; BALBINO, L. C.; SILVA, C. C. DA; OLIVEIRA, F. R. Integração lavoura-pecuária: estudo de caso vivenciado pela Embrapa Arroz e Feijão. In: PATERNIANI, E. (Ed.). Ciência, agricultura e sociedade. Brasília: Embrapa Informação e Tecnologia, 2006. p. 277-330.

LAL, R. Agricultural activities and the global carbon cycle. Nutrient Cycling in Agroecosystems, v. 70, n. 2, p. 103-116, 2004a. 
Soil carbon sequestration impacts on global climate change and food security.

Science, v. 304, n. 5677, p. 1623-1627, 2004b.

. Soil carbon sequestration to mitigate climate change. Geoderma, v. 123, n. 1-2, p. 122, 2004c.

Carbon sequestration. Philosophical Transactions of the Royal Society B-

Biological Sciences, v. 363, n. 1492, p. 815-830, 2008.

MARTIN, M. Z.; LABBE, N.; ANDRE, N.; WULLSCHLEGER, S. D.; HARRIS, R. D.; EBINGER, M. H. Novel multivariate analysis for soil carbon measurements using laserinduced breakdown spectroscopy. Soil Science Society of America Journal, v. 74, n. 1, p. 87-93, 2010.

MILORI, D.; GALETI, H. V. A.; MARTIN-NETO, L.; DIECKOW, J.; GONZALEZPEREZ, M.; BAYER, C.; SALTON, J. Organic matter study of whole soil samples using laser-induced fluorescence spectroscopy. Soil Science Society of America Journal, v. 70, n. 1, p. 57-63, 2006.

MILORI, D.; MARTIN-NETO, L.; BAYER, C.; MIELNICZUK, J.; BAGNATO, V. S. Humification degree of soil humic acids determined by fluorescence spectroscopy. Soil Science, v. 167, n. 11, p. 739-749, 2002.

MILORI, D.M.B.P.; MARTIN-NETO, L.; P.R.; FERREIRA, E. C.; SEGNINI, A.; FERREIRA, E.J. SANTOS, C.H. DOS; ROMANO, R.A.; SILVA, W.T.A. da; SIMÕES, M.L.; POSADAS, A. Avaliação de um equipamento portátil para determinação do grau de humificação da matéria orgânica de solos. In: INAMASU, R.Y.; NAIME, J. M.; RESENDE, A.V. de; BASSOI, L.H.; BERNARDI, A. C.. (Org.). Agricultura de precisão: um novo olhar. São Carlos: Editora Cubo, 2011a. v. 1, p. 91-95.

MILORI, D. M. P. B.; SEGNINI, A.; DA SILVA, W. T. L.; POSADAS, A.; MARES, V.; QUIROZ, R.; MARTIN-NETO, L. Emerging techniques for soil carbon measurements. In: WOLLENBERG, E.;NIHART, A.;TAPIO-BISTRÖM, M.-L. e GRIEG-GRAN, M. (Ed.). Climate change mitigation and agriculture. London: Earthscan, 2011b. v.2, p.1-30.

MIZIOLEK, A. W.; PALLESCHI, V.; SCHECHTER, I. Laser-Induced Breakdown Spectroscopy (LIBS): Fundamental and Applications. 1a ed. New York: Cambridge University Press, 2006. 640 p. 
MORAES, J. F. L.; VOLKOFF, B.; CERRI, C. C.; BERNOUX, M. Soil properties under Amazon forest and changes due to pasture installation in Rondonia, Brazil. Geoderma, v. 70, n. 1, p. 63-81, 1996.

MORAES, J. F. L.; VOLKOFF, B.; CERRI, C. C.; BERNOUX, M. Soil properties under Amazon forest and changes due to pasture installation in Rondonia, Brazil. Geoderma, v. 70, n. 1, p. 63-81, 1996.

NATIONAL INSTITUTE OF STANDARDS AND TECHNOLOGY (NIST). Atomic spectra database lines form. Gaithersburg, 2013. Disponível em:

<http://physics.nist.gov/PhysRefData/ASD/lines_form.html>. Acesso em: 12 fev. 2014

NICOLOSO, R. D. S. Dinâmica da matéria orgânica do solo em áreas de integração lavoura-pecuária sob sistema plantio direto. 2005. 149 f. Disssertação (Mestrado em Ciência do Solo) - Centro de Ciências Rurais, Universidade Federal de Santa Maria, Santa Maria, 2005.

NICOLODELLI, G.; MARANGONI, B. S.; CABRAL, J. S.; VILLAS-BOAS, P. R.; SENESI, G. S.; SANTOS, C. H.; ROMANO, R. A.; SEGNINI, A.; LUCAS, Y.; MONTES, C. R.; MILORI, D.M.B.P. Quantification of total carbon in soil using Laser-Induced Breakdown Spectroscopy (LIBS): a method to correct interference lines. Applied Optics, v. 53, n.10, p. 2170-2175, 2014.

NOMURA, C. S.; SILVA, C. S. D.; OLIVEIRA, P. V. Análise direta de sólidos por espectrometria de absorção atômica com atomização em forno de grafite: uma revisão.

Química Nova, v. 31, p. 104-113, 2008.

OLIVEIRA, P. P. A.; PENATTI, M. A.; CORSI, M. Correção do solo e fertilização de pastagens em sistemas intensivos de produção de leite. São Carlos: Embrapa Pecuária Sudeste, 2008. 56 p. (Documentos / Embrapa Pecuária Sudeste, 86).

PANOSSO, A. R.; MARQUES JUNIOR, J.; PEREIRA, G. T.; LA SCALA JUNIOR, N. Spatial and temporal variability of soil $\mathrm{CO} 2$ emission in a sugarcane area under green and slash-and-burn managements. Soil \& Tillage Research, v. 105, n. 2, p. 275-282, 2009.

PASQUINI, C.; CORTEZ, J.; SILVA, L. M. C.; GONZAGA, F. B. Laser induced breakdown spectroscopy. Journal of the Brazilian Chemical Society, v. 18, n. 3, p. 463-512, 2007. 
PEREZ, M. G.; BASTOS PEREIRA MILORI, D. M.; MARTIN-NETO, L.; COLNAGO, L. A.; DE CAMARGO, O. A.; BERTON, R.; BETTIOL, W. Laser-induced fluorescence of organic matter from a Brazilian oxisol under sewage-sludge applications. Scientia Agricola, v. 63, n. 3, p. 269-275, 2006.

POST, W. M.; IZAURRALDE, R. C.; JASTROW, J. D.; MCCARL, B. A.; AMONETTE, J. E.; BAILEY, V. L.; JARDINE, P. M.; WEST, T. O.; ZHOU, J. Z. Enhancement of carbon sequestration in US soils. Bioscience, v. 54, n. 10, p. 895-908, 2004.

PINHEIRO, É. F. M.; LIMA, E.; CEDDIA, M. B.; URQUIAGA, S.; ALVES, B. J. R.; BODDEY, R. M. Impact of pre-harvest burning versus trash conservation on soil carbon and nitrogen stocks on a sugarcane plantation in the Brazilian Atlantic forest region. Plant and Soil, v. 333, n. 1-2, p. 71-80, 2010.

PRIMAVESI, O.; PRIMAVESI, A. C.; CORREA, L. DE A.; ARMELIN, M. J. A.; FREITAS, A. R. F. Calagem em pastagem de Brachiaria decumbens recuperada com adubação nitrogenada em cobertura. São Carlos: Embrapa Pecuária Sudeste, 2004. 32p. (Embrapa Pecuária Sudeste. Circular Técnica, 37).

RAMOS, M. R. Atributos físicos e perda de solo, água e nutrientes em encotas sob sistema de produção de hortaliças convencional e orgânico. 2009. 77f. Dissertação (Mestrado em Ciência do Solo) - Setor de Ciências Agrárias, Universidade Federal do Paraná, Curitiba, 2009.

REZENDE, C. D.; CANTARUTTI, R. B.; BRAGA, J. M.; GOMIDE, J. A.; PEREIRA, J. M.; FERREIRA, E.; TARRE, R.; MACEDO, R.; ALVES, B. J. R.; URQUIAGA, S.; CADISCH, G.; GILLER, K. E.; BODDEY, R. M. Litter deposition and disappearance in Brachiaria pastures in the Atlantic forest region of the South of Bahia, Brazil. Nutrient Cycling in Agroecosystems, v. 54, n. 2, p. 99-112, 1999.

ROSCOE, R.; MERCANTE, F. M.; SALTON, J. C. Dinâmica da matéria orgânica do solo em sistemas conservacionistas: modelagem matemática e métodos auxiliares. Dourados: Embrapa Agropecuária Oeste, 2006. 304 p.

RURAL BR PECUÁRIA. ONU indica pecuária como responsável por 14,5\% das emissões de gases de efeito estufa pelo homem. São Paulo, 2014. Disponível em: $<$ http://pecuaria.ruralbr.com.br/noticia/2013/09/onu-indica-pecuaria-como-responsavel-por14-5-das-emissoes-de-gases-de-efeito-estufa-pelo-homem-4281792.html>. Acesso em: 24 fev. 2014 
RURAL CENTRO. Expogrande começa nesta sexta com palestra sobre sustentabilidade. Campo Grande, 2011. Disponível em:

$<$ http://www.ruralcentro.com.br/noticias/38554/expogrande-comeca-nesta-sexta-compalestra-sobre-sustentabilidade>. Acesso em: 10 fev. 2014.

SANTOS JUNIOR, D.; TARELHO, L. V. G.; KRUG, F. J.; MILORI, D. M. B. P.; NETO, L. M.; VIEIRA JUNIOR, N. D. Espectroscopia de emissão óptica com plasma induzido por laser (LIBS) - fundamentos, aplicações e perspectivas Revista Analytica, v. 24, p. 72-81, 2006.

SANTOS, L. M. D. Dinâmica da matéria orgânica e destino de metais pesados em dois solos submetidos à adição de lodo de esgoto. 2006. 142 f. Dissertação (Mestrado em Química Analítica) - Instituto de Química de São Carlos, Universidade de São Paulo, São Carlos, 2006.

SANTOS, M. E. R.; FONSECA, D. M. D.; BALBINO, E. M.; SILVA, S. P. D.; MONNERAT, J. P. I. D. S. Variabilidade espacial e temporal da vegetação em pastos de capim braquiária diferidos. Revista Brasileira de Zootecnia, v. 39, p. 727-735, 2010.

SEGNINI, A. Estrutura e estabilidade da matéria orgânica em áreas com potencial de sequestro de carbono no solo. 2007. 131 f. Tese (Doutorado em Química Analítica) Instituto de Química de São Carlos, Universidade de São Paulo, São Carlos, São Carlos, 2007.

SEGNINI, A.; POSADAS, A.; QUIROZ, R.; BASTOS PEREIRA MILORI, D. M.; SAAB, S. C.; NETO, L. M.; PEDRO VAZ, C. M. Spectroscopic assessment of soil organic matter in wetlands from the high andes. Soil Science Society of America Journal, v. 74, n. 6, p. 22462253, 2010.

SEGNINI, A.; POSADAS, A.; QUIROZ, R.; MILORI, D. M. B. P.; VAZ, C. M. P.; MARTIN-NETO, L. Soil carbon stocks and stability across an altitudinal gradient in southern Peru. Journal of Soil and Water Conservation, v. 66, n. 4, p. 213-220, 2011.

SEGNINI, A.; SANTOS, L. M. D.; SILVA, W. T. L. D.; MARTIN-NETO, L.; BORATO, C. E.; MELO, W. J. D.; BOLONHEZI, D. Estudo comparativo de métodos para a determinação da concentração de carbono em solos com altos teores de Fe (Latossolos). Química Nova, v. 31, p. 94-97, 2008.

SILVA, A. P.; IMHOFF, S.; CORSI, M. Evaluation of soil compaction in an irrigated shortduration grazing system. Soil \& Tillage Research, v. 70, n. 1, p. 83-90, 2003. 
SILVA-OLAYA, A. M. Emissão de dióxido de carbono após diferentes sistemas de preparo do solo na cultura da cana de açúcar. 2010. 101 f. Dissertação (Mestrado em Solos e Nutrição de Plantas) - Escola Superior de Agricultura "Luiz de Queiroz", Universidade de São Paulo, Piracicaba, 2010.

SISTI, C. P. J.; DOS SANTOS, H. P.; KOHHANN, R.; ALVES, B. J. R.; URQUIAGA, S.; BODDEY, R. M. Change in carbon and nitrogen stocks in soil under 13 years of conventional or zero tillage in southern Brazil. Soil \& Tillage Research, v. 76, n. 1, p. 39-58, 2004.

SKOOG, D. A.; HOLLER, F. J.; NIEMAN, T. A. Príncipios de análise instrumental. Porto Alegre: Bookman, 2002. 836 p.

SPAROVEK, G.; CORRECHEL, V.; BARRETTO, A. G. O. P. The risk of erosion in Brazilian cultivated pastures. Scientia Agricola, v. 64, n. 1, p. 77-82, 2007.

STEVENSON, F.J. Humus chemistry: genesis, composition, reaction. New York: Wiley Interscience, 1994. 443p.

TREVIZAN, L. C.; SANTOS, D.; SAMAD, R. E.; VIEIRA, N. D.; NUNES, L. C.; RUFINI, I. A.; KRUG, F. J. Evaluation of laser induced breakdown spectroscopy for the determination of micronutrients in plant materials. Spectrochimica Acta Part B-Atomic Spectroscopy, v. 64, n. 5, p. 369-377, 2009.

VELDKAMP, E. Organic-carbon turnover in 3 tropical soils under pasture after deforestation. Soil Science Society of America Journal, v. 58, n. 1, p. 175-180, 1994.

ZANATTA, J. A.; BAYER, C.; DIECKOW, J.; VIEIRA, F. C. B.; MIELNICZUK, J. Soil organic carbon accumulation and carbon costs related to tillage, cropping systems and nitrogen fertilization in a subtropical Acrisol. Soil \& Tillage Research, v. 94, n. 2, p. 510519, 2007. 